\title{
Wastes from Plutonium Conversion and Scrap Recovery Operations
}
D. C. Christensen
D. F. Bowersox
B. J. McKerley
R. L. Nance

\section{MAJIER}

\section{DISCLAIMER}

This report was prepared as an account of work sponsored by an agency of the United States Government. Neither the United States Government nor any agency_thereof, nor any of their employees, makes any warranty, express or implied, or assumes any legal liability or responsibility for the accuracy, completeness, or usefulness of any information, apparatus. product, or process disclosed, or represents that its use would not infringe privately owned rights. Reference herein to any specific commercial product, process, or service by trade name. trademart. manufacturer, or otherwise does not necescarily constitute or imply its endorsement, recommendation, or favoring by the United States Government or any agency thereof. The views and opinions of authors expressed herein do not necessarily state or reflect those of the United States Government or any agency thereof. 
TABLE OF CONTENTS

Abstract . . . . . . . . . . . . . . . . . . . . . . . . 1

I. Introduction . . . . . . . . . . . . . . . . . . . . . . . . . . 1

II. Definitions and Characterization of Recoverable Materials . . . . . . 4

A. Processing Concerns . . . . . . . . . . . . . . . . . . . . . . 4

I. Safeguards . . . . . . . . . . . . . . . . . . . . 4

2. Accountability . . . . . . . . . . . . . . . . . 4

3. Criticality Safety . . . . . . . . . . . . . . . . 5

4. Radiation Exposure . . . . . . . . . . . . . . . . . . . . . 5

5. Summary . . . . . . . . . . . . . . . . . . . . . . 5

B. Economic Discard Limit (EDL) . . . . . . . . . . . . . . . . . . 6

C. Levels of Recovery . . . . . . . . . . . . . . . . . . . . . . . 8

D. Assay of Scrap . . . . . . . . . . . . . . . . . . . . . . . . . 10

1. Destructive Techniques . . . . . . . . . . . . . . . . . . . 10

2. Nondestructive Techniques . . . . . . . . . . . . . . . . . 11

a. Alpha Counters . . . . . . . . . . . . . . . . . . . 11

b. Neutron Counters . . . . . . . . . . . . . . . . . . 11

c. Gamma-Ray Measurements . . . . . . . . . . . . . . . 12

d. Calorimetry . . . . . . . . . . . . . . . . . . 13

e. Other NDA Techniques . . . . . . . . . . . . . . . . . . 14

3. Summary . . . . . . . . . . . . . . . . . . . 14

III. Products Recovery and Utilization . . . . . . . . . . . . . . . . . . 15

A. Primary Treatment Approaches . . . . . . . . . . . . . . . . . . 15

1. Heac End Operations . . . . . . . . . . . . . . . . . . 15

2. Separation and Purification By Precipitations . . . . . . . 28

a. Plutonium(III) Oxalate . . . . . . . . . . . . . . . 29

b. Plutonium(IV) Oxalate . . . . . . . . . . . . . . . . . 29

c. Plutonium Peroxide . . . . . . . . . . . . . . . . . . . 32

d. Plutonium Hydroxide . . . . . . . . . . . . . . . . . . 34

e. Plutonium Fluoride - . . . . . . . . . . . . . . . . . . 34

f. Disposal of Oxalate and Peroxide Filtrates . . . . . . . 35 
3. Nitrate Anion Exchange . . . . . . . . . . . . . 35

a. Valence and Feed Adjustment . . . . . . . . . . 38

b. Loading . . . . . . . . . . . . . . . . . 40 40

c. Washing .................. 40

d. Elution ................... . 41

4. Chloride Operations . . . . . . . . . . . . . . . 42

B. Metal Preparation . . . . . . . . . . . . . . . . 48

1. Fluorides ..................48

2. Oxides .................... 50

3. Chlorides ................ . 51

4. Hydriding . . . . . . . . . . . . . 52

5. Pyroredox ................. . 52

c. Metal Purification ................. 53

1. Metal Production Line (MPL) . . . . . . . . . . . . 54

2. :rect Oxide Reduction (DOR) . . . . . . . . . . . . . . 57

3. Molten Salt Extraction (MSE) . . . . . . . . . . 61

4. Vacuum Melting and Casting ............. . 63

5. Electrorefining (ER) . . . . . . . . . . . 66

IV. Waste Management . . . . . . . . . . . . . . . . 75

A. Liquid Wastes . . . . . . . . . . . . . . . . . 76

B. Solid Wastes . . . . . . . . . . . . . . . . . . . . . 78

1. Process Residues . . . . . . . . . . . . . . . . 78

2. Combustibles and Noncombustibles . . . . . . . . . 80

v. Emerging Technologies ...................81

Acknowledgements . . . . . . . . . . . . . . . . . . 86

References . . . . . . . . . . . . . . . . . . . 87 
WASTES FROM PLUTONIUM CONVERSION AND SCRAP RECOVERY OPERATIONS

by

D. C. Christensen, D. F. Bowersox, B. J. Mckerley, and R. L. Nance

\section{ABSTRACT}

This report deals with the handling of defense-related wastes associated with plutonium processing. It first defines the different waste categories along with the techniques used to assess waste content. It then discusses the various treatment approaches used in recovering plutonium from scrap. Next, it addresses the various waste management approaches necessary to handle all wastes. Finally, there is a discussion of some future areas for processing with emphasis on waste reduction.

\section{INTRODUCTION}

Although very small quantities of plutoniurs exist in nature, it is essentially a manmade element produced in uranium-fueled power reactors. It is element number 94 and is a member of the actinide series. Researchers have identified isotopes ranging in mass from 232 through 246 , all of which are radioactive. The most abundant isotope, and therefore the most important, is $239 \mathrm{Pu}$.

Since its discovery by G. T. Seaborg and coworkers in 1940, an immense amount of research into the physical and chemical properties of the element has taken place. Scientists now know more about the chemistry and metallurgy of plutonium than they know about many of the more common elements. The chemistry and metallurgy are complex because plutonium exists in six allotropic phases and forms compounds in five different valence states. These complex properties both aid and hinder the handing and processing of plutonium. The separation of plutonium from other 
elements generally depends on the ability to control the oxidatint etate and to adjust it at will.

In the national defense complex, plutonium is first produced in production reactors. It is then extracted by solvent-extraction techniques and concentrated as a liquid plutonium nitrate. The nitrate is then converted to either an oxide or a fluoride and reduced to metal. The resulting product metal is sent for fabrication of various parts and components. It is this fabrication process that generates the major portion of waste and scrap.

Generation of nonspecification plutonium and plutonium-containing residues occurs in all phases of the production and recycle of compenents and in the chemical processing of scrap residues to recover that plutonium. The recovery of this scrap and the recycle of plutonium is the charter of the residue-processing facilities. Recovery of the plutonium from these residues is essential for $a$ number of reasons. The plutonium is expensive to produce in the reactors. The scrap is not amenable to waste disposal because of scrap matrix, intrinsic radiation, and plutonium content. The scrap therefore must be stored in certified storage vaults, a costiy process. Finally, the plutonium is a fissile material that requires extensive safeguards procedures to insure that the material is maintained in a secure environment. It is much easier and therefore much less costly to safeguard material in high-density and easily measured forms such as high-purity metals and oxides.

Plutonium-containing scrap can conveniently be divided into two categories. The first, primary scrap, is scrap that occurs in the plutonium foundry and results from the casting, alloying, forging, and machining of the metal. Another component of primary scrap is items that are removed from service and must be reprocessed. The primary scrap categoiy includes graphite from molds, fused salts from extractive metallurgy, plutonium oxide from burned casting and machining residues, impure plutonium metal, and a small amount of equipment and supplies such as cleaning rags, dry-box gloves, and dry-box windows. 
Secondary scrap, the second category of scrap, results from the processing of the primary scrap items. The ultimate goal for processing scrap is to return the plutonium to a usable form as quickly and efficiently as possible. Unfortunately, plutonium is an outstanding getter and exhibits a propensity to oxidize in an oxygen environment. These characteristics, together with the fact that plutonium readily forms compounds in five different valence states, make the task of efficient separation and recovery a challenging one. The processing of impure metals and oxides generates a wide variety of leaner scrap forms including ash, undissolved oxide heels, metal reduction slags and salts, ceramics, sludges, chloride salts, and miscellaneous items. These items constitute secondary scrap. They are characteristically leaner in plutonium content and more difficult to process.

A number of facilities have been established to recover both primary and secondary scrap. The technology used in these facilities ranges from 1950s vintage processes up to state-of-the-art methods. Much of this technology was designed into the facilities just before commissioning and has not undergone much renovation. Most facilities are now undergoing new capital construction, and management realizes the need to update the technology to improve process efficiency, reduce scrap generation, reduce waste generation, reduce radiation exposure to workers, improve accountability and safeguards, and improve cost efficiency. Future facilities will take advantage of improved process-control technologies, automation and robotics, and on-line or at-line analytical capabilities. In addition, waste management will play an ever-increasing role in dictating how plutonium residues will be handled and processed.

This report first defines how residues/wastes from plutonium conversion are classified and then discusses the state of technology for residue-processing methods. (We do not intend the discussion to be a comprehensive treatise on residue processing, but rather a summary of proven techniques. References, where appropriate, allow the reader to quickly find more detailed information on a particular subject.) Next, we 
review current waste-treatment techniques and conclude with a statement on the potential of emerging technologies.

II. DEFINITIONS AND CHARACTERIZATION OF RECOVERABLE MATERIALS

\section{A. Processing Concerns}

Any chemical processing system seeks to provide a high-quality product while generating a minimum quantity of sidestream material. The sidestream quite often contains a concentration of reactants as well as a concentration of the product. It also quite often is made up of more than one type of item. Almost always, economic considerations determine if this sidestream warrants further processing or whether discard is appropriate. The criterla for determining the economics include the cost of recovery of materials, waste disposal including transportation, the value of reactants and products, and social or political consequences (social risk).

Although nost plutonium facilities use this sane approach in evaluating the disposition of sidestreans in plutoniu processing, there are significant differences that add to the costs. These differences include additional costs for safeguards, accountability, criticality safety, and protection fron radiation exposure.

1. Safeguards. Because plutonium is a fissile material, facilities must provide safeguards to insure limited access to the material. Safeguards are also important when material leaves facilities in transit to processing sites. Safeguards includes all physical and mechanical barriers, guard forces to insure active response, and security-awareness training and certification.

2. Accountability. Because plutonium is a fissile material, facilities must account for it in much the same way banks account for money. The variety of plutonium isotopes, each having different radioactive properties and different masses, causes the biggest accountability problem. Many 1sotopes exist in a homogeneous mixture in 
each plutonium-containing item. The techniques used for accountability include physical-property measurements (weight and density), radioactiveproperty measurements (neutron counts and gamma scans), and chemicalproperty measurements. None of these are exact sciences. Accountability is therefore a technique of using the best approach available to arrive at a close estimate of the quantity of plutonium in each item.

3. Criticality Safety. Some isotopes of plutonium undergo spontaneous fission and therefore pose a hazard because of small critical masses. Process equipment is designed to prevent assembly of a critical mass if the equipment or process undergoes an upset. For this reason, many processes are designed with limited flow rates, limited reactor dimensions (small sizes), and/or limited batch sizes. Economics of scale, realized by large chemical-processing plants, are rarely transferable to plutonium processing facilities. These considerations directly affect processing costs.

4. Radiation Exposure. Plutonium emits alpha particles, neutrons, and gamma rays. These forms of radiation can be damaging to biological tissue if the exposure time and intensity of the radiation are sufficient. Alpha radiation is a nompenetrating form of radiation and is generally eliminated by the glove-box operations. On the other hand, shielding can moderate neutron and gamma radiation but not completely eliminate it under normal working environments. All plutonium facilities observe personnel radiation-exposure guidelines deemed to be safe. To comply with these guidelines, facilities quite often need additional shielding. In areas of particularly high radiation exposure, personnel are often rotated among jobs so that one exployee does not receive an excessive level of exposure. Both of these activities add cost to the operations. An additional burden to the operations is the constant monitoring required to assess radiation exposure levels.

5. Summary. These four items do not constitute a comprehensive list of challenges to the plutonium-processing industry, but they are major examples of unique cost impacts. The costs associated with these processing concerns are generally hidden within the direct operating costs 
because they are, indeed, considered necessary to perform the direct operation. These unique costs, therefore, are incorporated into the cost of plutonium recovery and become part of the considerations in deciding the disposition of sidestreams.

\section{B. Economic Discard Limit (EDL)}

The result of calculations that take into account all costs of plutonium handling is the economic discard limit (EDL), 1 a level of plutonium concentration above which recovery would be economical. In other words, the EDL represents the plutonium concentrations at which recovery costs would equal the value of the recovered plutonium. The procedure for calculating EDL values is easily derived from the following definition:

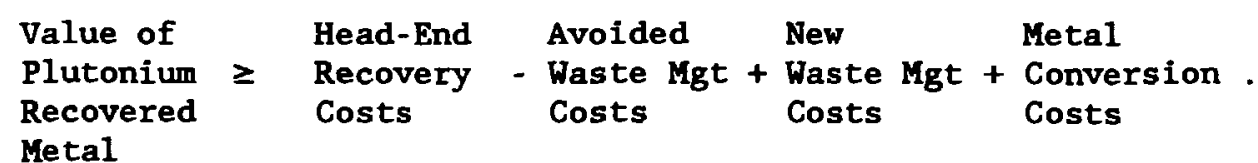

Substitution of costs in the above expression and rearrangement of the terms yield the following relationship for the EDL:

$$
E D L=\frac{C_{r}+C_{w}(1-f)}{\left(V-C_{C}\right) Y}
$$

where

EDL - economic discard limit, concentration of plutonium in the residue or scrap material (g Pu/kg bulk),

$C_{r}$ - unit cost of recovering plutonium from bulk and converting it to a concentrated nitrate or oxide $(\$ / \mathrm{kg}$ bulk),

$C_{w}$ - total waste management cost of initial bulk residue, including packaging, storage, and shipping $(\$ / \mathrm{kg})$,

$\mathrm{f}$ - ratio of the quantity of new waste (after processing) to original bulk, 
$v$ - value of plutonium $(\$ / g)$,

$c_{c}$ - cost of converting purified plutonium concentrate as oxide or nitrate to spec-grade metal $(\$ / g \mathrm{Pu})$, and

$Y$ - yield, or fraction of plutonium in original residue converted to spec-grade metal (includes immediate recycle but not secondary recoveries).

Two important terms emerge from the use of this calculation: scrap and waste. Scrap is that material having a plutonium concentration above the EDL value for that matrix and is therefore material that will undergo further processing for plutonium recovery. (Often the terms scrap and residue are used interchangeably to define recoverable material.) Waste, on the other hand, is that material having a plutonium concentration below the EDL value for that matrix and is therefore destined for disposal.

The operating costs used to derive the unit-cost terms include all direct and indirect costs related to the recovery operations such as direct labor, indirect labor, materials and supplies, technical and engineering support, health protection, and analytical/standard laboratories. Also included are shared or distributed building costs such as building maintenance and utilities.

The term $v$ in the equation above represents the value of plutonium. In reality, it represents the cost of producing and recovering virgin plutonium from production reactors and converting it to usable metal. Historically, the value of plutonium and the cost of recovery ( $\left.C_{r}\right)$ have been the predominant factors in determining the EDL. More recently, the costs associated with waste management $\left(C_{w}\right)$ have become more significant. Indeed, they will likely become the dominant aspect in determing EDLs in the future.

Waste-management costs also include direct labor, indirect labor, materials, supplies, technical and engineering support, health protection, analytical/standard laboratories, and building maintenance and utilities. Other indirect charges include packaging, certification, storage, shipment, and final disposal including monitoring. At present, the only site 
certified for receipt of plutonium-contaminated waste is the Waste Isolation Pilot Plant (WIPP) In Carlsbad, New Mexico. The facility has developed an extensive waste acceptance criteria (WAC) for defining such things as packaging, radiation levels, material content, reactivity, and particle size.

The Department of Energy (DOE) provides the following official definition of transuranic (TRU waste): 2

TRU Waste. Without regard to source or form, radioactive waste that at the end of institutiona?. control periods is contaminated with eipha-zisting transuranium radionuclides with half-lives greater than 20 years and concentrations greater than $100 \mathrm{nCi} / \mathrm{g}$. Regarding the Wasto Isolation Pilot Plant, high-level waste and spent nuclear fuel as defined by this order are specifically excluded by this definition.

\section{Levels of Recovery}

The EDL now becomes the criteria for defining the level of recovery for scrap items. Scrap, unfortunately, exists as a large number of different items and in a large variety of matrices. To simplify the evaluation of scrap items, researchers have developed a list of categories and have clustered scrap items using categorical criteria. The initial criteria segregate material into three major catagories: High-Level, Major Low-Leve1, and Other Low-Leve1.

The High-Level category encompasses high-plutonium-concentration items that can be processed quickly and inexpensively. Items in this category generically include oxides and impure metals in which plutonium concentrations are generally above 808 .

The Major Low-Level category encompasses items that involve moderate turnaround times, routine processing sequences, and well-established and routine techniques. These items are almost exclusively processed by aqueous dissolution and purification, although in some instances high- 
temperature extractive metallurgical techniques offer acceptable alternatives. Items in this category generically include reduction slags and salts, impure oxides, and ash.

The Other Low-Level category encompasses items that are not routinely processed, items that are not produced in high enough volumes to justify routine processing, and items that require special handling. They generally have very low plutonium concentrations and, because of their unusual cature, are somewhat more expensive to process than items in the Major Low-Level category. Items in this category include ceramic crucibles, graphite, combustibles, and insulation.

Unfortunately, breaking the plutonium scrap into these three categories does not sufficiently allow definition of recovery cost or assessment of a proper EDL value for these items. There are simply too many different techniques used to recover items in each broad category to accurately assess recovery costs. Therefore, to further facilitate the analysis of recovery cost, the specific materials commonly processed for plutonium recovery are further broken into the following 24 higher-order categories :

Low-Level Scrap

1. Graphite

2. Combustibles

3. Incinerator Ash (Major Low-Level)

4. Oxide Heels

5. Reduction Slags

(Major Low-Level)

6. Insulation

7. Ceramics

8. Scrap Metal (Iron, Plutonium)

9. Glass

10. Rubber

11. Sludge

12. Chloride-Based Salts
a. Extractive Metallurgy
(Major Low-Leve1)
b. Electrolyte
c. Solvent

(Major Low-Level)

13. Pu/U Mixtures

14. Pu/Th Mixtures

15. $\mathrm{Pu} / \mathrm{Be}$ Mixtures

16. $\mathrm{Pu} / \mathrm{Np}$ Mixtures

17. $\mathrm{Pu} / \mathrm{Zr}$ Mixtures

18. Pu/Al Mixtures 
High-Level Scrap

19. Impure Hetal

a. Nonspecification Metal

b. Anode Heels

20. Rich Plutonium Oxide ( $>858$ )

21. Lean Plutonium Oxide $(<858)$

The materials within each of the 24 categories have similar properties and require basically the same processing steps for pliconium recovery. We can therefore measure the cost of recovery and calculate an independent EDL for each category.

\section{Assay of Scrap}

The application of the EDL is straightforward. The units associated with the EDL are grams of plutonium per kilogram of bulk weight. When a discrete scrap item is generated, the operator must assay the scrap and measure the concentration of plutonium. ${ }^{3}$ There are a variety of satisfactory techniques for determining the plutonium concentration, but all fall within two categories: destructive and nondestructive.

1. Destructive Techniques. Destructive techniques involve taking representative samples from the scrap matrix and performing detailed chemical analysis. Plutonium assay, for instance, involves dissolving the sample in hydrochloric acid (HCl), reducing it with a lead reductant, rinsing it, titrating it with cerium(IV), and detecting the end point poicentiometrically. Each sample requires that a reagent blank be run in parallel to compensate for reagent interference. The reliability varies with the quality of the feed sample but can be accurate to within $0.05 \%$. Certain elements, including iron, molybdenum, titanium, uranium, tungsten, vanadium, and chrome, interfere with the reliability of the analysis and can cause serious deviations in results if the analyst does not compensate for them. 
Ancther very important destructive technique is the determination of different plutonium isotopes by mass spectroinetry. This process involves sample dissolution in $\mathrm{HCl}$, Ion exchange, elution, and rinsing. The analyst then injects the sample into the mass spectrometer, which shows the discribution of isotopes within the sample. This analysis is important because of its use in conjunction with the various nondestructive techniques for providing quantitative analysis.

2. Nondestructive Techniques. Nondestructive assay (NDA) techniques used in assaying plutonium-bearing scrap include alpha counters, neutron counters, gamma scans, and calorimetry. All techniques used for nuclearmaterial assay must be calibrated with appropriate and approved reference standards. All calibration standards should be traceable to the appropriate National Measurement System standards.

a. Alpha Counters. Alpha spectrometry is an isotope-specific rather than element-specific analytical method that is po:ticularly well-suited to measuring low plutonium concentrations in waste streams. The method also has been applied to the determination of plutonium in dissolver solutions following such presesses as solvent extraction. Quantitative alphaparticle spectrometry is based on measurement of the alpha-radiation intensity of the sample. The major problem is that alpha particle energy interactions with electrons rapidly degrade and are completely attenuated by as little as $5 \mathrm{~cm}$ of air. Attenuation by water and self-absorption are even more rapid. Analysts perform normal alpha spectrometry on thin, dry films using standard alpha detectors such as proportional, scintillation, and solid-state counters.

b. Neutron Counters. NDA techniques using neutron counting are either passive or active. Passive assay uses naturally occurring neutrons as direct elemental or isotopic signatures. Active assay involves irradiating the sample with neutrons or photons to induce nuclear or electronic interactions in the sample matrix. The resulting neutrons are interpreted to determine the amount of the desired element present. 
Neutrons from plutonium samples arise from either $(\alpha, \mathfrak{n})$ reactions or fission. The $(\alpha, n)$ neutrons result from the alpha decay of plutonium and the subsequent action of the alpha particles on light elements in the sample matrix. The neutron yield is a function of alpha-particle energy, the ( $a, n$ ) cross sections of the matrix elements, and the matrix configuration. Furtherwore, the alpha-particle intensity depends on the isotopic composition and is particularly sensitive to $298 \mathrm{pu}$ content. As a censequence: $(\alpha, n)$ neutrons ordinarily are not useful as a quantitative signature for plutonium, and, in fact, they usually constitute a large background that must be eliminated from most measurements.

Fission reutrons result from spontaneous fission or from fissions induced by an external neutron source such as ${ }^{252} \mathrm{Cf}$. Because the fission process produces more than one neutron per fission, coincidence counting can differentiate fission neutrons from $(\alpha, n)$ neutrons.

With passive neutron methods, analysts can measure both spontaneous fission and $(\alpha, n)$ neutrons. The $(\alpha, n)$ neutron yield is sensitive to the light-element content, particularly fluoride. Using coincidance-counting techniques can make this method specific for spontaneous fission neutrons, but some sensitivity will be lost.

c. Gamma-Ray Measurements. Passive gamma-ray techniques benefit conventional materials accounting of uranium and plutonium because investigators can use these emission techniques to quantify any ${ }^{235} \mathrm{U}$ and $23^{\circ} \mathrm{Pu}$ contained in the solid low-level waste generated by reprocessing and conversion operations.

For assay of ${ }^{235} \mathrm{U}$ and ${ }^{239} \mathrm{Pu}$ contained in 55-gal. drums of low-level waste, analysts measure the $186-\mathrm{keV}$ and $414-\mathrm{keV} 1 \mathrm{ines,}$ respectively. A drum scanner that uses a sodium iodide (NaI) detector to measire the 414-keV gamma ray from ${ }^{23{ }^{\circ}} \mathrm{Pu}$ can detect $-1 \mathrm{~g}$ of ${ }^{239} \mathrm{Pu}$ in a 5-min scan; a lithium-drifted germanium (GE[Li]) detector can provide much higher resolution. The relative accuracy for measuring $>10 \mathrm{~g}$ of $239 \mathrm{Pu}$ can be as good as $10 \%$ in matrices of low atomic number and ranges to $50 \%$ in unknown 
matrices. Hence, the measurement accuracy depends largely on the administrative control exercised in sorting waste to ensure reproducible matrices.

In addition to $\mathrm{NaI}$ and $\mathrm{Ge}(\mathrm{LI})$ detectors, intrinsic germanium detectors also provide gamma-ray measurements. The Ge(LI) and intrinsic germanium detectors provide much better energy resolution for adjacent peaks, but they require liquid-nitrogen cooling. Nevertheless, one or the other is required if good quantitative data on isotopic abundances are to be obtained. Because it is a rugged on-line instrument, investigators prefer the NaI detector if overlapping spectra are not a problem.

d. Calorimetry. Plutonium calorimetry is an NDA technique based on measuring heat generated by the radioactive decay of plutonium and americium. All but a negligible part of the decay energy is transformed into heat when the sample and calorimeter walls absorb the decay particles and rays (alpha, beta, and low-energy gamma). In plutonium from processed reactor fuels, the energy from alpha decay predominates, and the energy release from ${ }^{238} \mathrm{Pu}$, the plutonium isotope with the highest specific activity, is dominant.

The calorimetric method consists essentially of measuring the electrical energy needed to duplicate or balance the rate of heat emission (power) from the sample. A thermal resistance separates the heat source (standard or unknown sample) in the calorimeter chamber from a constanttemperature environment (heat sink). In steady-state operation, establishing a constant temperature difference between the calorimeter chamber and the surrounding environment determines equilibrium; the thermal energy transferred to the environment must equal that generated in the calorimeter chamber.

Calorimetry is applicable to the assay of materials such as oxide powder or metals that have high plutonium concentrations. An analyst can determine the total power of a sample without subsampling or aliquoting, permitting assay of sealed containers of material. Furthermore, 
calorimetry is relatively insensitive to the geometry and matrix effects that are major concerns in many other NDA methods.

Calorimetry is both precise and accurate. In spite of potential sources of error. the precision of a plutonium assay by calorimetry, expressed in terms of relative standard deviation (RSD), typically is 0.58 or better. However, because the design and construction of a calorimeter depend on the magnitude of the sample power, the physical size of the sample, and the type of radiation emitted, a universal calorimeter for all measurement is neither practical nor economical.

e. Other NDA Techniques. Other NDA techriques, not elaborated on here, include balances and densitometers. Naturally, these types of equipment require regular calibration verification. They are frequently used for confirmation measurements in concert with other analytical techniques but in some cases are used as the primary means of accounting for plutonium.

3. Summary. Evaluating the variety of techniques for determining the plutonium content of a scrap item makes obvious the fact that no one technique can be used in all cases. In fact, investigators generally use two or more techniques to assay every discrete item. No single technique is absolute, and a certain margin of variability exists with each technique. These are crucial points in evaluation processing parameters, operational safety, and, in particular, criticality safety.

The way that material is categorized rogether with the assay techniques represents the basis for designing recovery techniques. Processing approaches are designed around the feed matrices. The desired end product and ways to minimize waste are also crucial considerations. Operating constraints including criticality, radiation exposure, and batch sizes further help to design the processing approach. The following sections further discuss the various approaches used in recovering plutonium from different scrap matrices. 


\section{PRODUCTS RECOVERY AND UTILIZATION}

\section{A. Primary Treatment Approaches}

The processing technology for plutonium is especially interesting and challenging because of the many scrap matrices, the wide range of chemical contaminants, and the stringent health, s-fety, and materials accountability requirements employed in the nuclear industry. In addition, plutonium possesses the unique chemical property that allows the simultaneous existence in solution of the III, IV, V, and VI oxidation states. To make she situation even more challenging, there is a relatively small oxidation potential difference between each state. This multiplicity of states and plutonium's ability to form complexes in the III and IV states provide the foundation for the separation and purification of the plutonium from other elements.

Plutonium solution-processing technology is composed of unit operations that can be conveniently divided into four main categories:

- head-end operations,

- separation and purification by precipitation,

- nitrate anion exchange, and

- chloride operations.

Processes must provide the flexibility to handle extremely low level combustible and noncombustible scrap such as cheesecloth, glove-box gloves, and high-efficiency particulate air (HEPA) filters; chloride-based residues such as direct oxide reduction (DOR) and electrorefining (ER) salts; ant residues such as impure oxides and impure plutonium metal containing high percentages of plutonium.

1. Head-End Operations. The principal unit operations involved in this area of plutonium processing include incineration, leaching of noncombustibles, conversion of pyrophoric metal and compounds to stable oxides, and dissolution. 
Plutonium-recovery cost depends upon the plutonium concentration in the residues to be processed and upon the matrix material involved. The more dilute the pluconium is, the more nonradioactive material has to be processed to obtain a given amount of plutonium. The ratio of the weight of the nonradioactive material to the weight of plutonium is often significantly greater in solid residues, such as rags, than in feed solutions. Recovering plutonium from solution by solvent-extraction, ionexchange, or precipitation techniques can be quite easy. Unfortunately, no single method now exists that will scavenge the plutonium from solid materials.

Incineration, the preferred method for cellulosics such as rags and paper (Fig. 1), reduces the original volume of dry rags by approximately one order of magnitude. Because completely burning rubber and plastics is difficult and because burning polyvinyl chloride (PVC) liberates corrosive $\mathrm{HCl}$, researchers developed an alternate processing method that involves pickling compatible plastics such as PVC and polypropylene in boiling nitric acid $\left(\mathrm{HNO}_{3}\right)$ and fluoride ion $\left(\mathrm{F}^{-}\right)^{4,5}$ (Fig. 2). However, some sites prefer to burn rubber and plastics in an oxygen-fed incinerator constructed with a stainless steel shell lined with fire brick. For reasons explained on page 21, experts do not recommend incineration of leaded glove-box gloves that have been exposed to $\mathrm{HNO}_{3}$ for extended periods.

Depending upon feed material, the incinerator operates between $200^{\circ} \mathrm{C}$ and $900^{\circ} \mathrm{C}$. When the incinerator burns cellulosic material such as paper and cheesecloth, lower temperatures are sufficient. However, more complete combustion of plastics and rubber occurs only at higher temperatures. This high-temperature incineration tends to create refractory oxides of plutonium that are significantly more difficult to leach from the resultant incinerator ash.

A pretreatment calcination step ameliorates the potential difficulties in processing incinerator ash from the combustion of rubber and plastics. At Los Alamos, this operation uses rotary calciners to romove incompleteiy oxidized organic material from the incineration of materials such as 


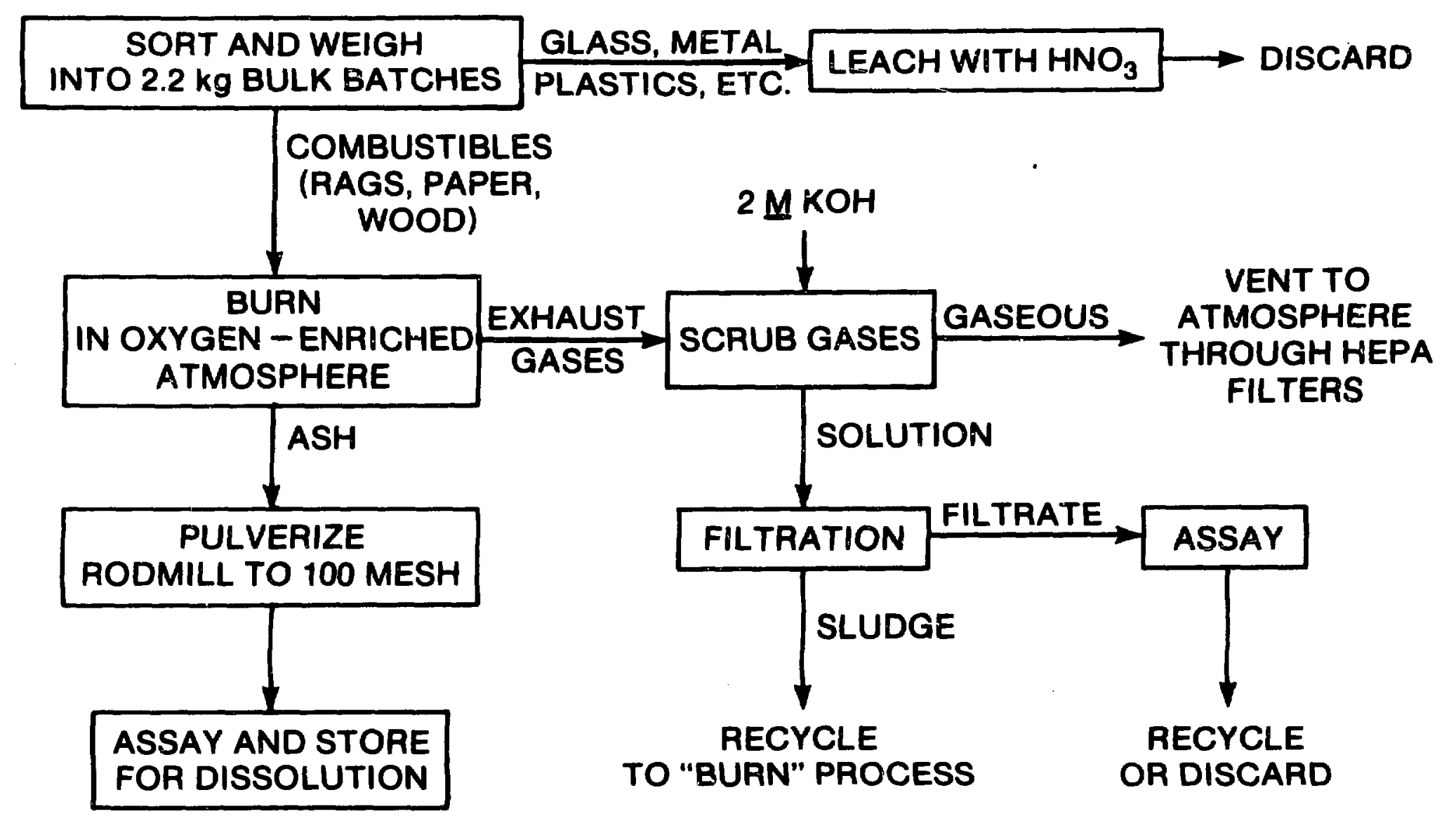




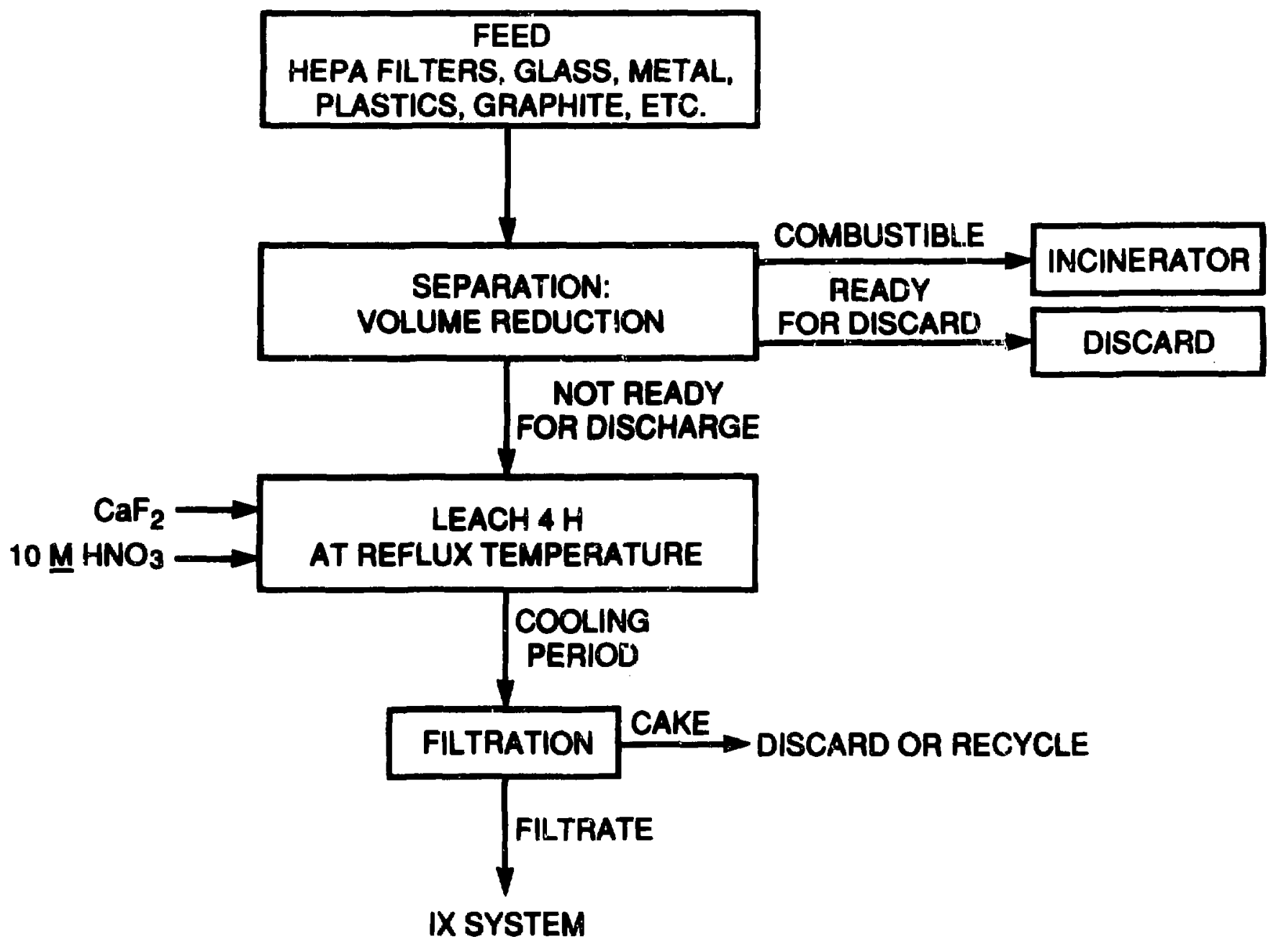

Fig. 2. Noncombustible leaching process. 
plastics, rubber, wood, cellulose, and oil (Fig. 3). This calcination step requires the flow of pure oxygen for a length of time and at a temperature $\left(550^{\circ} \mathrm{C}\right)$ that will result in almost total oxidation of the organic materials. 6 A rotary calciner consists of a stainless steel tube encased in large resistance heaters and containing the material that is being calcined. A rotating paddle inserted in the calcination tube keeps the material agitated so that the ash particles will be evenly exposed to oxygen and heat and will burn more completely. Agitation also prevents both localizcd overheating because of combustion and the subsequent melting of the ash to form chunks. This pretreatment process is quite advantageous for the following reasons:

- Organic materials sometimes react vigorously and foam when treated with strong $\mathrm{HNO}_{3}$.

- Emulsions that impede filtration may form when $\mathrm{HNO}_{3}$ reacts with the organic material.

- These viscous residues also coat the ash-leaching equipment, gloves, and glove box, resulting in severe housekeeping problems.

- Some of the organic materials dissolve in the $\mathrm{HNO}_{3}$ to yield a dark solution that in turn severely discolors the ion-exchange resin.

- Organic materials impede the dissolution process. Consequently, following their removal, leaching operations require less $\mathrm{HNO}_{3}$.

Graphite molds used in foundry operations generate graphite residues . The general process for plutonium recovery from these residues includes pretreatment, multiple leaching, and purification. Pretreatment includes the mechanical removal of the surface of the graphite containing most of the plutonium. The remaining graphite is usually sufficiently decontaminated to be discarded. The accumulated scrapings become candidate material for leaching in swo $_{3}$ and $F^{-}$until the leached residue meets discard limits. Experience has shown that 50\% to 908 of the plutonium becomes soluble during each leaching nperation and that four passes are sufficient. The graphite scrapings may also be burned in an oxygen atmosphere and the residue from this operation treated as an impure oxide.4 Rubber and plastics, as mentioned earlier, can be classified as either 


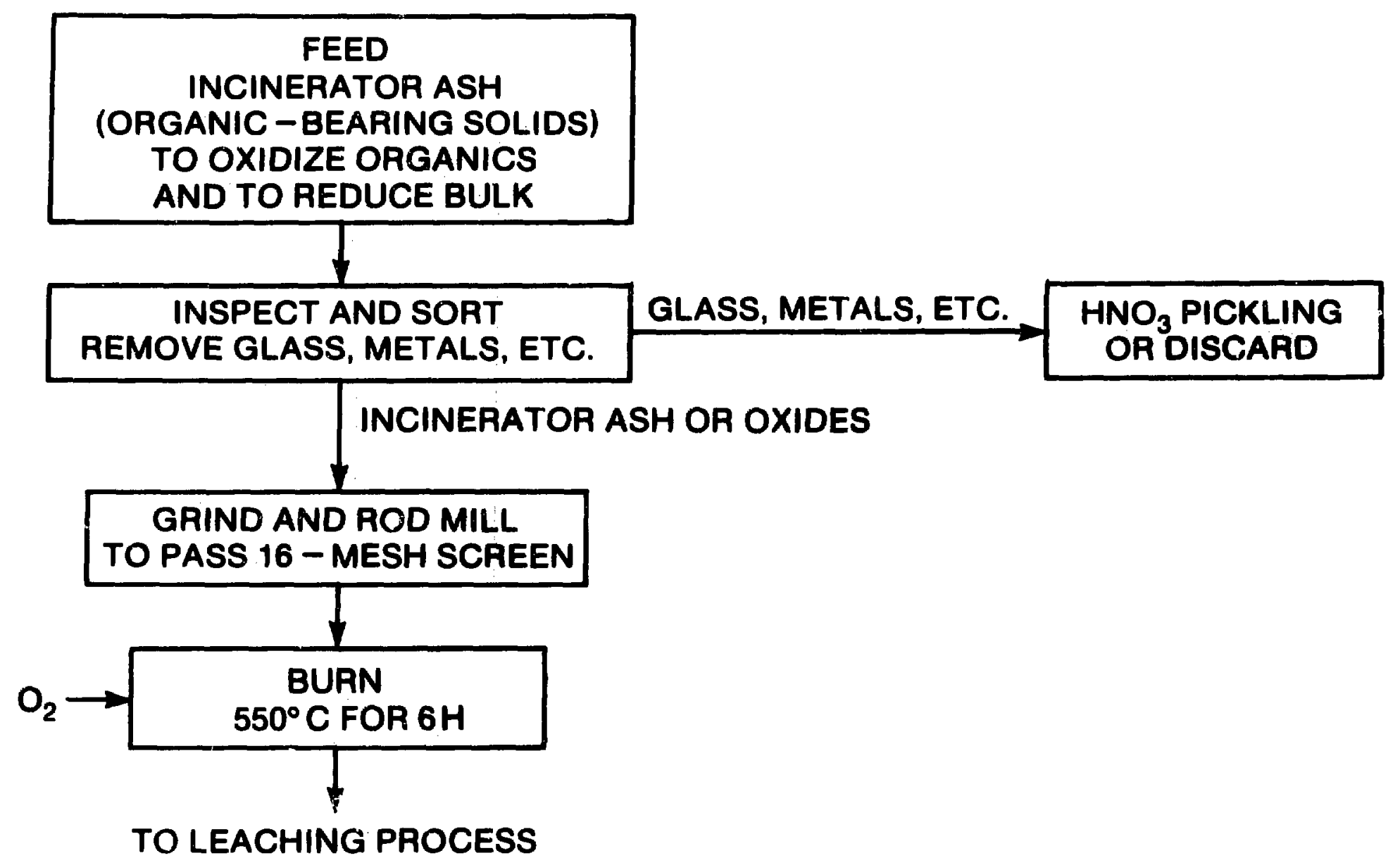

Fig. 3. Rotary calciner. 
combustible or noncombustible. If these materials are treated as noncombustibles, wiping the surface with $\mathrm{HNO}_{3}$ and $\mathrm{F}^{-}$frequently provides decontamination. Wiping is particularly effective on items that have been generated a short time before processing. Older, stored materials require more drastic processing techniques, including leaching in boiling $\mathrm{HNO}_{3}$ and $\mathrm{F}^{-}$(Fig. 2). Monitoring the material and removing hot spots can reduce the volume of material to be leached.

Long and $\mathrm{Smith}^{\mathbf{7}}$ report that an explosive material, identified as a mixture of carboxylic acids containing nitro groups and lead nitrate, was formed when leaded giove-box gloves were exposed to $\mathrm{HNO}_{3}$ and then dried. The time required for the nitration reaction depended upon the area of leaded layer exposed, the temperature, and acid concentration. One hour was sufficient when the leaded layer was in contact with hot, concentrated $\mathrm{HNO}_{3}(15.7 \mathrm{M})$. Approximately two weeks were required when operators used Hypalon* or neoprene to separate the leaded layer from $7 \underline{M}$ acid at room t.emperature. The diffusion of $\mathrm{HNO}_{3}$ through the protective surface limited the rate of reaction, but the action of $\mathrm{HNO}_{3}$ vapors on the leaded layer also contributed to the reaction. Soaking the explosive material in water at $95^{\circ} \mathrm{C}$ for $15 \mathrm{~min}$ yielded a nonexplosive solid and a liquid. The liquid could safely be evaported to dryness and safely decomposed by heat.

Glove-box operations and R\&D projects routinely generate nonplutonium scrap metal. Washing or leaching this material in $\mathrm{HNO}_{3}$ and $\mathrm{F}^{-}$(Fig. 2) is a relatively easy decontamination method. Several techniques allow for the removal of gross quantities of plutonium that have been deposited on metallic scrap. Hydriding converts plutonilm metal to a plutonium hydride that can be easily removed from the base material. The plutonium can also be oxidized, or in some cases compounds can be thermally decomposed. Abrasion of the metallic surfaces may also remove the contamination. Dissolution or leaching of these plutonium-bearing products makes the plutonium soluble. Researchers are also testing techniques such as

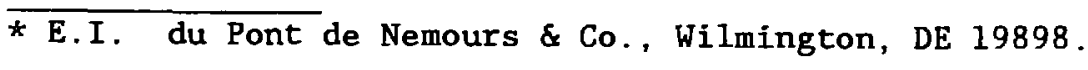


vibratory polishing, electropolishing of stainless steel, and electrolytic dissolution for possible use on these residues.

Plutonium-processing facilities generate contaminated glass residues, including materials such as Raschig rings, glove-box windows, and processing equipment. The leaching process for these materials uses $\mathrm{HNO}_{3}$ and hydrofluoric acid ( $\mathrm{HF}$ ) or calcium difluoride ( $\mathrm{CaF}_{2}$ ) (Fig. 2). Several leachings might be necessary to achieve a glass residue that may be discarded. A potential hazard in processing glass residues is the presence of glass shards that can easily penetrate gloves and injure the operator.

HEPA filters are another type of material widely used in the plutonium-processing facilities. After the filters have reached their filtering capacity, they may be discarded or, if they contain concentrations above the discard limit, they must be processed. The general steps in treating this type of material include disassembling the filters, leaching the filter media in refluxing $\mathrm{HNO}_{3}$ and $\mathrm{F}^{-}$(Fig. 2), and discarding the residues. The frames that house the filtering media may usually by discarded withult processing.

Some production facilities use the generic term sludge to designate material that has settled to the bottom of solution-storage tanks or other process vessels. The precipitate found in most waste and process streams may also be referred to as sludge. Depending upon the nature and source of the residue, facilities may treat this material by washing, leaching, or dissolution in $\mathrm{HNO}_{3}$ plus $\mathrm{HF}$ or $\mathrm{CaF}_{2}$.

Sand, slag, and crucibles are the residues from the calcium reduction of plutonium cetrafluoride $\left(\mathrm{PuF}_{4}\right)$ to form plutonium metal. The sand and crucible materials are magnesium oxide (MgO), which may contain a silicon dioxide binder, and slag, which is principally a mixture of $\mathrm{CaF}_{2}$ and minor amounts of calcium oxide $(\mathrm{CaO})$. Sand, slag, and crucibles from some sites contain large amounts of calcium iodide, which operators add before the initiation of the reduction step to boost the reaction temperature and allow the reaction to go to completion. Careful sorting of this material 
may allow discard of low-level plutonium residues. Material requiring further processing is sent to a pretreatment operation where a crusher/pulverizer converts it to a powder. This step allows an auger feeder to add the material to the first stage of a 6-in. cascade dissolution system. ${ }^{8}, 9$ Technicians add pulverized sand, slag, and crucible, $\mathrm{HNO}_{3}$, and aluminum nitrate $\left[\mathrm{Al}\left(\mathrm{NO}_{3}\right)_{3} \cdot 9 \mathrm{H}_{2} \mathrm{O}\right]$ concurrently to the first dissolver, and air-lift mixing provides for adequate solid/liquid contact (Figs. 4 and 5). An immersion steam loop heats the material to about $90^{\circ} \mathrm{C}$. The solution cascades through the second and third stages before filtration. The small heel remaining after dissolution is usually combined with the next feed material. The off-gas from this process passes through a condenser and is then scrubbed in caustic solution to neutralize the volatilized iodine and to retard the corrosion of process equipment. After filtration, the solution is processed by solvent extraction or ion exchange. Several facilities also use pot dissolvers and slab dissolvers in the dissolution step.

Ceramics is ancther category of scrap generated in pyrochemical operations and analytical chemistry. Pyrochemical processes, including DOR and ER, use magnesia crucibles. Analytical chemistry employs LECO crucibles in the determination of carbon in plutonium dioxide $\left(\mathrm{PuO}_{2}\right), a$ procedure that results in a refractory $\mathrm{PuO}_{2}$ imbedded in the crucible. The magnesia crucibles from $\mathrm{Ca} / \mathrm{PuF}_{4}$ reductions may be processed in the same manner as sand, slag, and crucibles, or the crucible pieces may be pickled in HCl. The LECO crucibles are a particularly intractable residue, and no one has yet developed a suitable process to recover the plutonium from this category of material.

We have already described dissolution in $\mathrm{HNO}_{3}$ for sand, slag, crucibles, and incinerator ash and $\mathrm{HNO}_{3}$ pickling of extraneous materials. High-percentage plutonium in oxide is normally dissolved with $10-16 \mathrm{MNO}_{3}$ and $0.05-0.4 \mathrm{M} \mathrm{F}^{-}$from $\mathrm{HF}$ or a fluoride salt such as $\mathrm{CaF}_{2}$ (Fig. 6). At Los 


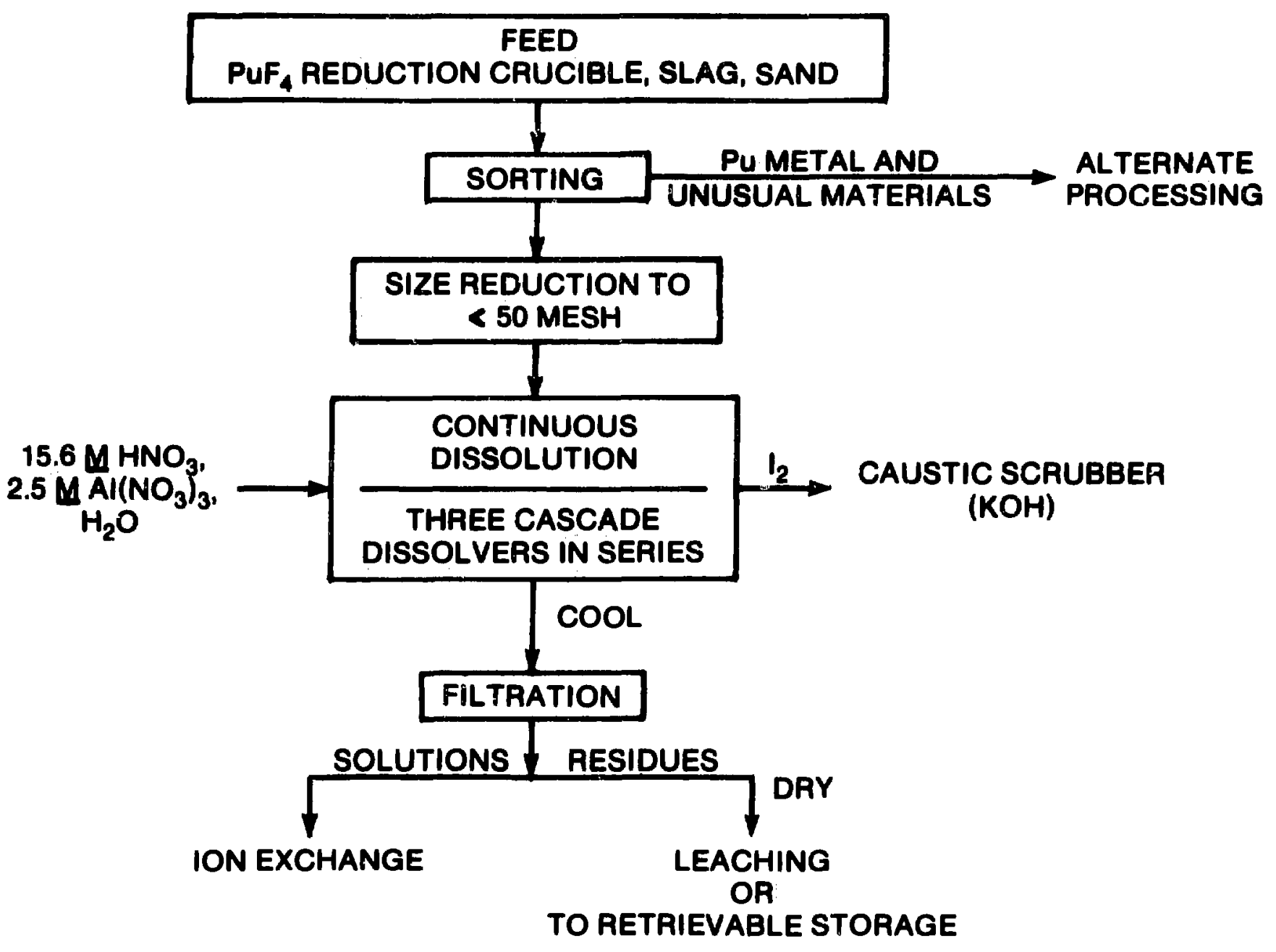

Fig. 4. Slag and crucible dissolution. 


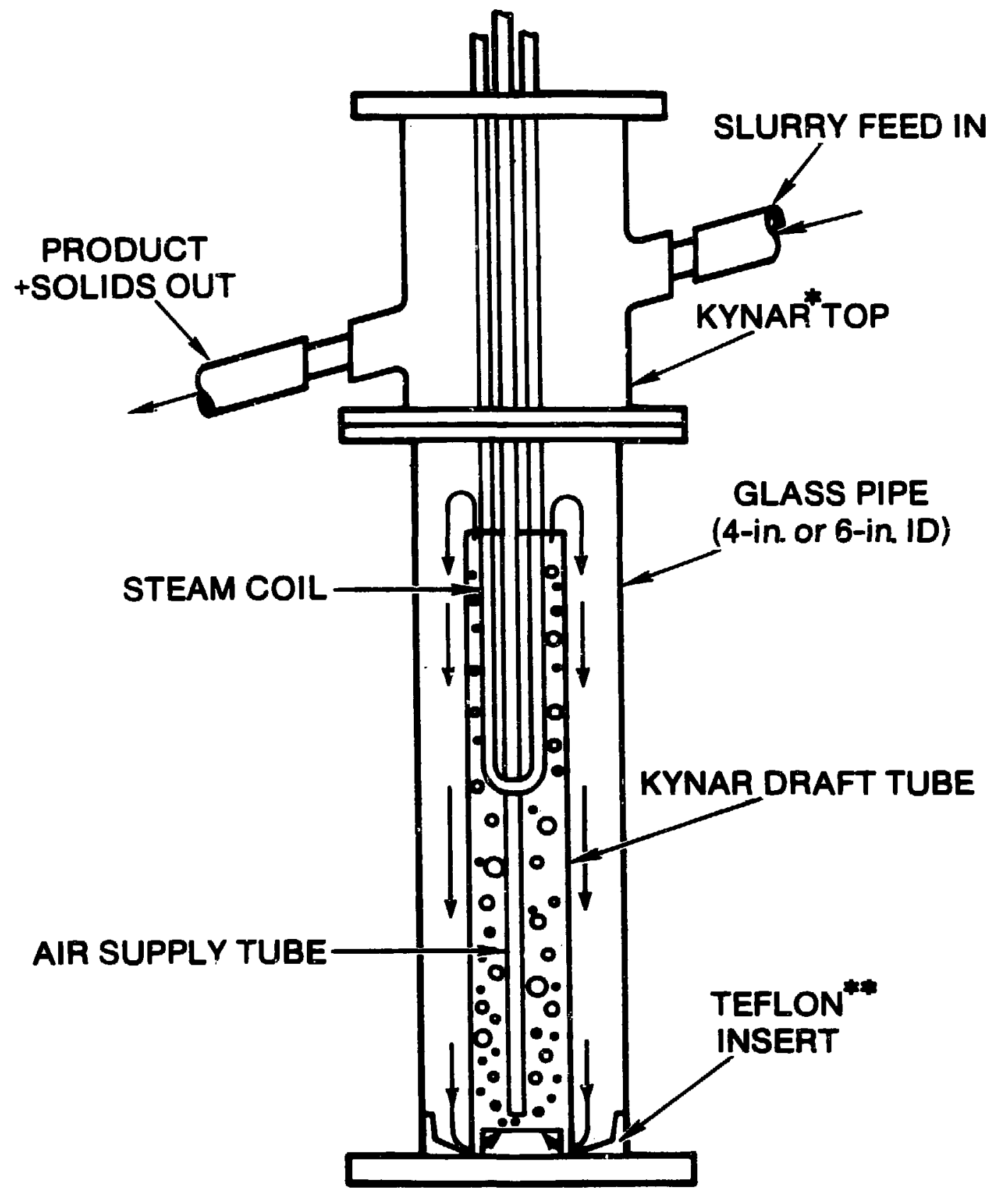

Fig. 5. Operating principle of 4-in. and 6-in. cascade dissolvers. (Normal operation requires three dissolvers in series.)

* Pennsalt Chemicals Corp., 3 Penn Center, Philadelphia, PA 19102.

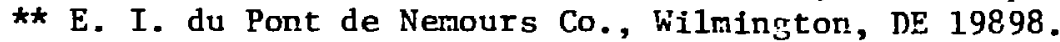




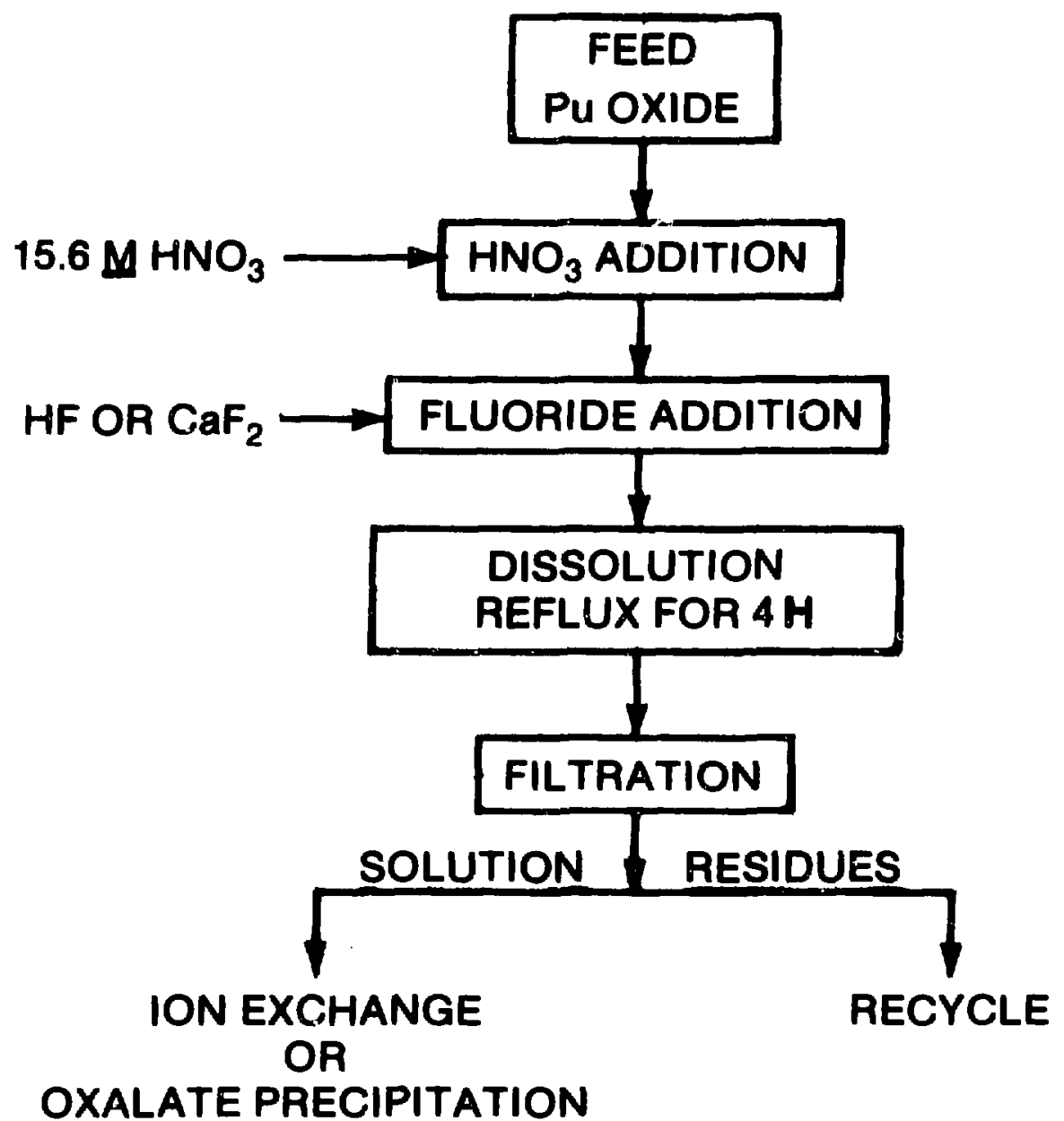

Fig. 6. Dissolution of $\mathrm{PuO}_{2}$. 
Alamos, traditional dissolutions, dating from the early 1950s, "involved the spterical 5-l Pyrex* dissolution vessel with heating mantle, sparge inlet, and reflux or distillation condenser. Although the earlier system was convenient for speciai lots of material, a more efficient method utilizes the 4-in. cascade dissolution system, which is a scaled-down version of the 6-in. system described earlier (Fig. 5). Rocky Flats Plant (RFP) developed the cascade dissolvers, which were recently installed, tested, and put into routine use at Los Alamos National Laboratory. Advantages include higher efficiency, a higher rate or production, and lower plutonium(VI) content in the product.

Heels, a particularly prolific category of residue, are the undissolved residue of a feedstock after one or more leaching/dissolving cycles. The original feedstock may have been $\mathrm{PuO}_{2}$, incinerator ash, impure metal, blasting grit, or nitrate salts. Generally, heels are repeatedly leached in $\mathrm{HNO}_{3}$ plus $\mathrm{HF}$ or $\mathrm{CaF}_{2}$. The usual method of processing permits the addition of fresh feed material to the heels to make the repeated leachings more efficient.

$\mathrm{PuO}_{2}$ that has been subjected to high temperatures is a very refractory material and is difficult to dissolve by normal techniques. Oxides that have been heated to less than $600^{\circ} \mathrm{C}$ are usually easier to dissolve than are oxides heated to temperatures between $600^{\circ} \mathrm{C}$ and $1000^{\circ} \mathrm{C}$. Oxides that have been fired at temperatures greater than $1000^{\circ} \mathrm{C}$ recuire more extreme dissolution measures. 4 Researchers often cite t., ability of refluxing $\mathrm{HNO}_{3} / \mathrm{HF}$ to dissolve $\mathrm{PuO}_{2}{ }^{10,11}$; however, the high-temperature oxide dissolves only very slowly in this acid mixture. Bjorkland and Staritzky 12 found an increase in the refractive index of $\mathrm{PuO}_{2}$ prepared from plutonium(III) or plutonium(IV) oxalate as the ignition temperature increased. Experimental results indicate that perfection of the originally

* Corning Glass Horks, Corning, NY 14832 . 
highly disoriented (and nonstoichiometric) $\mathrm{PuO}_{2}$ lattice is responsible for the refractive nature of the high-fired oxide.

Several methods for attacking very refractory oxides involve high cost and various processing problems; they are therefore used only when priorities dictate the extra effort. One very effective procedure developed by Pritchard and Johnson utilizes a NaF- $\mathrm{K}_{2} \mathrm{~S}_{2} \mathrm{O}_{7}$ fusion followed by dissolution of the solidified melt in $\mathrm{HNO}_{3}-\mathrm{Al}\left(\mathrm{NO}_{3}\right)_{3}$. Total plutonium dissolution is very good, but the method produces large volumes of highsalt solutions and, therefore, higher processing costs. Oxidation of plutonium(IV) to plutonium(VI) can increase the dissolution effectiveness by liberating fluoride complexed by plutonium(IV). 11

2. Separation and Purification by Precipitations. The separation of plutonium from aqueous solutions makes use of many different precipitations, the most common being oxalate, peroxide, hydroxide, and fluoride. The following are the more common reasons for conducting the precipitations:

- Relatively concentrated plutonium nitrate or chloride solutions can be largely or partially purified from many cationic impurities.

- A convenient method for changing the principal anion is to precipitate the plutonium from $\mathrm{HCl}$ or sulfuric acid $\left(\mathrm{H}_{2} \mathrm{SO}_{4}\right)$ as an oxalate, 4 convert the plutonium to $\mathrm{PuO}_{2}$, and dissolve it in $\mathrm{HNO}_{3} / \mathrm{HF}$.

- Precipitation of plutonium(III) oxalate from the very large volumes of nitrate anion-exchange eluates is a very quick and convenient concentration step.

- Calcination at $500^{\circ}-600^{\circ} \mathrm{C}$ can easily convert properly precipitated oxalates of plutonium(III) and plutonium(IV) to reactive $\mathrm{PuO}_{2}$ suitable for hydrofluroination prior to metal preparation by calcium reduction. 13,14 If the oxalates are heated in air to $800^{\circ} \mathrm{C}$ to remove residual carbon and acids, the resulting oxide is suitable for DOR. ${ }^{15}$ As we note later, some precipitated plutonium fluorides can also be precursors for reduction to the metal.16,17

- Precipitation of plutonium and americium hydroxides from waste solutions such as oxalate or peroxide filtrates is an effective method to allow discard of the alkaline filtrate and recycle of the plutonium and americium in the separated solids. 
In the following sections we describe some of the more important precipitations and the disposal of their filtrates.

a. Plutonium(III) Oxalate. Since the early days of the Manhattan Project, researchers have found it advantageous to produce large-particlesize precipitate by reducing plutonium to the III state and precipitating $\mathrm{Pu}_{2}\left(\mathrm{C}_{2} \mathrm{O}_{4}\right)_{3} \cdot 10 \mathrm{H}_{2} \mathrm{O}^{4,18,19}$ (Fig. 7) by the controlled addition of aqueous oxalic acid $\left(\mathrm{H}_{2} \mathrm{C}_{2} \mathrm{O}_{4}\right)$. Solid $\mathrm{H}_{2} \mathrm{C}_{2} \mathrm{O}_{4}$ will produce a smaller-particle-size precipitate. The typical precipitate filters readily and has a practical production solubility of $0.1-0.5 \mathrm{~g} \mathrm{Pu} / \ell$. The solubility is directly proportional to the free $\mathrm{H}^{+}$and inversely proportional to the concentration of $\mathrm{H}_{2} \mathrm{C}_{2} \mathrm{O}_{4}$. As the percentage of plutonium(IV) increases from 08 to $109 \%$, the plutonium oxalate color changes from turquoise-blue to blue-grey and finally to light tan. At $500^{\circ} \mathrm{C}-600^{\circ} \mathrm{C}$ both plutonium(III) and plutonium(IV) oxalate convert readily in air to a reactive, slightly substoichiometric oxide that is quite reactive4,20 during hydrofluorination or dissolution in $\mathrm{HNO}_{3} / \mathrm{HF}$. Plutonium(III) oxalate purifications give good decontamination factors from such impurities as $\mathrm{Al}^{+3}, \mathrm{Fe}^{+3}$, and $\mathrm{UO}_{2}^{+2}$. There is less decontamination from sodium, potassium, and calcium and none from americium(III).

b. Plutonium(IV) Oxalate. Plutonium(IV) oxalate $\left[\mathrm{Pu}\left(\mathrm{C}_{2} \mathrm{O}_{4}\right)_{2} \cdot 6 \mathrm{H}_{2} \mathrm{O}\right]$ precipitates readily from dilute acids $16,17,21,22$ but is usually quite fine and often gummy. Precipitation at elevated temperatures can greatly improve precipitate characteristics. Experience at Los Alamos indicates the best precipitate is produced by the simultaneous addition of plutonium nitrate solution and $1 \mathrm{M} \mathrm{H}_{2} \mathrm{C}_{2} \mathrm{O}_{4}$ solution to well-stirred $1.5 \mathrm{M} \mathrm{HNO}_{3}$ maintained at about $60^{\circ} \mathrm{C}$ (Fig, 8). The precipitate is quite coarse and compares favorably with the best plutonium(III) oxalate precipitates. Hanford $23: 24$ treats the fairly pure plutonium-nitrate feed with hydrogen peroxide $\left(\mathrm{H}_{2} \mathrm{O}_{2}\right)$ to reduce plutonium(VI) to plutonium(IV) because plutonium(VI) oxalate is quite soluble. Investigators found the higher iron content of the miscellaneous feed solutions at Los Alamos increased $\mathrm{H}_{2} \mathrm{O}_{2}$ decomposition for a similar pretreatment. They added the $\mathrm{H}_{2} \mathrm{O}_{2}$ at the 


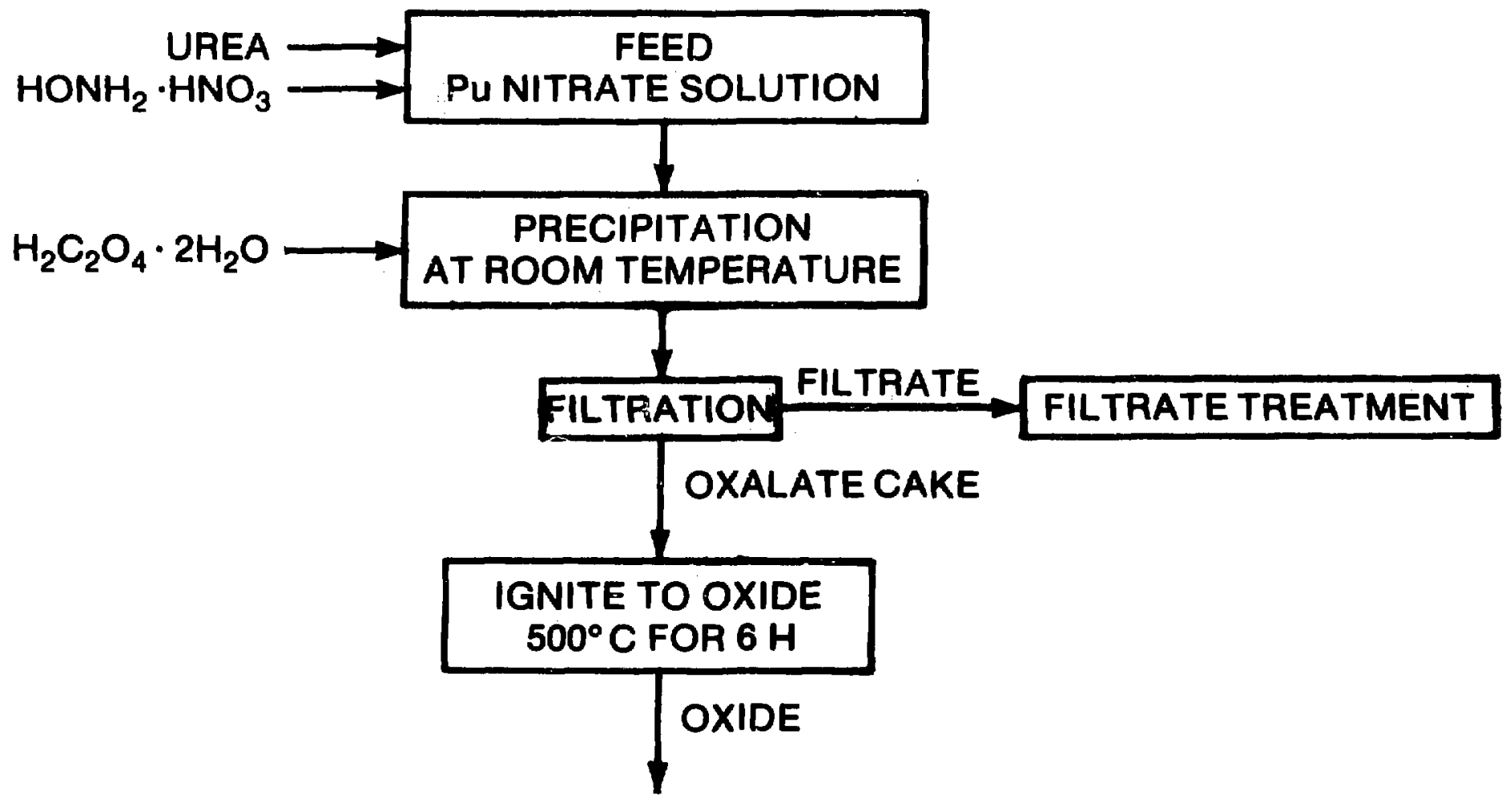

Fig. 7. Plutonium(III) oxalate precipitation. 


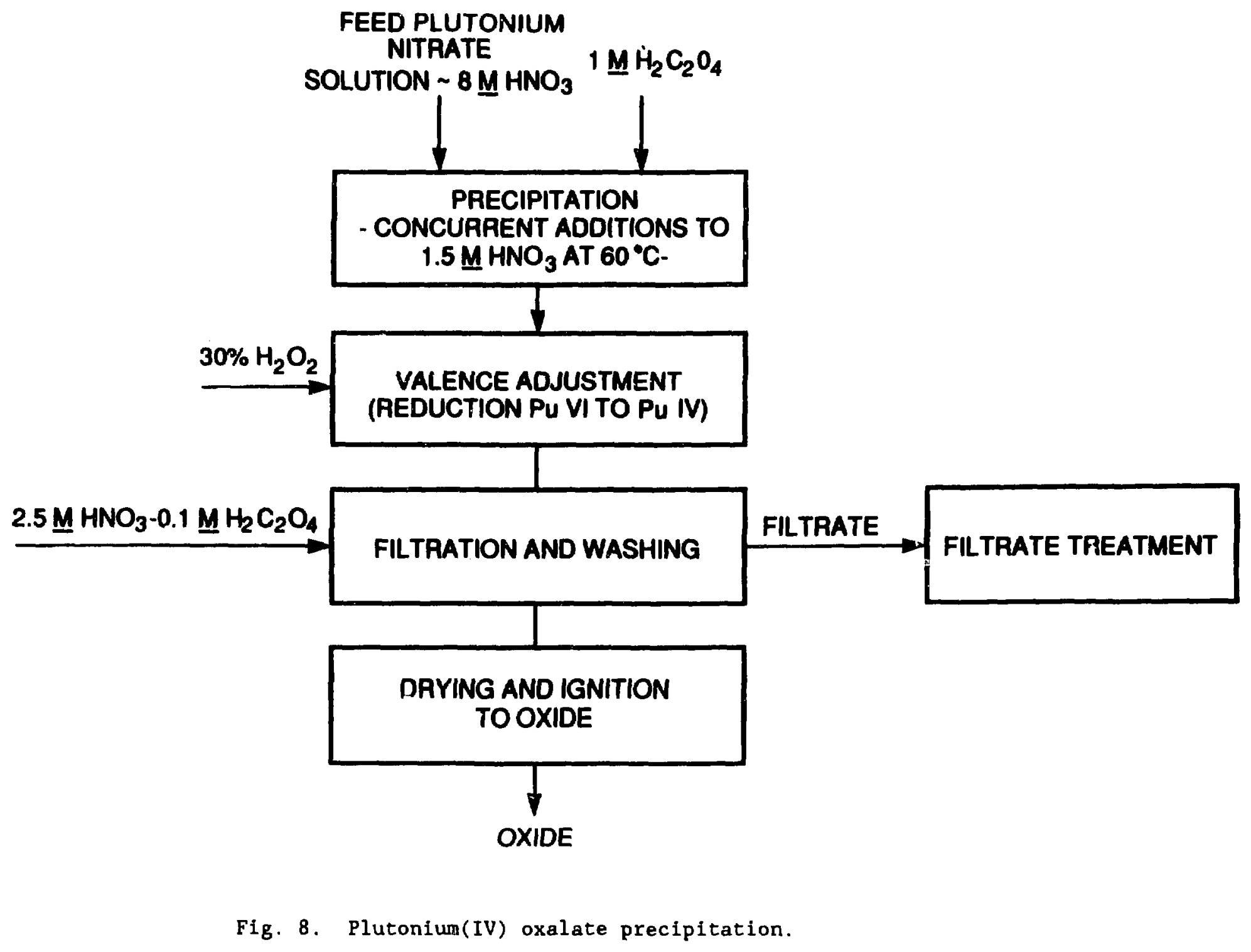


end of the precipitation because the ferric iron was complexed by oxalate ion and was therefore less effective in $\mathrm{H}_{2} \mathrm{O}_{2}$ destruction. The Hanford precipitation is continuous, whereas the Los Alamos precipitation is a batch process. The Los Alamos precipitate is medium tan and quite coarse. Filtration and washing are very rapid, and the oyide product is a freefluwing powder with few or no lumps. Recovery filtrate losses are approximately $0.2-0.5 \mathrm{~g} \mathrm{Pu} / \ell$. Because of their higher acidity, $\mathrm{Fe}^{+3}, \mathrm{Al}^{+3}$ and $\mathrm{UO}_{2}{ }^{+2}$ have higher decontamination factors than do plutonium(III) oxalates. The solubility of plutonium(IV) oxalate in the presence of excess $\mathrm{H}_{2} \mathrm{C}_{2} \mathrm{O}_{4}$ generally exhibits a minimum value in the range of $1-3 \mathrm{M}$ free $\mathbf{H}^{+}$. At lower acidities, a strong oxalate complex increases the solubility, and at higher acidities the solubility increases because of the solvent action of the strong acid.

c. Plutonium Peroxide. Plutonium peroxide is an olive-green precipitate formed by the addition of $308-508 \mathrm{H}_{2} \mathrm{O}_{2}$ to a solution of plutonium(IV) (Fig. 9). The useful range for nitric solution is 2.5-5.5 $\mathrm{H}^{+}$. A brown peroxy complex forms during the first addition of $\mathrm{H}_{2} \mathrm{O}_{2}$; a red complex follows.2s Finally, the olive-green peroxide precipitate forms. To prevent appreciable $\mathrm{H}_{2} \mathrm{O}_{2}$ decomposition, operators hold the temperature at $10^{\circ} \mathrm{C}-15^{\circ} \mathrm{C}$; however, if the reaction is stable; $15^{\circ} \mathrm{C}-20^{\circ} \mathrm{C}$ is appropriate. High levels of iron, copper, manganese, or nickel will catalyze the destruction of $\mathrm{H}_{2} \mathrm{O}_{2}$, producing a rapid decomposition. In respect to other precipitations, the peroxide purification probably gives the best overall decontamination from cations. Unlike oxalates, peroxides give scellent decontamination from 241 Am. At higher acidities and with careful $\mathrm{H}_{2} \mathrm{O}_{2}$ addition, the readily filterable hexagonal form of plutonium peroxide will precipitate. ${ }^{26}$ At lower acidities, an undesirable, gelatinous, cubic form will precipitate. Mixtures of hexagonal and cubic phases do occur. Sulfate ion added to the plutonium-nitrate feed solution at 0.1-0.3M concentration tends to improve precipitate characteristics. Plutonium peroxide is not a stoichiometric compound, but its $0 / \mathrm{Pu}$ ratio may approximate 3.5. Anions such as $\mathrm{NO}_{3}^{-}$, $\mathrm{SO}_{4}^{--}$, and $\mathrm{Cl}^{-}$are incorporated into the structure. RFP hydrofluorinates 


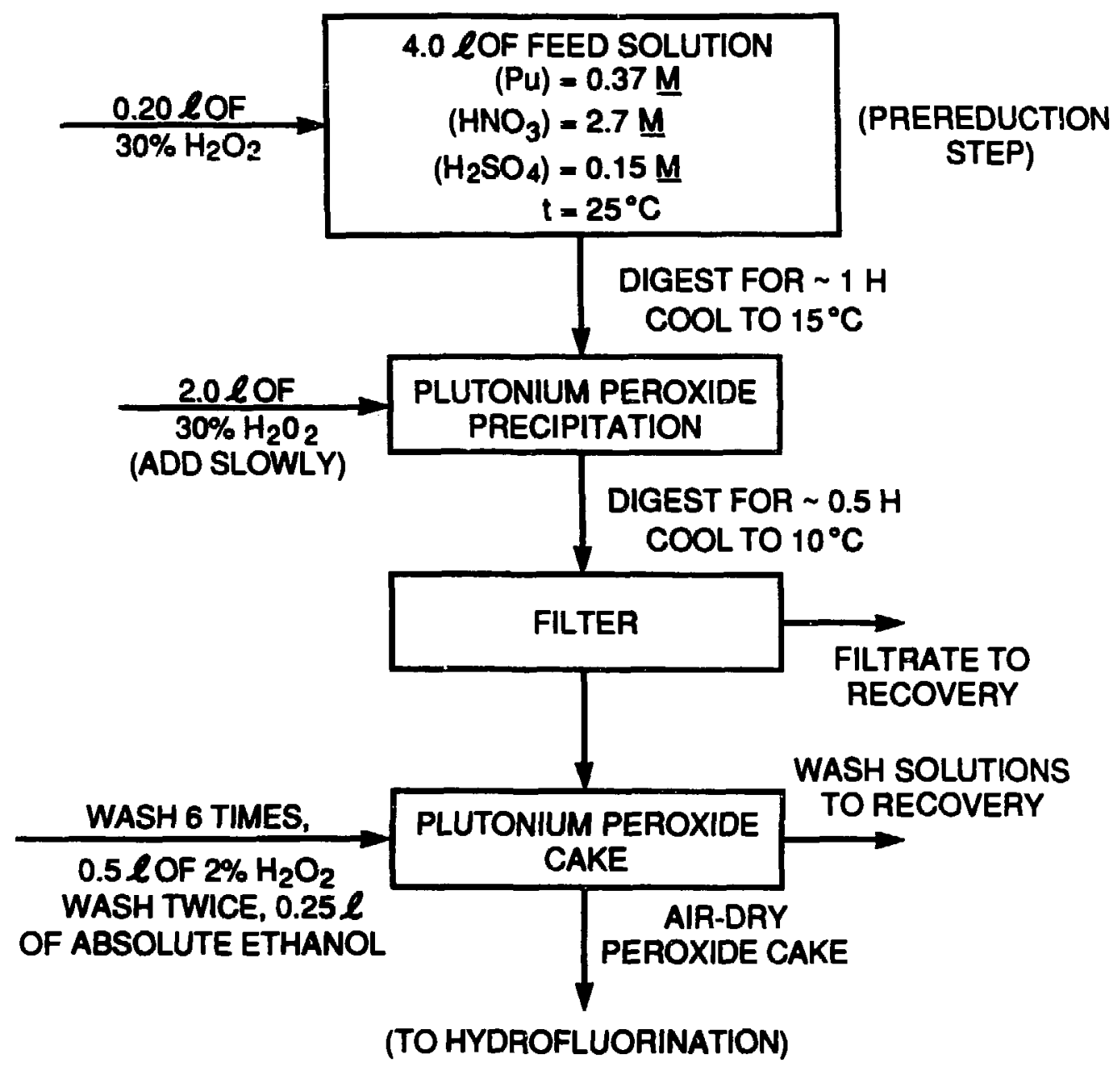

Fig. 9. Plutonium peroxide precipitation. 
plutonium peroxide to obtain plutonium tetrafluoride ( $\mathrm{PuF}_{4}$ ) for calcium reduction to metal. Los Alamos formerly used this process but now uses plutonium peroxides exclusively for purification. The dissulution of the peroxides is followed by a plutonium(III) oxalate precipitation and calcination either to provide oxide for the Fast Flux Test Facility breeder-reactor experiment or to provide a feed for metal production. It should be noted that calcination of oxalates is more easily controlled than calcination of peroxides. ${ }^{27}$

d. Plutonium Hydroxide. As we noted earlier, hydroxide precipitations are quite useful for producing a filtrate that can be discarded to final waste management. Frequently, facilities treat oxalate and peroxide filtrates with sodium hydroxide ( $\mathrm{NaOH})$ or potassium hydroxide (KOH) for precipitation of plutonium and ${ }^{241} \mathrm{Am}$ hydroxides and destruction of $\mathrm{H}_{2} \mathrm{O}_{2}$. If plutonium(III) is present, plutonium(III) hydroxide will precipitate, but it will then slowly oxidize to plutonium(IV), which is much less soluble and has a solubility product of $10^{-52}$ to $10^{-56} .^{25}$ The plutonium(IV) hydroxide is generally a green gelatinous precipitate that occludes many ions from the solution. As we noted before, the objective is to use the precipitation as a scavenger because purification is not very good. Hydroxide precipitations are particularly valuable as a method for discarding waste chloride solutions because there are no serious corrosion effects in stainless steel if the solutions are alkaline. One difficult problem is the handling of voluminous precipitates of such elements as magnesium and calcium, unless the $\mathrm{pH}$ can be carefully controlled.

e. Plutonium Fluoride. Although the process is not as common as oxalate and peroxide precipitations, some facilities have precipitated plutonium as $\mathrm{PuF}_{3}$ and $\mathrm{CaPuF}_{6}{ }^{16,17}$ to provide precursors to metal reduction. Both compounds can be precipitated, filtered, and dried, although $\mathrm{HF}, \mathrm{O}_{2}$, and elevated temperatures are necessary for pure $\mathrm{PuF}_{3}$, and argon or nitrogen is used to dry $\mathrm{CaPuF}_{6}$. Dried $\mathrm{PuF}_{3}$ may be roasted in $\mathrm{O}_{2}$ to produce a mixture of $\mathrm{PuF}_{4}$ and $\mathrm{PuO}_{2}$, which will give $958-978$ yields of plutonium metal upon reduction with calcium metal. Precipitated $\mathrm{PuF}_{4} \cdot 2.5 \mathrm{H}_{2} \mathrm{O}$ is hard 
to filter, handle, and dehydrate, so it is not a metal-reduction precursor. Decontamination from many impurities is not good for plutonium fluoride, so the feed solutions must be relatively pure. Savannah River has used variations of the $\mathrm{PuF}_{3}$ process, but Los Alamos, Hanford, and RFP use hydroflucrination of oxalates, oxides, or feroxides.

f. Disposal of Oxalate and Peroxide Filtrates. Because facilities cannot directly discard oxalate and peroxide filtrates to final waste management, the materials must undergo further treatment. Oxalate filtrates cannot be easily and directly recycled because $\mathrm{H}_{2} \mathrm{C}_{2} \mathrm{O}_{4}$ interferes appreciably with tributylphosphate (TBP) solvent extraction and with absorption of plutonium on a nitrate anion-exchange column. Addition of $\mathrm{Al}\left(\mathrm{NO}_{3}\right)_{3}$ or increasing the $\mathrm{HNO}_{3}$ to $9 \mathrm{M} \mathrm{HNO}_{3}$ can allow the nitrate anionexchange technique to be used.' At Los Alamos, evaporation of the oxalate filtrates destroys a relatively large amount of the oxalate ion while: allowing a more economical volume of solution to be recycled through the ion-exchange column. Hanford and Savannah River use 0.02-0.04M $\mathrm{Mn}^{+2}$ to catalyze elevated-temperature destruction of $\mathrm{H}_{2} \mathrm{C}_{2} \mathrm{O}_{4}$. Heat will decompose $\mathrm{H}_{2} \mathrm{O}_{2}$, but operators must use caution to prevent violent decomposition.

As we noted above, both peroxide and oxalate filtrates are amenable to hydroxide precipitation and subsequent discard of their filtrates. The hydroxide cakes can be recycled for recovery of the plutonium and americium.

3. Nitrate Anion Exchange. At Los Alamos and RFP, nitrate anion exchange is the major technique employed in the aqueous concentration and purification of plutonium. Originally, the resin of choice was a gel-type Dowex $^{*} 1 \times 4$ (50-1.00 mesh), 1,28 which was used at Los Alamos and other sites for many years. However, Los Alamos now uses a macroporous resin in production-scale columns. 29

* The Dow Chemical Co., Midland, MI 48640. 
Nitrate anion exchange is an extremely powerful technique for recovering and separating plutonium from most of the elements in the periodic table. Figure 10 presents distribution coefficients for certain elements in a nitrate anion-exchange system operated at room temperature and using $7 \mathrm{M} \mathrm{HNO}_{3}$ and Dowex $1 \times 4$ (50-100 mesh) resin.30 The hexanitrato complex, $\mathrm{Pu}\left(\mathrm{NO}_{3}\right) \overline{6}^{2}$, formed by plutonium under these conditions results in the large distribution coefficient ( $\mathrm{Kd}-1000) .4$ The $\mathrm{HNO}_{3}$ concentration of the feed solution may vary depending upon the amount of nitrate salts present. The absorption of plutonium increases with increasing nitiate concentration at constant acidity. Aluminum will complex such anions as fluoride and oxalate,, 25 which would normally complex the plutonium and prevent full plutonium absorption on the resin.4,3i The plutonium must be in the IV state to form the hexanitrato complex and, as is well known, plutonium in aqueous solutions can exist in a multiplicity of the four possible valences. The potentials separating the oxidation states, although small, are sufficient to allow operators to obtain the desired oxidation state by a judicious selection of the sequence and type of reducing and oxidizing agents.

Ion-exchange operations may be conveniently divided into the following steps: (1) oxidation-state feed adjustment, (2) loading, (3) washing, (4) elution, and (5) readjustment of the column from the low-acid elution step to $7 \mathrm{M} \mathrm{HNO}_{3}$ in preparation for the next step.

Although plutonium operations have used many reducing and oxidizing agents, the major reagents used in production operations include hydroxylamine nitrate $\left(\mathrm{NH}_{2} \mathrm{OH} \cdot \mathrm{HNO}_{3}\right), 32$ ferrous ammonium sulfate $\left[\mathrm{Fe}\left(\mathrm{SO}_{4}\right) \cdot\left(\mathrm{NH}_{4}\right)_{2} \mathrm{SO}_{4}-6 \mathrm{H}_{2} \mathrm{O}\right]$ sodium nitrite $\left(\mathrm{NaNO}_{2}\right)$, urea $\left[\mathrm{CO}\left(\mathrm{NH}_{2}\right)_{2}\right]$ and $\mathrm{H}_{2} \mathrm{O}_{2}$. Depending upon the processing history of the plutonium solution, the plutonium(VI) content may vary over a wide range. Generally speaking, solutions that have been boiled for extended periods (for example, recycle solutions from the production-scale thermosiphon evaporator) or solutions that have been maintained at less than $3 \mathrm{M}^{\mathrm{H}} \mathrm{HNO}_{3}$ at elevated temperatures 3 tend to contain large amounts of plutonium(VI). Consequently, Los Alamos 


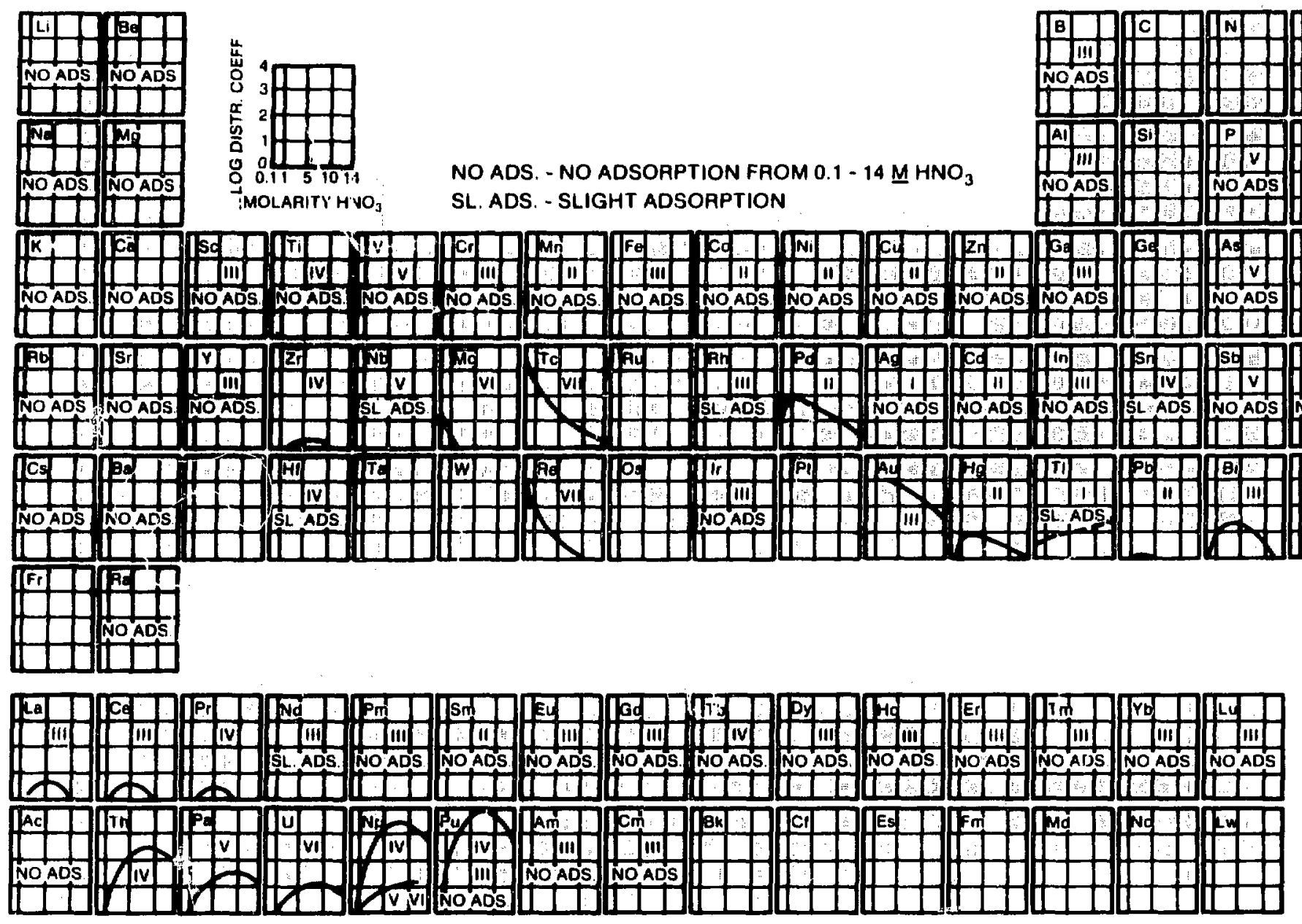


uses two oxidation-state adjustment schemes, the full-reduction flow sheet and the partial-reduction flow sheet.

a. Valence and Feed Adjustment. For the solutions suspected of having large quantities of plutonium(VI) the full-reduction flow sheet is indicated (Fig. 11). ${ }^{5}$ This flow sheet consists of the following steps:

1. Operators reduce the $\mathrm{H}^{+}$concentration to $<3 \mathrm{M}$ to prevent a violent reaction. The addition of $\mathrm{CO}\left(\mathrm{NH}_{2}\right)_{2}$ before $\mathrm{NH}_{2} \mathrm{OH} \cdot \mathrm{HNO}_{3}$ destroys the nitrite that would otherwise corsume the reducing agent before it could react with the plutonium. Then technicians add 1.5 moles of $\mathrm{NH}_{2} \mathrm{OH} \cdot \mathrm{HNO}_{3}$ per mole of plutonium.

2. The addition of $\mathrm{Fe}\left(\mathrm{SO}_{4}\right) \cdot\left(\mathrm{NH}_{4}\right)_{2} \mathrm{SO}_{4} \cdot 6 \mathrm{H}_{2} \mathrm{O}$ ensures the complete reduction of the plutonium(VI). The process requires a digestion period of at least 45 min.

3. The addition of $\mathrm{AL}\left(\mathrm{NO}_{3}\right)_{3} \cdot 9 \mathrm{H}_{2} \mathrm{O}$ enhances plutonium absorption by complexing the $\mathrm{F}^{-}$ion and increasing $\mathrm{NO}_{3}^{-}$concentration.

4. Operators add $\mathrm{NaNO}_{2}$ to oxidize the plutonium(III) to plutonium(IV). The process requires a digestion period of at least 15 min to ensure complete oxidation.

5. Operators adjust the $\mathrm{HNO}_{3}$ concentration to $7 \mathrm{M}$ by adding $15.6 \mathrm{M} \mathrm{HNO}_{3}$ and then feed the solution to the anion-exchange column.

This flow sheet is extremely effective in converting all plutonium to plutonium(IV). However, it adds relatively large amounts of salts and causes a significant volume increase.

Fnr feed solutions containing a low concentration of plutoniun(VI), the experimental partial reduction flow sheet discussed below may work successfully. 


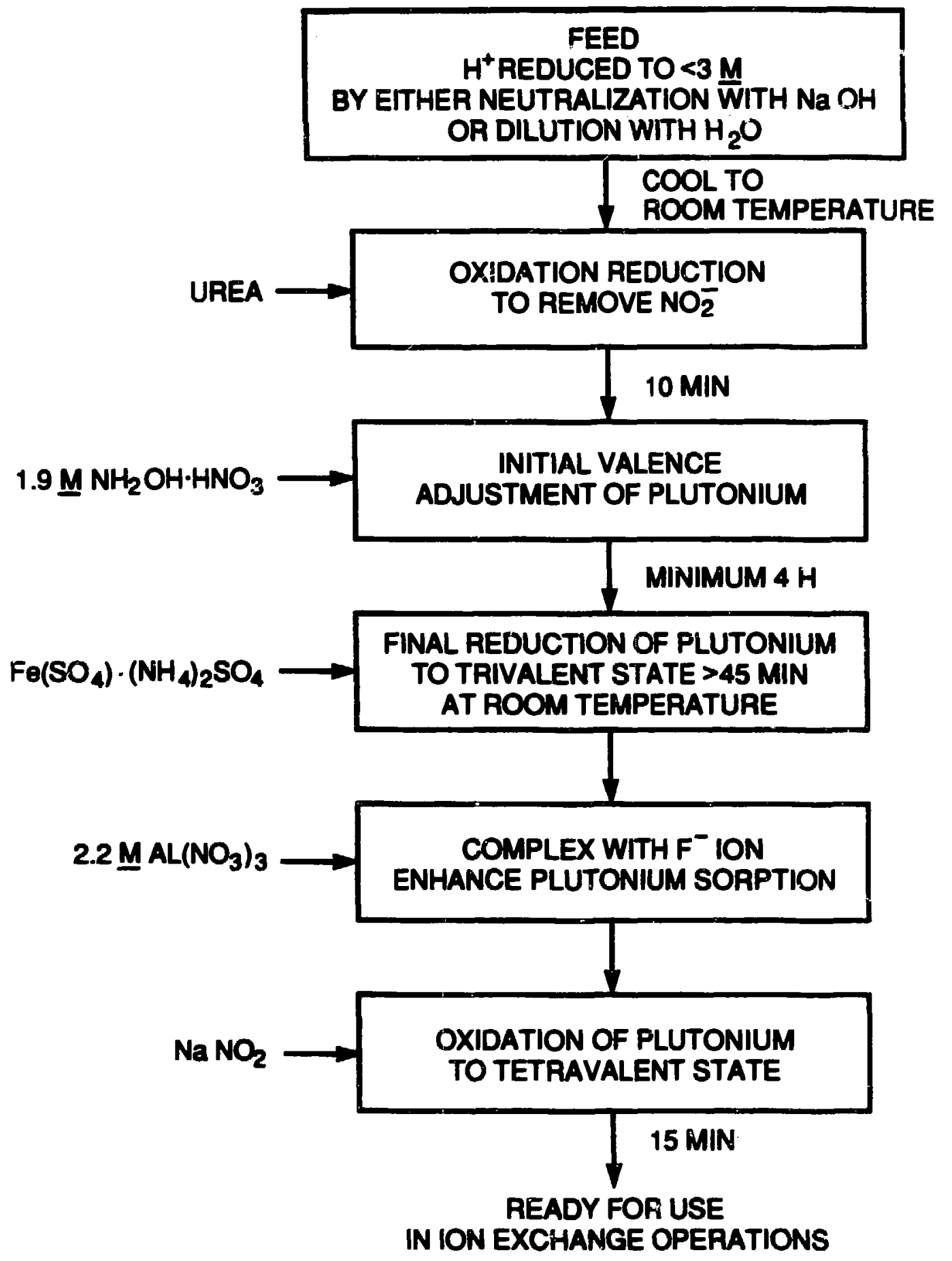

Fig. 11. Stabilization of plutnoium(IV). 
1. In the past, $\mathrm{NaNO}_{2}$ was added initially. However, researchers doubt its efficiency in the reduction of plutonium(VI) to plutonium(IV). Based on earlier work, current experiments by S. F. Marsh at Los Alamos involve the production-scale use of $\mathrm{H}_{2} \mathrm{O}_{2}$ as an agent for reducing plutonium(VI) to plutonium(IV). ${ }^{34}$

2. The addition of $\mathrm{Al}\left(\mathrm{NO}_{3}\right)_{3}$ complexes the $\mathrm{F}^{-}$ion. S. F. Marsh has quantified this effect. ${ }^{31}$

3. Operators adjust the $\mathrm{HNO}_{3}$ concentration to $7 \underline{\mathrm{M}}$.

4. Technicians load the treated feed solution on the anion-exchange resin bed.

b. Loading. Flow rates for feed solutions passing through the resin bed vary according to plutonium concentration. At Los Alamos, solutions containing up to $10 \mathrm{~g} \mathrm{Pu} / \mathrm{l}$ are pumped through the bed at a rate of $60 \mathrm{l} / \mathrm{h}$. Recent work by Marsh ${ }^{35}$ indicates that these flow rates may be increased by use of the new macroporous resin LEWATIT MP-500-FK. * For solutions containing $>10 \mathrm{~g} \mathrm{Pu} / \ell$, operators decrease the flow rate to $10 \mathrm{l} / \mathrm{h}$. A recently developed on-1ine gamma detector allows the constant monitoring of the behavior of uranium, plutonium, and americium during the process, and column breakthrough is readily Identified.36,37 Also, technicians can see the plutonium band thrcugh the glass column and can vary flow rates to meet the prevailing conditions. Scientists at Savannah River are also evaluating on-line passive gamma analyzers. ${ }^{38}$

c. Washing. After loading the plutonium on the resin bed, technicians wash the impurities from the bed using $7 \mathrm{M} \mathrm{HNO}_{3}$. The plutonium content of the wash requires most of this solution to be recycled. The fraction of

*Mobay Chemical Corporation, Pittsburgh, PA 15205. 
impurity remaining on the column is a function of the wash volume. As a rule of thumb, elements having a distribution coefficient of zero can be washed from the resin bed with 1-2 column volumes (here defined as void volume) of $7 \mathrm{M} \mathrm{HNO}_{3}$. Elements having higher distribution coefficients exhibit a more complex behavior and several column volumes may be required for the wash, depending upon the element. Separation of elements such as thorium, neptunium, and the precious metals by standard flow sheets is relatively ineffective, and other separation techniques must be utilized." However, thorium and neptunium can be absorbed on the resin if the plutonium is reduced to the III state by hydrazine/ferrous sulfamate using Savannah River techniques. ${ }^{39}$ Note that these are guidelines only. For example, uranium has a $\mathrm{Kd}$ of approximately 15, yet operating experience at Los Alamos indicates that uranium is rather efficiently removed in most cases.

d. Elution. Following the washing of the impurities from the resin bed with $7 \mathrm{MNO}_{3}$, technicians pump $10 \ell$ of $\mathrm{IM} \mathrm{HNO}_{3}$ through the bed, thus reducing the acid concentration in preparation for the elution step. At Los Alamos, the addition of $10 \ell$ of $0.3 \mathrm{M} \mathrm{NH}_{2} \mathrm{OH}-\mathrm{HNO}_{3}$ reduces plutonium(IV) to the III state and elutes it from the column. The elution is completed using $0.3 \mathrm{M} \mathrm{NH}_{2} \mathrm{OH} \cdot \mathrm{HNO}_{3} / 0.5 \mathrm{M} \mathrm{HNO}_{3}$. The acid added to the second volume of eluate prevents polymer formation, but the acid is not necessary in the first volume of eluate because the residual $\mathrm{HNO}_{3}$ in the resin bed keeps the acid concentration $>0.5$. $^{4}$ At RFP, elution uses only low concentrations of $\mathrm{HNO}_{3}$ that destroy the absorbed hexanitrato complex; however, experience at Los Alamos has shown that the increased rates and associated volumes are unacceptable from a production-volume standpoint for columns operated at room temperature. James ${ }^{40}$ has described this low $^{\mathrm{HNO}_{3}}$ elution.

For safety, elution is done at room temperature at Los Alamos. Van Slyke 1 addresses some safety concerns of elevated-temperature column operation. 
The $\mathrm{NH}_{2} \mathrm{OH} \cdot \mathrm{HNO}_{3} / \mathrm{pluton}$ :um(III) eluate at Los Alamos is suitable for plutonium(III) oxalate precipitation. The parameters are discussed in Section $2 . a$, the section on precipitations.

4. Chloride Operations. Chloride salts are a very important category of residues and are by-products from many pyrochemical operations. The pyrochemical chloride-based operations currently in operation include the following:

- DOR,

- ER,

- molten salt extraction (MSE), and

- pyroredox.

These chloride-based residues are especially challenging for aqueous recovery because of the difficulty of handling this material in stainless steel equipment. Los Alamos will soon install Kynar-lined glove boxes to monitor their behavior in production-scale operations. RFP has also had extensive experience in aqueous recovery of chloride-based residues. 12,43

The pyrochemical conversion of $\mathrm{PuO}_{2}$ to metal generates DOR residues. ${ }^{16}$ This process utilizes a molten calcium chloride $\left(\mathrm{CaCl}_{2}\right)$ solvent and a calcium metal reductant and is described in more detail in Section III.B. The scrap consists of $\mathrm{CaCl}_{2} / \mathrm{CaO}$ and may cortain up to several percentage points of plutonium by weight, a percentage that depends on the type of oxide feed. Active oxides such as those resulting from the calcination and roasting of plutonium oxalate give yields up to 998 . Foundry oxides, which are less reactive, produce lower yields.

Los Alamos facilities have recovered plutonium from DOR salts using the chloride anion-exchange process (Fig. 12). The general flow scheme, presented below, is an outgrowth of research described by James 4 and clifton. 45 


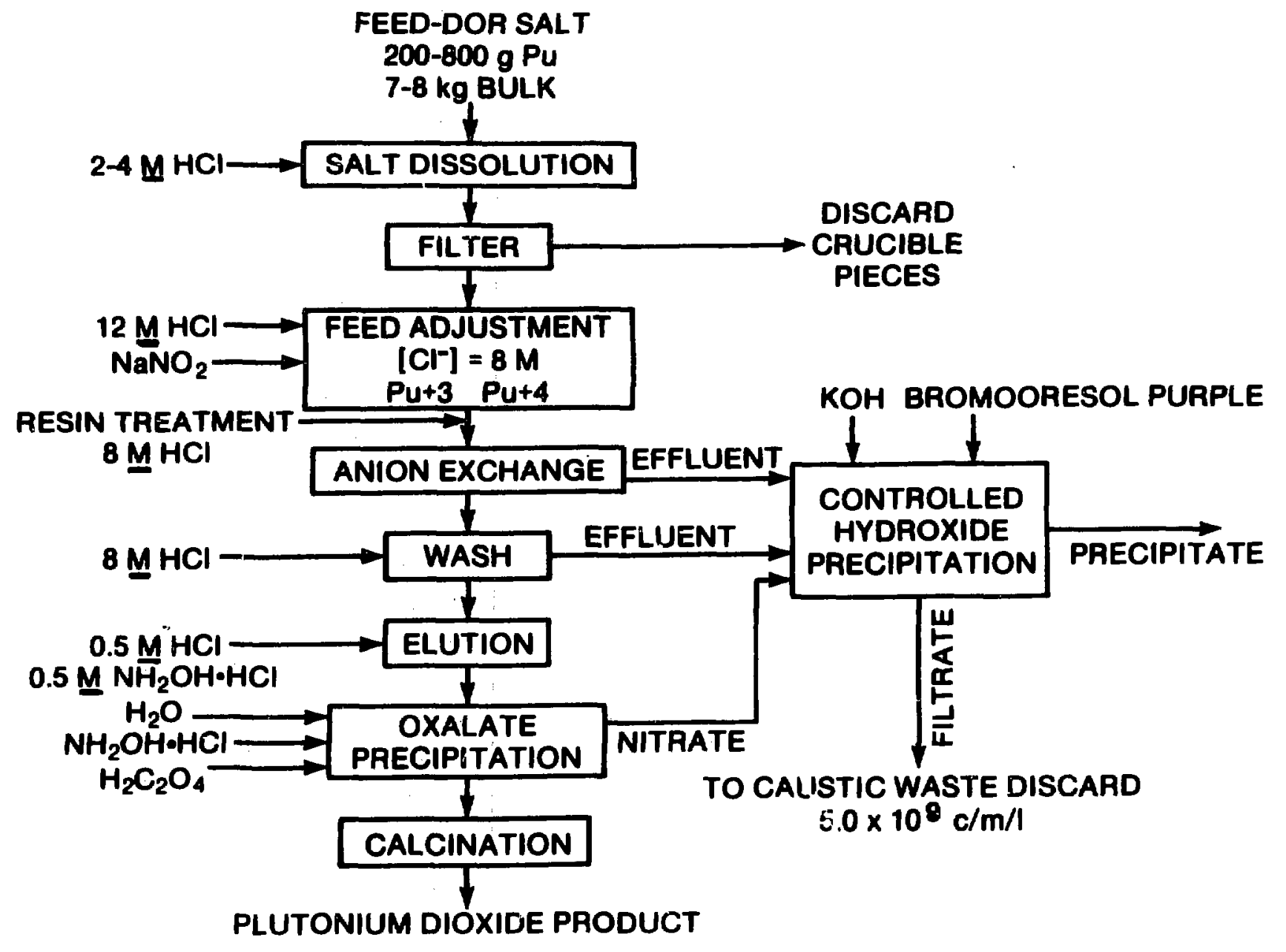

Fig. 12. Chloride anion exchange. 
1. The salt is dissolved in a minimum amount of $2-4 \mathrm{M} \mathrm{HCl}$.

2. The addition of $\mathrm{NaNO}_{2}$ stabilizes the plutonium in the IV state and the operator adjusts the chloride concentration to 8-10M and the $\mathrm{H}^{+}$ concentration to $2 \mathrm{M}$.

3. The feed solution then passes through a 6-in. by 24-in. glass column filled with chloride-form anion-exchange resin. The plutonium(IV) is absorbed on the resin.

4. The operator washes the impurities from the column with $8 \mathrm{M} \mathrm{HCl}$.

5. The plutonium is reduced to the III valence and is eluted from the resin bed with $0.5 \mathrm{M} \mathrm{HCl}$ and $0.5 \mathrm{M} \mathrm{HCl} / 0.5 \mathrm{M} \mathrm{NH}_{2} \mathrm{OH} \cdot \mathrm{HCl}$.

6. The addition of solid oxalic acid precipitates the plutonium(III) from the eluate solution.

7. The operator collects the plutonium(III) oxalate by filtration, washes it with dilute $\mathrm{HCl}$, and transfers it to a calcination vessel.

8. The oxalate cake is thermally converted to $\mathrm{PuO}_{2}$ at $500^{\circ} \mathrm{C}$ for $5 \mathrm{~h}$.

9. The chloride effluent undergoes a controlled hydroxide precipitation up to $\mathrm{pH}$ 7-8 in an attempt to reduce the amount of cations precipitating with the plutonium.

10. The operator discharges the hydroxide filtrate to the causticwaste treatment area if discard limits are met.

11. The precipitate, depending upon plutonium content, is either dried and discarded or sent to the chloride head-end processing for recycle. 
12. The filtrate from step 6 is reprocessed through steps 9-11.

13. The oxide generated by this process is then suitable for conversion to metal and purification by ER techniques.

The major process for the pyrochemical purification of impure plutonium metal is ER. The residues from ER are the anode heel, the solvent salt consisting of sodium chloride/potassium chloride ( $\mathrm{NaCl} / \mathrm{KCl}$ ), and lesser amounts of plutonium, americium, and magnesium in the form of metals, oxides, and chlorides. Also, the Mgo reaction crucible, which is mechanically broken at the completion of the ER cycle in order to recover the pure plutonium metal ring, is part of the ER residues requiring additional processing. A pyroredox operation can recover the plutonium from the spent anode heel. Also, the pyrochemical salt-stripping operation recovers a large portion of the ER salt residues. These residues are also recovered using aqueous techniques. Facilities often recover the spent anode using the flow sheet for impure plutonium metal. The anode heel can be oxidized in air to form impure $\mathrm{PuO}_{2}$ and then purified using the standard nitrate flow sheet. Los Alamos has recovered ER salts using chloride anion exchange. The flow sheet is very similar to the one used for DOR salts. The MgO crucible fragments are leached in $6 \mathrm{M} \mathrm{HCl}$ and can usually be discarded after one or two passes. The leachate can be handled by either the chloride anion-exchange or solvent-extraction flow sheets presented in this section.

A pyrochemical process for the rapid and economical extraction of very active metals from plutonium metal is MSE. Section III.C. 3 gives more detailed information. It is primarily used for the efficient removal of ${ }^{241} \mathrm{Am}$, which is the radioactive decay product of $241 \mathrm{Pu}$. This pyrochemical method uses magnesium chloride $\left(\mathrm{MgCl}_{2}\right)$ in equimolar $\mathrm{NaCl} / \mathrm{KCl}$ to oxidize americium (and some plutonium), thus allowing it to extract into the salt phase. The very prevalent $60 \mathrm{keV}$ gamma emission from the americium necessitates great care and extensive shielding for any glove-box hands-on 
MSE salt-recovery operations. Where possible, operators should use remote control for recovery operations.

Recovering plutonium from MSE salts has involved either direct aqueous techniques or indirect techniques where a pyrochemical, aluminum reduction product of the plutonium, americium, and magnesium is then processed by aqueous methods. Los Alamos produced an experimental calcium reduction product that was subsequently processed by nitric dissolution and peroxide purification. 46 At RFP, the all-aqueous process for piutonium recovery from MSE salts consists of the following steps:

1. The salt is crushed and cissolved in a large volume of dilute $\mathrm{HCl}$; this step is followed by absorption of plutonium and americium on a cation column and, finally, by column washing.

2. Technicians then elute the plutonium and americium with $\mathrm{HNO}_{3}$. Following feed adjustment, the plutonium is absorbed on a nitrate anionexchange column. The effluent, containing the americium, is concentrated for either waste-management disposal or subsequent recovery of the americium, depending upon the prevailing economic factors.

3. Operators elute the plutonium from the nitrate anion-exchange column and merge it with other fairly pure feed streams.

At Los Alamos, the first al1-aqueous method for the MSE salts had to meet severe process-volume constraints for chloride solutions. Consequently, the Laboratory developed the following precipitation process. 4

1. Technicians dissolve the salt in a minimal volume of $1 \mathrm{M} \mathrm{HC1}$. 
2. The plutonium and americium are coprecipitated as their trivalent oxalates.

3. A controlled-pH hydroxide precipitation conducted on the oxalate filtrate results in minimal magnesium precipitation and a hydroxide filtrate that can be discarded.

4. Technicians filter and thoroughly wash the coprecipitated oxalates. This process is followed by thermal $\left(350^{\circ} \mathrm{C}-500^{\circ} \mathrm{C}\right)$ conversion to mixed oxides, dissolution in $\mathrm{HHO}_{3} / \mathrm{HF}$, and distillation to remove chlorides and some acid.

5. The plutonium is purified by a peroxide precipitation that attains americium decontamination factors of 100 to 200 .

6. An excess of $\mathrm{NaOH}$ destroys $\mathrm{H}_{2} \mathrm{O}_{2}$ in the peroxide filtrate. Cperators reacidify the slurry and americium oxalate precipitates with about $10 \%$ of the precipitate being plutonium oxalate.

7. Thermal conversion of the dense and relatively easily handled americium-oxalate cake gives an impure oxide. This is a convenient form for either further purification or waste-management disposel.

Originally, steps 6 and 7 consisted solely of the hydroxide steps, but filtration problems and a low-density, gummy, hard-to-handle precipitate made the hydroxide/oxalate procedure attractive.

A recent process developed initially at Argonne National Laboratory and placed under further development at Los Alamos utilizes solvent extraction to immediately separate plutonium from the large amounts of americium and salts. 18 
1. After technicians dissolve the MSE salt in a small volume of dilute $\mathrm{HCl}$, the plutonium is oxidized to the IV state and is extracted with TBP in tetrachloroethylene. This process is followed by a dilute Hil strip and plutonium oxalate precipitation.

2. Current development work involves extracting the americium from the TBP raffinate with carbamoylmethylphosphineoxide (CMPO) in tetrachloroethylene and stripping with dilute $\mathrm{HCl} / 1 \mathrm{M}_{2} \mathrm{C}_{2} \mathrm{O}_{4}$. These steps are followed by an americium oxalate precipitation. Depending upon the market for americium, a simple oxalate precipitation on the TBP raffinatemay suffice for waste-management purposes.

Los Alamos is performing the extraction and stripping in centrifugal annular contactors (Fig. 13) designed by Argonne National Laboratory for the TRUEX process, 40,50,51 and built by Los Alamos using Hastelloy $c^{\star}$ for corrosion resistance.

\section{B. Metal Preparation}

A number of operations such as conversion to fluoride, oxide, or chloride can prepare plutonium metal from scrap or oxide.52,53 The compound can then be reduced to metal, usually in an impure form. In pyrochemical operations, a series of processes changes this impure metal to high-purity metal. In this section, we describe operations now used to purify the material, the waste streams generated, and methods available to recover plutonium from the residues.

1. Fluorides. Reactive oxides formed by the calcination of oxalate or peroxide precipitates formed by the addition of oxalate and $\mathrm{H}_{2} \mathrm{O}_{2}$ to a suitable aqueous solution of plutonium(III) can be treated in a hydrofluorinator to form $\mathrm{PuF}_{4} .^{64}$ In addition, $\mathrm{PuF}_{3}$ can be precipitated

* Union Carbide Corporation, 270 Park Avenue, New York, NY 10017. 

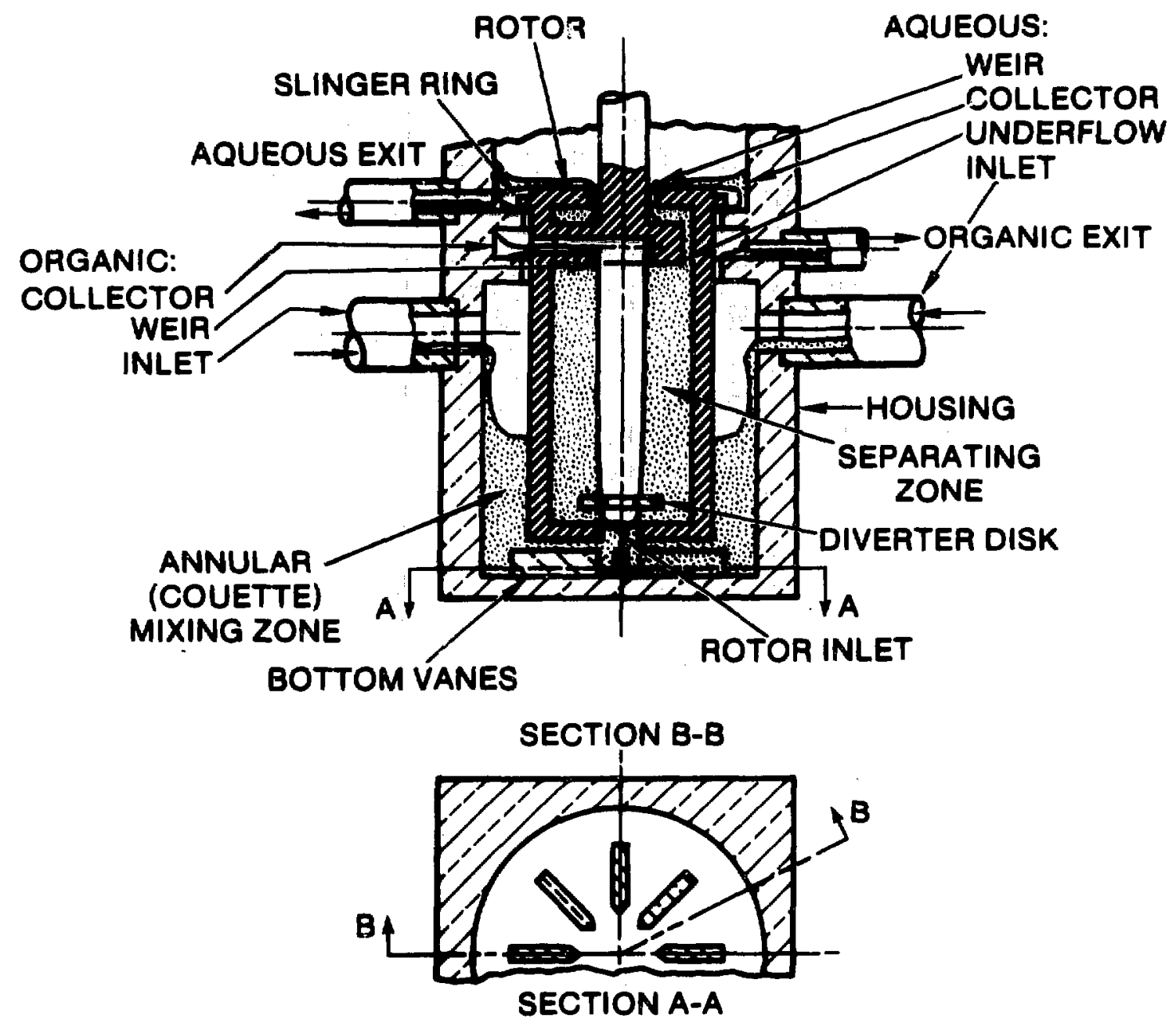
directly from nitrate solution through the reaction with HF. Controlled heating can then convert this $\mathrm{PuF}_{3}$ to $\mathrm{PuF}_{4} \cdot \mathrm{PuO}_{2}$. Mixing the $\mathrm{PuF}_{4}$ or $\mathrm{PuF}_{4} \cdot \mathrm{PuO}_{2}$ with calcium and heating it to reaction forms $\mathrm{CaF}_{2}$ and metal plutonium. Quite often a booster such as iodine) both initiates the reaction and provides sufficient energy to ensure the complete reaction:

$$
\begin{aligned}
& \mathrm{PuO}_{2}+4 \mathrm{HF} \rightarrow \mathrm{PuF}_{4}+2 \mathrm{H}_{2} \mathrm{O} \text { and } \\
& \mathrm{PuF}_{4}+3 \mathrm{Ca}+\mathrm{I}_{2} \rightarrow \mathrm{Pu}+2 \mathrm{CaF}_{2}+\mathrm{CaI}_{2} .
\end{aligned}
$$

This method of preparation does not produce any purification; however, it does not introduce impurities.55 with a high-purity oxide such as that often produced by the PUREX process, the fluoride process can produce a metal that meets purity specifications for most applications. Wastes generated include $\mathrm{MgO}$ sand (which is added for heat transfer), $\mathrm{CaF}_{2}$, and the MgO reaction crucible. As we stated earlier, these residues are treated by aqueous methods to recycle any plutonium. The subsequent wastes are discarded.

The major disadvantage of the process is the high neutron-radiation field from the $(\alpha, n)$ reaction, which constitutes a hazard to personnel.

2. Oxides. Most scrap containing plutonium can be converted to oxide by burning it at an elevated temperature in air. The oxide, if reactive, can then be converted to fluoride for reduction. However, unreactive or high-fired cxide does not react to form fluroide; instead the addition of a strong reducing agent in a solvent salt can reduce the oxide to metal.55 The impure metal product forms a button in the bottom of the crucible that is covered by a fused oxide/salt layer. The reaction is

$$
\mathrm{PuO}_{2}+\mathrm{n} \mathrm{M}+\mathrm{Pu}+\mathrm{M}_{\mathrm{n}_{2}} \mathrm{O}_{2}(\mathrm{salt})
$$

where $\mathrm{M}^{\mathrm{O}}$ is the reductant. 
The salt acts as a heat sink and a solvent for the oxide of the reductant that forms during the reaction. The button can be separated mechanically from the salt. In DOR, one pass produces yields of up to 998; the residue, under present criteria, is less than the EDL value and is discarded or placed in long-term storage.

3. Chlorides. Another alternative for treating plutonium oxides is to convert the oxide to chloride. ${ }^{56}$ The synthesis of plutonium metal by bonb reduction of the trichloride with calcium metal and an iodine booster has, in fact, been demonstrated on the same scale as the fluoride reduction. ${ }^{6}$ ? The reactions are

$$
\begin{aligned}
& 2 \mathrm{PuO}_{2}+3 \mathrm{Cl}_{2}+2 \mathrm{PuCl}_{3}+2 \mathrm{O}_{2} \text { and } \\
& 2 \mathrm{PuCl}_{3}+3 \mathrm{Ca} \rightarrow 2 \mathrm{Pu}+3 \mathrm{CaCl}_{2} .
\end{aligned}
$$

$\mathrm{PuCl}_{3}$ is extremely hygroscopic, and investigators have not solved the engineering problems associated with moisture. Furthermore, although the chloride process was intially proposed for converting oxide formed by direct calcination of $\mathrm{PuO}_{2}\left(\mathrm{NO}_{3}\right)_{2} \cdot 6 \mathrm{H}_{2} \mathrm{O}$ solutions to the chloride, the oxide was not active enough to promote the reaction.

The chloride, however, would decrease the neutron-radiation problem present with $\mathrm{PuF}_{4}$. Engineering problems could be addressed from the 1980s materials position. Finally, the use of inert boxes could overcome the problem of the hydroscopic nature of the salt.

$\mathrm{PuCl}_{3}$ could also be a good replacement for $\mathrm{MgCl}_{2}$ in several steps of the integrated pyrochemical process. Its use would significantly decrease the introduction of magnesium into the metal stream. 
4. Hydriding. Hydriding and dehydriding or hydriding followed by oxidation can recover plutonium metal scrap adhering to other metals.58 Even at room temperature, plutonium reacts with hydrogen to form a metallike powder. The reaction is

$$
2 \mathrm{Pu}+3 \mathrm{H}_{2} \rightarrow 2 \mathrm{PuH}_{3} \text {. }
$$

Heating the hydride in a vacuum removes the hydride powder from the inert substrate and recovers the plutonium metal. As an alternative, the hydride can be slowly oxidized in air to form the oxide by the reaction

$$
4 \mathrm{PuH}_{3}+7 \mathrm{O}_{2}+4 \mathrm{PuO}_{2}+6 \mathrm{H}_{2} \mathrm{O} \text {. }
$$

The oxide can then be treated to recover metal.

5. Pyroredox. Pyroredox is a two-step process in which plutonium is initially oxidized to remove impurities less reactive than the oxiding agent. The plutonium is subsequently reduced back to metal, leaving impurities more reactive than the reducing agent in the salt phase.60-61 The reactions are

$$
\begin{aligned}
& \mathrm{Pu}(0)+(0 \mathrm{x})+\mathrm{Pu}(\mathrm{III})+(0 \mathrm{x}) \text { and } \\
& \mathrm{Pu}(\mathrm{III})+(\mathrm{Re})+\mathrm{Pu}(0)+(\mathrm{Re})
\end{aligned}
$$

where $(O x)$ and $(R e)$ are the oxidizing and reducing agents, respectively. Table I provides relative reactivities for estimating separation factors. The resulting metal contains impurities such as zinc, calcium, anda which can be removed by vacuum distillation, MSE, and metal liquidation. 
TABLE I

FREE ENERGIES OF FORMATION OF CHLORIDES AT $1000 \mathrm{~K}$ $-\Delta G_{f}^{O}(k c a l / g-E Q U I V A L E N T$ C1)

\begin{tabular}{llll}
\hline $\mathrm{BaCl}_{2}$ & 83.4 & $\mathrm{CmCl}_{3}$ & 58.8 \\
$\mathrm{KCl}$ & 81.4 & $\mathrm{PuCl}_{3}$ & 58.5 \\
$\mathrm{RbCl}$ & 81.2 & $\mathrm{MgCl}_{2}$ & 57.7 \\
$\mathrm{SrCl}_{2}$ & 81.0 & $\mathrm{NpCl}_{3}$ & 54.1 \\
$\mathrm{CaCl}$ & 80.0 & $\mathrm{UCl}_{3}$ & 51.8 \\
$\mathrm{SmCl}_{2}$ & 80.0 & $\mathrm{ZrCl}_{2}$ & 49.2 \\
$\mathrm{LiCl}$ & 78.8 & $\mathrm{ClCl}_{2}$ & 49.2 \\
$\mathrm{CaCl}_{2}$ & 77.9 & $\mathrm{FeCl}_{2}$ & 26.6 \\
$\mathrm{NaCl}$ & 75.7 & $\mathrm{NbCl}_{5}$ & 24.6 \\
$\mathrm{LaCl}$ & 67.0 & $\mathrm{M}_{\mathrm{DCl}}$ & 8.0 \\
$\mathrm{PrCl}_{3}$ & 66.3 & $\mathrm{TcCl}_{3}$ & 7.0 \\
$\mathrm{CeCl}_{3}$ & 66.3 & $\mathrm{RhCl}_{3}$ & 5.8 \\
$\mathrm{NdCl}_{3}$ & 64.2 & $\mathrm{PdCl}_{2}$ & 3.8 \\
$\mathrm{YCl}_{3}$ & 61.2 & $\mathrm{RuCl}_{3}$ & 1.4 \\
\multicolumn{1}{c}{} & & & \\
\hline
\end{tabular}

The pyroredox process can upgrade lower-purity plutonium metal for further purification, usually by ER. The next section describes specific processes. 62

\section{Metal Purification}

In this section we describe the integrated pyrochemical process to present a fairly systematic approach for recovering plutonium and for treatment of residues. Over the last six years, Los Alamos has produced significant quantities of high-purity metal from impure refractory oxides by this approach. 16,63 RFP conducts similar operations, and both the Atomic Weapons Establishment in the UK and Lawrence Livermore National Laboratory 
plan to use this approach. A pyrochemical method is also proposed for recovering plutonium and uranium in the Integrated Fast Reactor (IFR) at Argonne National Laboratory. As part of the IFR program, Argonne is evaluating halide slagging and ER.

Figure 14 shows the present system at Los Alamos. The major processes are

- bomb reduction of $\mathrm{PuF}_{4}$,

- DOR,

- MSE,

- anode casting, and

- ER.

As the figure shows, each operation produces residues that are treaied either by pyrochemical or aqueous means to recover plutonium. We will discuss the pyrochemical processes in detail.

1. Metal Preparation Line (MPL). The MPL produces plutonium metal from $\mathrm{PuF}_{4}$ by the high-pressure reaction between the fluoride and calcium metal.13 After fluorination of oxide, a booster, such as iodine, Initiates the second reaction:

$$
\begin{aligned}
& \mathrm{PuO}_{2}+4 \mathrm{HF} \rightarrow \mathrm{PuF}_{4}+2 \mathrm{H}_{2} \mathrm{O} \text { and } \\
& \mathrm{PuF}_{4}+3 \mathrm{Ca}+\mathrm{I}_{2} \rightarrow \mathrm{Pu}+2 \mathrm{CaF}_{2}+\mathrm{CaI}_{2} .
\end{aligned}
$$

Figure 15 shows the reduction furnace. The action of HF converts plutonium peroxide, oxalate, or a low-fired (under $800^{\circ} \mathrm{C}$ ) oxide to fluroide. About $2 \mathrm{~kg}$ of the tetrafluoride, calcium metal, and magnesia slag are thoroughly mixed in a molded, open-porosity nagnesia crucible. Iodine, added before the equipment is assembled and heated, acts as an initiator and reaction booster. At approximately $325^{\circ} \mathrm{C}$, calcium and iodine react exothermally to rapidly raise the temperature. At $600^{\circ} \mathrm{C}$ the reduction of tetrafluoride begins and, with reaction, the system temperature rises rapidly to nearly $2000^{\circ} \mathrm{C}$. The slag remains molten while the molten plutonium sinks to the 


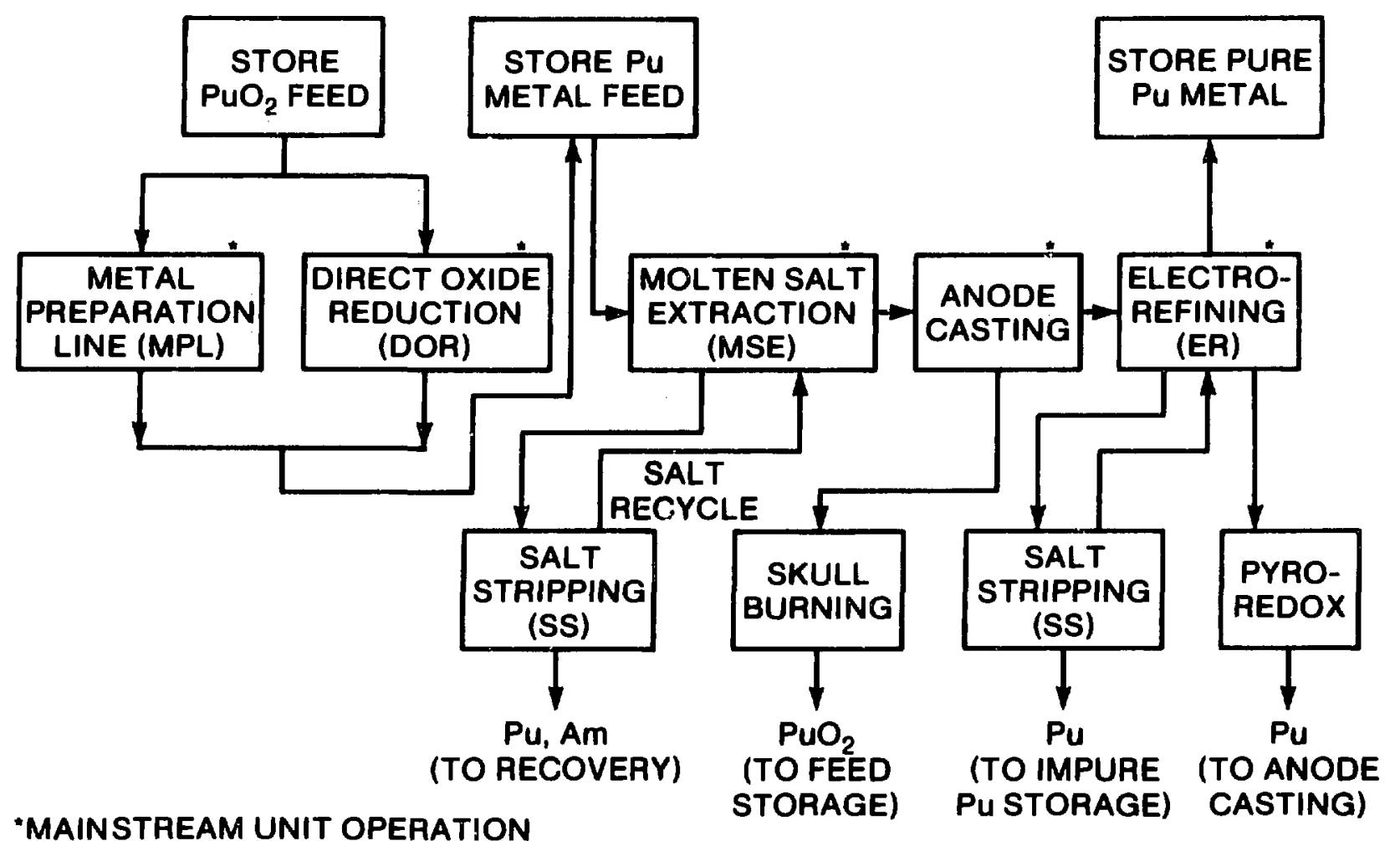




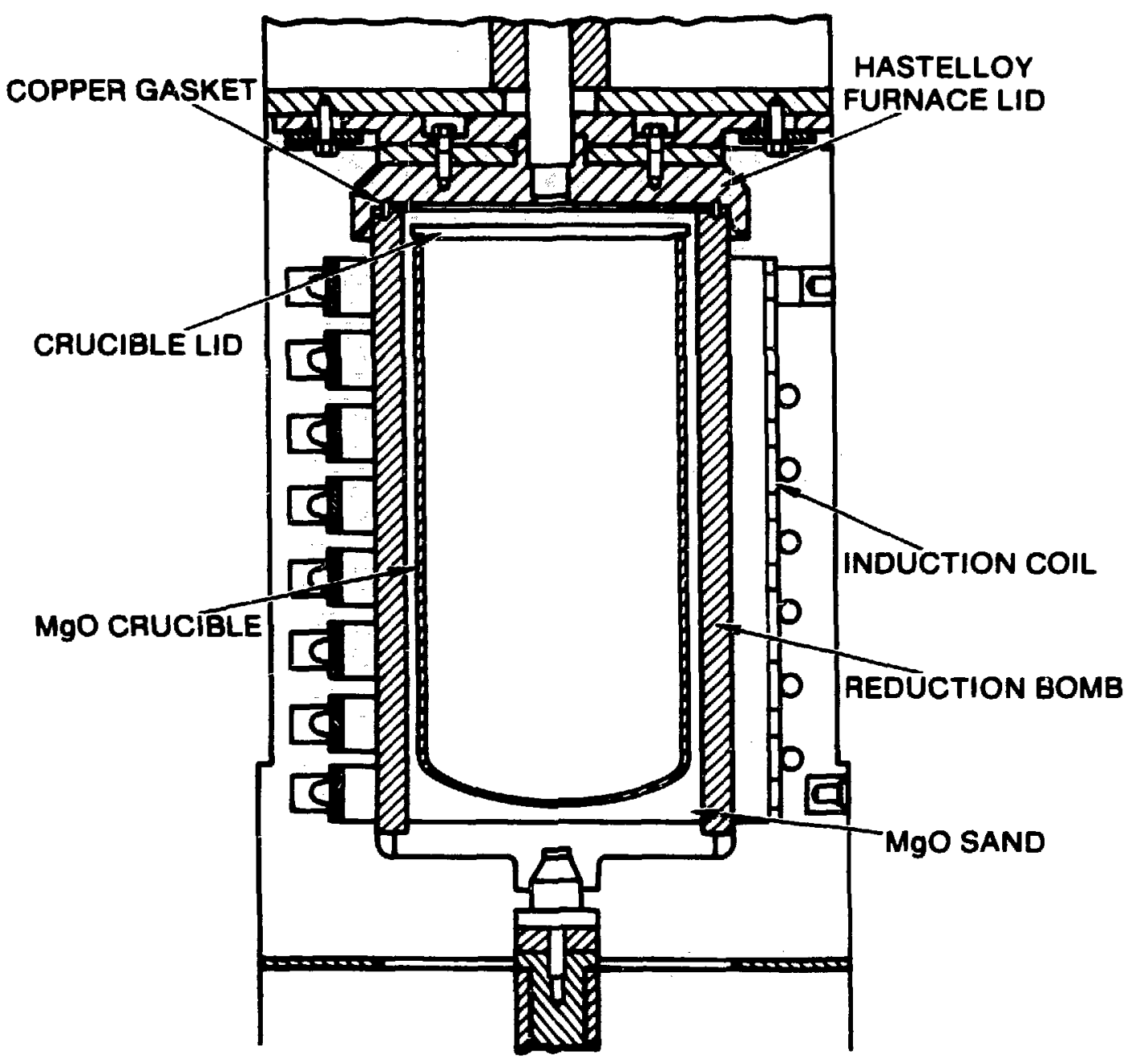

Fig. 15. Los Alamos $\mathrm{PuF}_{4}$ reduction furnace. 
bottom of the crucible and solidifies. After the equipment has cooled, technicians disassemble it and break the crucible to recover the metal button (which is mechanically separated from the slag). ${ }^{63}$

The waste streams are slag $\left(\mathrm{CaF}_{2}-\mathrm{CaCl}_{2}\right)$, crucible, and magnesia sand. Aqueous processing recovers any plutonium in the slag or crucible, and the sand is reused. During fluorination, the off-gases are scrubbed with potassium hydroxide solution, which is tested for plutonium content and transferred to waste management when either it is exhausted chemically or its plutonium concentration reaches the discard limit.

Little or no purification occurs during the process, and the metal purity is similar to that of the feed material.52 However, reagents introduce no impurities and, if sufficiently pure feed is used, the resulting metal is satisfactory for high-purity applications. Yields usually range from 978 to 998.14

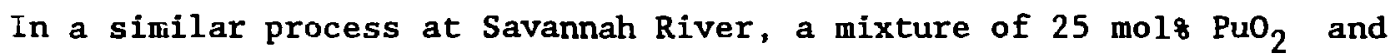
$\mathrm{PuF}_{4}$ is the feed, and yields range from 958 to 998.64

2. Direct Oxide Reduction (DOR). All oxide for the DOR process is calcined at $800^{\circ} \mathrm{C}$, sampled, and transferred into the DOR processing area. ${ }^{63}$ Technicians place up to $1 \mathrm{~kg}$ of oxide in a magnesia crucible with $5 \mathrm{~kg}$ of fused $\mathrm{CaCl}_{2}$ and add a charge of calcium (508 calculated excess).65 Figure 16 shows the equipment. The standard reaction vessel is vitrified magnesia, although some development work has investigated the use of tungsten or tantalum. For the magnesia reaction vesse1, each reduction requires a new crucible, and holdup is minimized. The $\mathrm{CaCl}_{2}$ salt can be replaced with a lower melting eutectic, $\mathrm{CaCl}_{2} 26 \mathrm{~mol}^{\circ} \mathrm{CaF}_{2}$, for the heat sink and solvent. ${ }^{6}$ This replacement might reduce any side reaction of calcium with the magnesia crucible. In experiments at Los Alamos, investigators found no marked advantages with the eutectic and, in fact, high-melting salts apparently formed during eutectic preparation. 


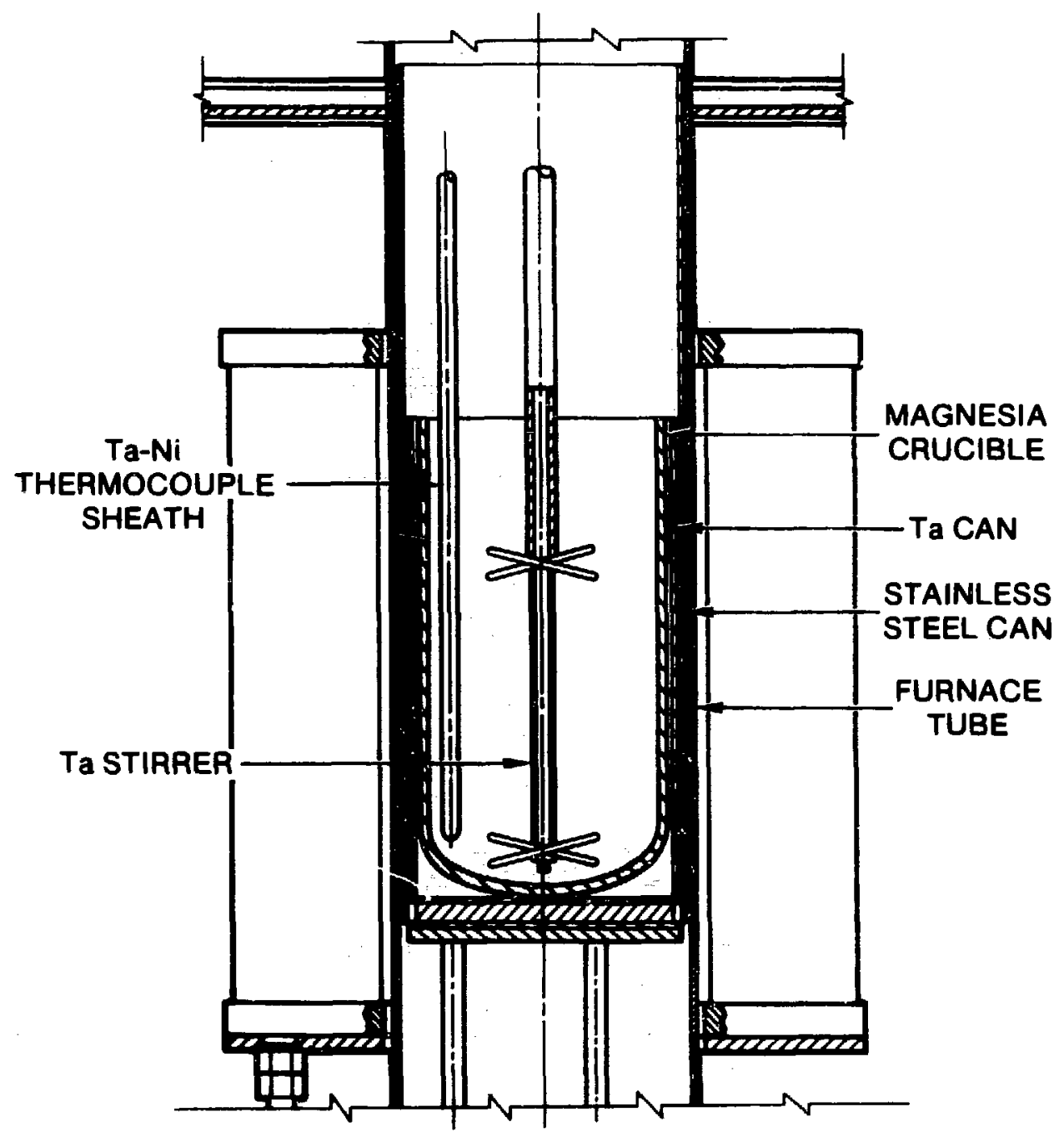

Fig, 16. DOR equipment. 
Development work in this area continues at both Lawrence Livermore National Laboratory and Los Alamos National Laboratory.

The $\mathrm{CaCl}_{2}$ is cast before use and contains no detectable water. However, the reduction transfers small amounts (parts per million [ppm]) of impurities from salt to the plutonium metal. The resulting metal is almost always more impure than the oxide from which it is formed. Efforts to produce high-purity metal by using purified reagents have not been successful, and facilities must further process metal formed by DOR to meet purity specifications.

Typically, the reaction begins at about $820^{\circ} \mathrm{C}$ with a temperature spike to $875^{\circ} \mathrm{C}$. Reaction is complete within 15 min. The overall chemical reaction is

$$
\mathrm{PuO}_{2}+2 \mathrm{Ca}-\mathrm{Pu}+2 \mathrm{CaO}
$$

and the free energy of formation $(\Delta F)$ is estimated at $-44.3 \mathrm{kcal}$ at $1000^{\circ} \mathrm{C} .55$ The reaction proceeds to completion when excess calcium is present, sufficient $\mathrm{CaCl}_{2}$ is available to dissolve the CaO that is produced, and rapid stirring is applied.

The reaction vessel cools until the products solidify. Almost all the plutonium forms a button at the bottom of the crucible. The salt immediately above the button contains a layer of metal shot, and the bulk of the salt solidifies above the metal. Technicians mechanically separate the button and recover the shot by reheating the shot-rich layer (usually with calcium present) above the melting point to consolidate the metal. Product yields are greater than 95\%. 15 The metal phase contains significant impurities, as Table II shows. Both the spent salt and calcium are sufficiently low in plutonium to be discarded under present wastemanagement practices. However, the salt is by far the largest waste 
TABLE II

REDUCTION OF "PURE" PLUTONIA TO METAL BY DOR

Concentration of Impurity (g Element $/ 10^{6} \mathrm{~g}$ of Sample)

Element $\quad \underline{\mathrm{CaCl}_{2}}$

Li

Be

B

$\mathrm{Na}$

$\mathrm{Mg}$

A1

Si

K

$\mathrm{Ca}$

$\mathrm{Cr}$

Mn

Ni

Sr

Ag

$\mathrm{Ta}$

Fe

$\mathrm{Ga}$

U

C

$\mathrm{Pu}(w t 8)$
200

$<1$

90

6,000

200

30

175

16,000

4,000

$<350$

6,000

$<1$

$<100$

55

$<3$

$-\quad<10$

110
Run 1

Ca $\quad \underline{\mathrm{PuO}_{2}}$

$<10$

$<5$

$<5$

$<35$

$<10$

$<5$

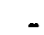

$<10$

5

14

700

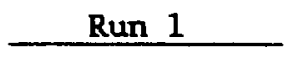

$<1$

$<1$

2

7

$<1$

$<5$

$<$

15

80

$<5$

2

$<5$

$<5$

$<1$

$<100$

110

$<10$

$<10$

$\underline{\mathbf{P u}}$

$\underline{\mathrm{PuO}_{2}}$

$\underline{\text { Pu }}$

Run 2

Run 2


generated during the integrated process and is a promising candidate for recycle. ${ }^{05}$

3. Molten Salt Extraction (MSE). The MSE process separates the morereactive elements, such as americium, rare earths, alkali metals, and alkaline earth metals, from plutonium.59,67,68 Technicians place a ternary salt, consisting of an oxidizing agent and a salt eutectic, in coniact with the impure metal. This process is the first step at RFP in extracting americium from kilogram quantities of plutonium. Los Alamos employs the process only if the americium content is greater than $1000 \mathrm{ppm}$. Other processing sites may apply other criteria. The oxidizing agent is $\mathrm{MgCl}_{2}$ contained in a $\mathrm{NaCl} / \mathrm{KCl}$ eutectic. The major reactions are 69,70

$$
\begin{aligned}
& 2 \mathrm{Am}+3 \mathrm{MgCl}_{2}=2 \mathrm{AmCl}_{3}+3 \mathrm{Mg}, \\
& 2 \mathrm{Pu}+3 \mathrm{MgCl}_{2}=2 \mathrm{PuCl}_{3}+3 \mathrm{Mg}, \text { and } \\
& \mathrm{Am}+\mathrm{PuCl}_{3}-\mathrm{AmCl}_{3}+\mathrm{Pu} .
\end{aligned}
$$

The americium and plutonium contents in the salt depend on the amount of oxidant added, the concentrations of the elements in the feed, the temperature, the number of contacting stages, and the mode of operation. Under the process conditions at Los Alamos, as much as 908 of the americium and 108 of the plutonium are transferred from the feed into the salt. ${ }^{3}$ The process equipment is very similar to that used in DOR (Fig. 16), but a reusable tantalum vessel replaces the magnesia crucible. The batch size is $4.5 \mathrm{~kg}$ with a $12-\mathrm{h}$ temperature cycle to $750^{\circ} \mathrm{C}$. (The actual reaction time is only 30 min.) After the equipment has cooled to room temperature, technicians remove the fused salt and metal button from the crucible and separate them. Usually each feed button goes through two batch extractions. 


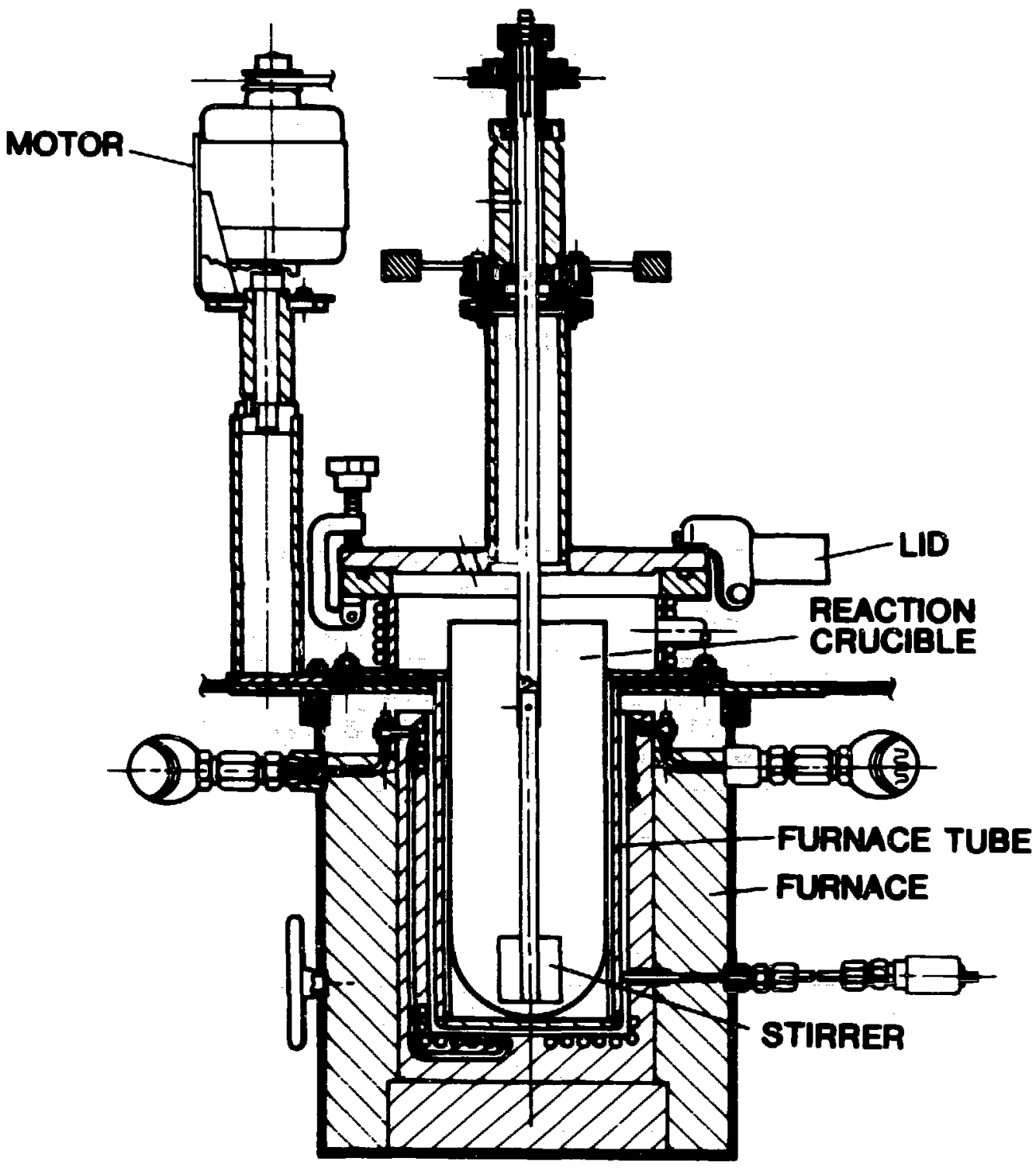

Fig. 17. RFP MSE equipment. 
In the RFP procedure, workers load $2.2 \mathrm{~kg}$ of impure plutonium metal into a tantalum crucible with a $\mathrm{NaCl} / \mathrm{KCl}$ eutectic containing $\mathrm{MgCl}_{2}$ as a reducing agent. ${ }^{71}$ Figure 17 shows the reaction cell. The salt moves through two extraction stages countercurrent to the flow of the metal in two batch operations. ${ }^{67}$

In both the Los Alamos and RFP processes, the final metal product is free of significant quantities of americium. Yields are satisfactory, reaching more than 758 in the two-stage countercurrent process. At present, Los Alamos recovers the salt residue by aqueous processing. RFP combines the plutonium with aluminum in a metal alloy and transfers it to the Savannah River Plant for aqueous reprocessing. 71 The high americium content in the spent salt is a potential radiation hazard that is presently minimized by using lead shielding and limiting operator exposure times. Studies of pyrochemical methods of recovery of both plutonium and americium from the spent salt have been proposed, and the possibilities are being examined.

4. Vacuum Melting and Casting. Technicians shape the impure metal button from DOR or MSE into a right circular cylinder $7 \mathrm{~cm}$ in diameter and $10 \mathrm{~cm}$ long to properly fit into the ER cel1.72 The addition of sufficient gallium ensures a critically safe geometry. Casting is accomplished by mixing about $6 \mathrm{~kg}$ of impure metal with gallium in a tantalum pour crucible and inductively heating the system to $800^{\circ} \mathrm{C}$ under vacuum. Figure 18 shows the apparatus. The metal and gallium mix upon melting and are bottompoured from a tantalum crucible (Fig. 19) into a graphite mold.

Molten plutonium is very reactive, and the reaction

$$
10 \mathrm{Pu}(1)+3 \mathrm{Ta}_{2} \mathrm{O}_{5}(\mathrm{~s}) \rightarrow 5 \mathrm{Pu}_{2} \mathrm{O}_{3}(\mathrm{~s})+6 \mathrm{Ta}
$$

probably occurs during heating. ${ }^{70}$ The oxide, however, forms a protective coating on the crucible walls and prevents further reaction. 73,74 


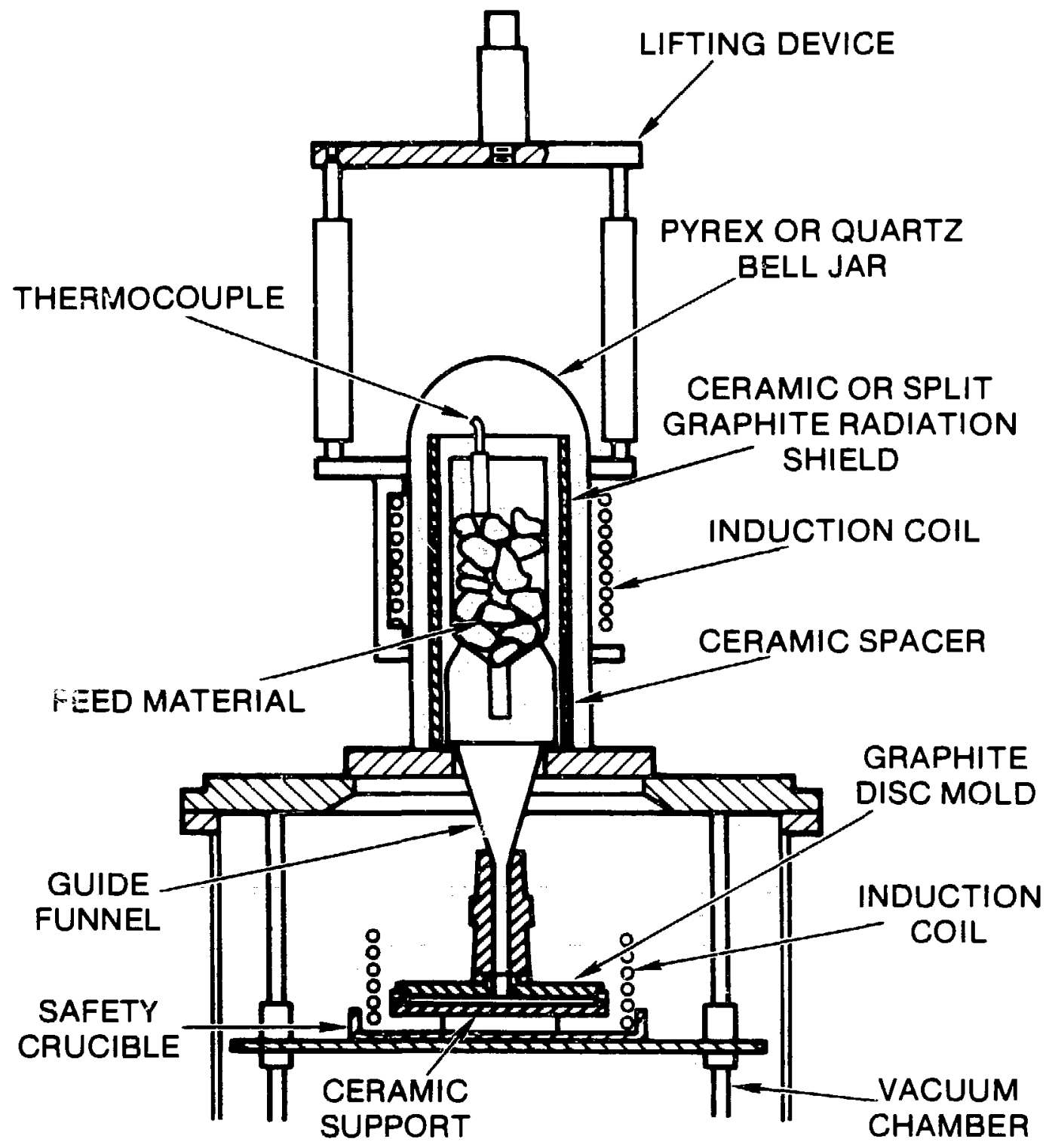

Fig. 18. Los Alamos vacuum casting equipment. 


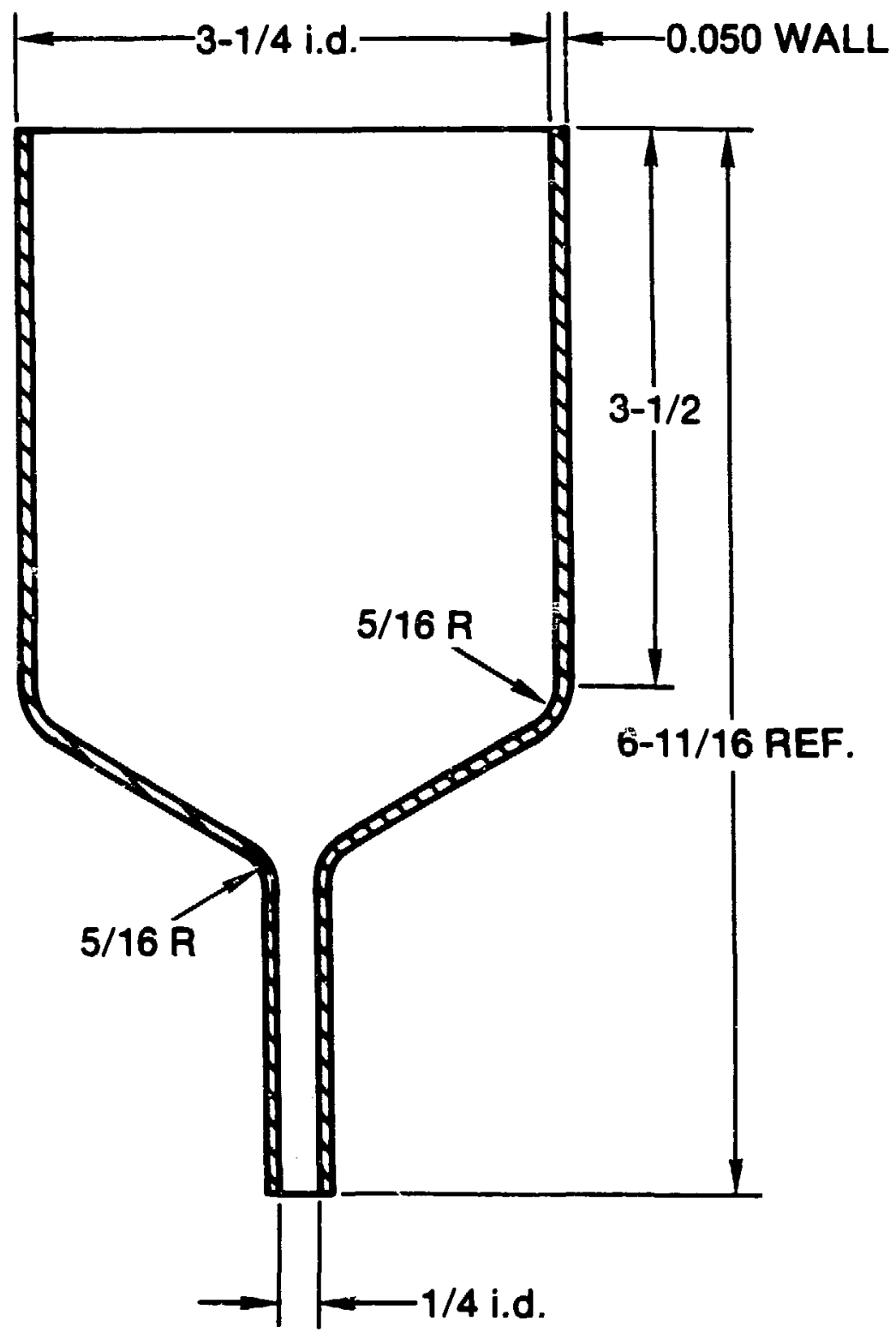

Fig. 19. Bottom-pour tantalum melt crucible. 
Vacuum melting conditions may cause partial volitalization of metallic impurities such as sodium, calcium, and magnesium. Pouring releases more of the magnesium and calcium, which form a dark coating on the sides of the quartz envelope. Thorium, americium, alkali metals, and alkaline-earth and rare-earth metals tend to oxidize preferentially and concentrate in the casting residue (skul1). ${ }^{75}$ Insoluble impurities (oxides, carbides, and some metals) will float on the melt surface and generally remain in the crucible. 68

Figure 20 shows a typical ingot. Yields are quite high, averaging over 908. Impurity levels decrease during casting as shown in Table III, which surnmarizes high-purity casting feed. A casting residue always forms. It is burned in air, and the resulting oxide is rerouted either to DOR or to an aqueous process.

5. Electrorefining (ER). The major process for purifying impure plutoniun at Los Alamos is ER. Liquid plutonium oxidizes from the anode into a molten-salt electrolyte. The plutonium ion is transported through the salt to the cathode, where it is reduced to metal. The reactors are

$$
\begin{aligned}
& \text { anode : } \mathrm{Pu}\left(\text { impure, 1) }=\mathrm{Pu}^{+3}+3 \mathrm{e}^{-}\right. \text {, } \\
& \text { cathode: } \mathrm{Pu}^{+3}+3 \mathrm{e}^{-}=\mathrm{Pu}(\text { pure, 1), and } \\
& \text { overa11: } \mathrm{Pu}(\text { impure, 1) }=\mathrm{Pu} \text { (pure, 1). }
\end{aligned}
$$

The process produces extremely pure metal if the current is sufficiently low and if the process is terminated while plutonium is still the reacting species. Yields depend upon the purity of the feed metal; Los Alamos specifies the plutonium content of anode metal to be greater than 958 to ensure satisfactory results. 


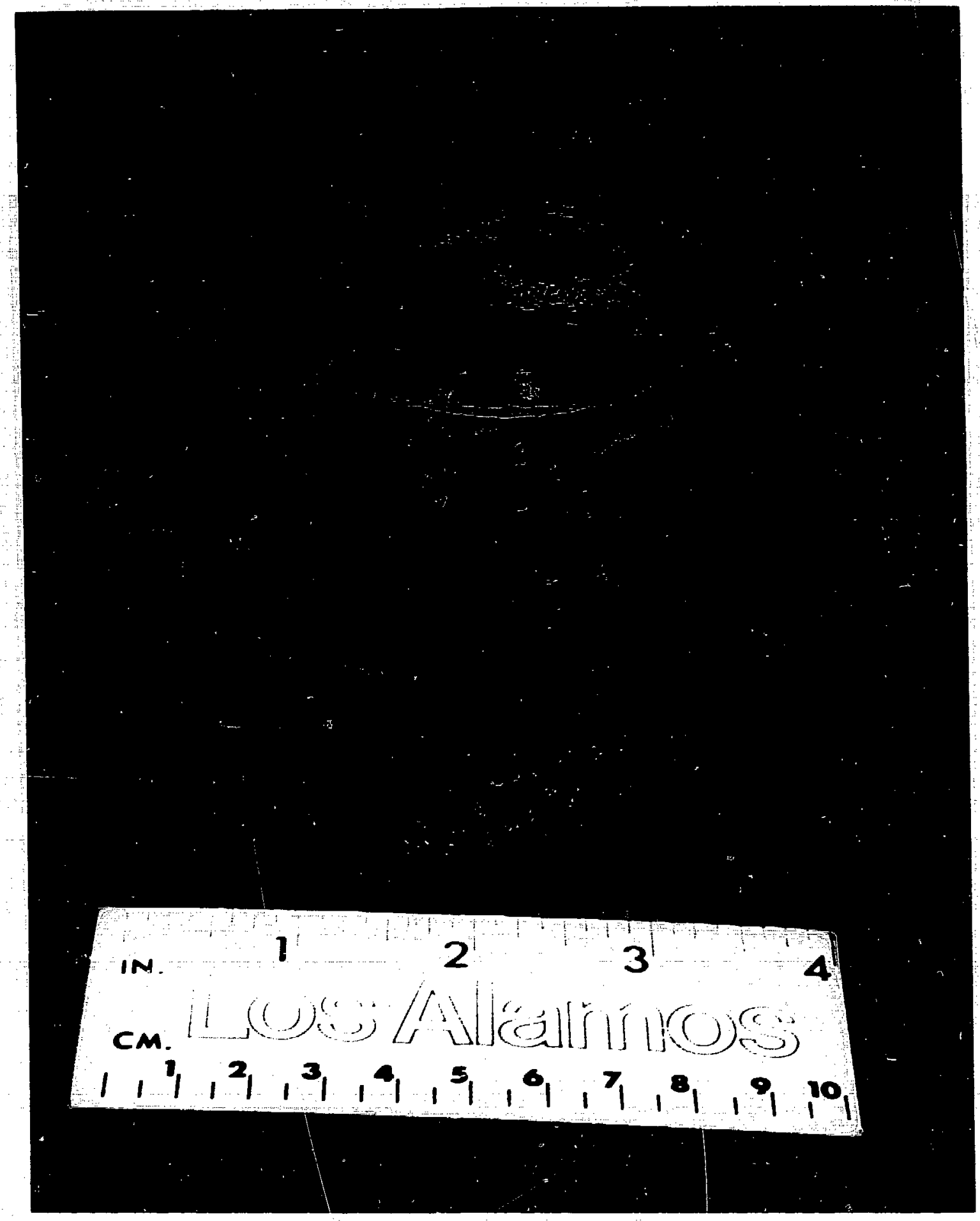

Fig. 20. Ingot from vacuum casting. 
TABLE III

IMPURITY LEVELS IN HIGH-PURITY CASTING FEED AND CAST PARTS

Metal Feed, Parts per Million

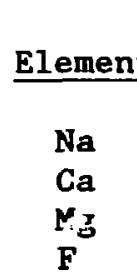

A1

si

$\mathrm{Pb}$

$\mathrm{Cu}$

Sn

Cr

Mn

Zn

Zr

Mo

Th

$\mathrm{U}$

$\mathrm{w}^{*}$

$\mathrm{Ga}$

Ni

$\mathrm{Fe}$

C

0

H

N

Am (varies with feed)
Most

Frequent

$\leq 2$

$\leq 3$

$\leq 5$

$-$

$\leq 5$

8

$\leq 1$

$\leq 1$

$\leq 1$

$\leq 1$

$\leq 1 \quad \leq 0.5$

$-$

$-$

$-$

$\leq 0.5$

$$
\begin{aligned}
& \leq 0.5 \\
& \leq 10 \\
& \leq 10 \\
& \leq 0.5 \\
& 5
\end{aligned}
$$

20

20

80

$\leq 2$

5

4

$\leq 5$

50

$\leq 0.2$

$\leq 0.5$

12

10

65

$\leq 0.5$

$\leq 0.5$

$\leq 5$

20

20

10

$\leq 10$
Gast Part, Parts per Million

Most

Frequent

High Low

$$
\leq 1
$$

$\leq 1$

$\leq 2$

$\leq 2$

$\leq 2$

$\leq 1$

$\leq 0.5$

$\leq 1$

$\leq 0.5$

$\leq 1$

$\leq 0.5$

-

-

$-$

$-$

10

$\leq 5$

40

$\leq 0.2$

$\leq 0.5$

$\leq 2$

$\leq 10$

10

$\leq 5$

$\leq 1$ $\leq 1$

$\leq 1$

$\leq 2$

$\leq 2$

5

$\leq 5$

$\leq 0.5$

$\leq 1$

$\leq 0.5$

$\leq 1$

0.5

$\leq 5$

$\leq 0.1$

$\leq 0.5$

$\leq 2$

12

10

65

$\leq 0.5$

$\leq 5$

$\leq 5$

10

15

10

5

$\mathrm{Pu}$ (weight difference) $\quad 99.9858$

99.9858

Elements below detectable limits.

$\begin{array}{llrlrl}\mathrm{Li} & \leq 0.005 \mathrm{ppm} & \mathrm{Bi} & \leq 0.5 & \mathrm{Y} & \leq 0.1 \\ \mathrm{Be} & \leq 0.1 & \mathrm{~K} & \leq 0.5 & \mathrm{Cs} & \leq 2 \\ \mathrm{~B} & \leq 0.3 & \mathrm{Ti} & \leq 0.2 & \mathrm{Ba} & \leq 0.1 \\ \mathrm{Co} & \leq 0.5 & \mathrm{~V} & \leq 0.5 & \mathrm{Hf} & \leq 0.5 \\ \mathrm{Cd} & \leq 0.5 & \mathrm{Rb} & \leq 0.5 & \mathrm{Re} & \leq 0.5 \\ \mathrm{La} & \leq 1 & \mathrm{Sr} & \leq 0.1 & & \end{array}$

${ }^{*}$ Can be reduced to $\leq 2.5 \mathrm{ppm}$ with more expensive TaC cathode. 
Figures 21 and 22 show the Los Alamos ER reaction cell and equipment. ${ }^{76}$ Two concentric magnesia crucibles joined at the base form the cel1. In typical operations, technicians place 4-6 kg of impure plutonium metal in the inner crucible and add an equimolar mixture of $\mathrm{NaCl} / \mathrm{KCl}$ containing 5 wt. $\&$ magnesium as an oxidant. This operation produces plutonium(III) in the electrolyte before a current is passed and assures the initial reduction of plutonium at the cathode. Workers assemble the cell in a stainless steel furnace tube, evacuated it, and back-fill it with argon. They then heat the cell to $740^{\circ} \mathrm{C}$ and lower the stirrer, anode, and cathode into the position shown in the figure. Direct current is passed through the cell and the solution is stirred until the plutonium is no longer the primary ion being formed at the anode. An increase in the static-cell potential, measured by a back emf sampling unit, indicates this event. ${ }^{77}$ At a preset potential, the current automatically terminates and an operator withdraws the hardware from the melt. The operator turns off the heat, and the system cools to room temperature. The ceramic crucibles are broken to recover the salt, which is a primary residue, and the metal product. A technician mechanically separates the product ring, shown in Fig. 23, from the salt, samples it, and transfers it for future use.

The purity of typical product is greater than 99.958 plutonium. ${ }^{78}$ Table IV gives the purities typically obtained for production runs. The elements less active than plutonium remain in the anode, along with a metal heel, to form the spent anode residue, which contains up to 108 of the feed metal. The residue is treated by pyroredox to recover the plutonium.

Figure 24 shows an alternative ER cell developed first at Argonne National Laboratory and later demonstrated at RFP. ${ }^{1}$ Its design minimizes crucible breakage and cooling times in production runs.

The major residues in the process are the anode heel, the electrolyte, and metal trapped on the crucible, stirrer electrodes, and thermocouple well. These can be recovered by a number of aqueous and pyrochemical processes.62,79-1 


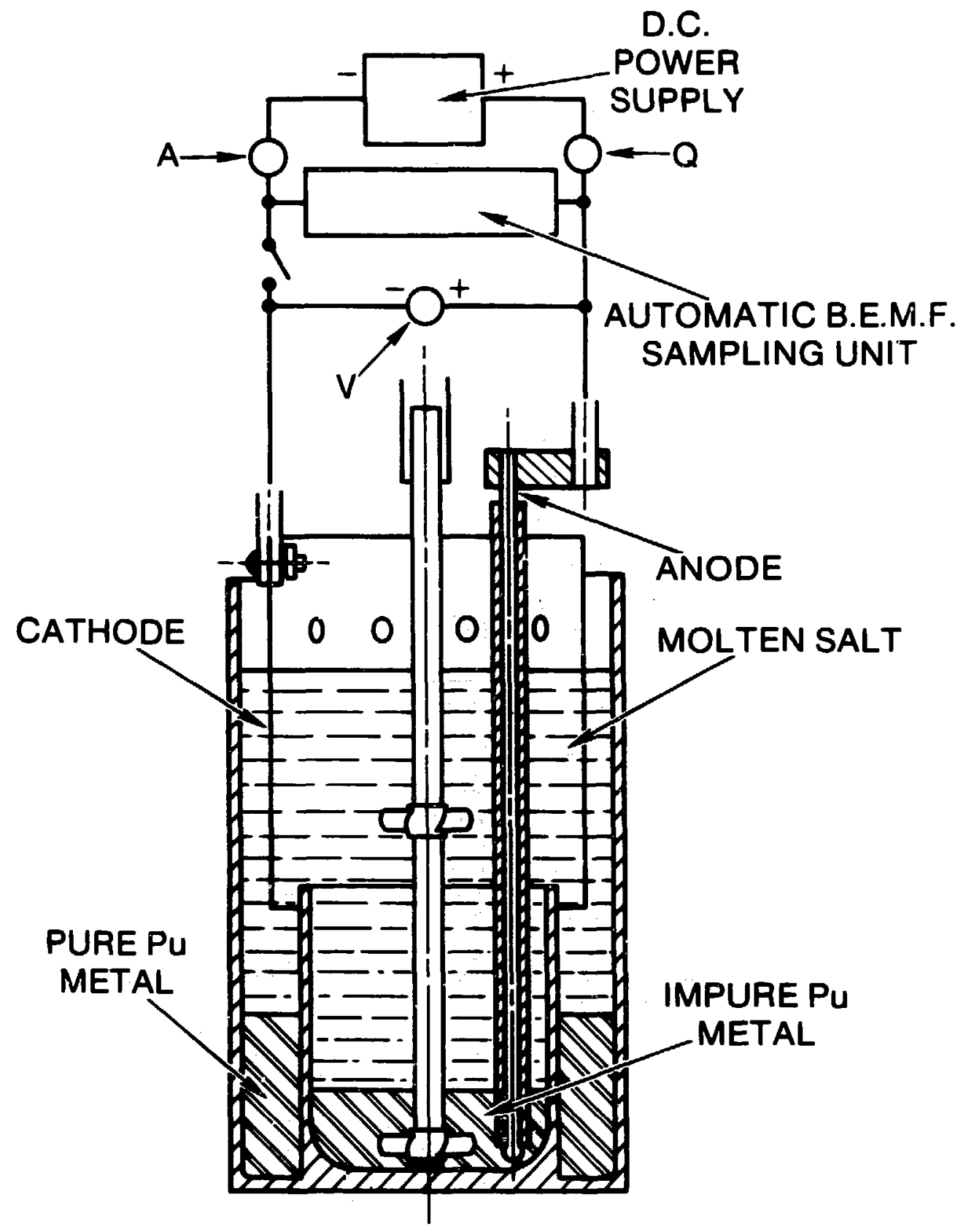

Fig. 21. Los Alamos ER cell. 


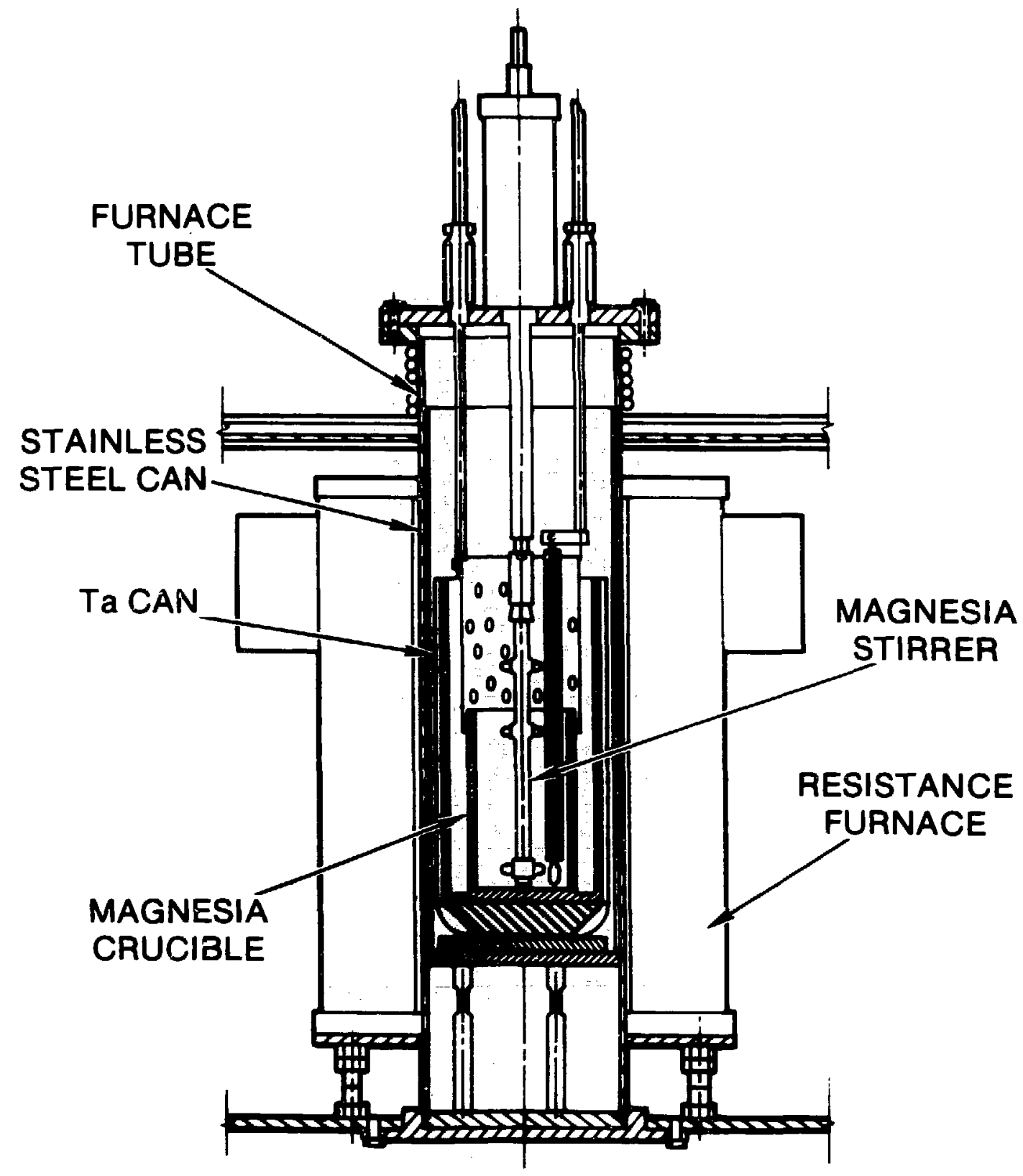

Fig. 22. ER equipment, 6-kg scale. 


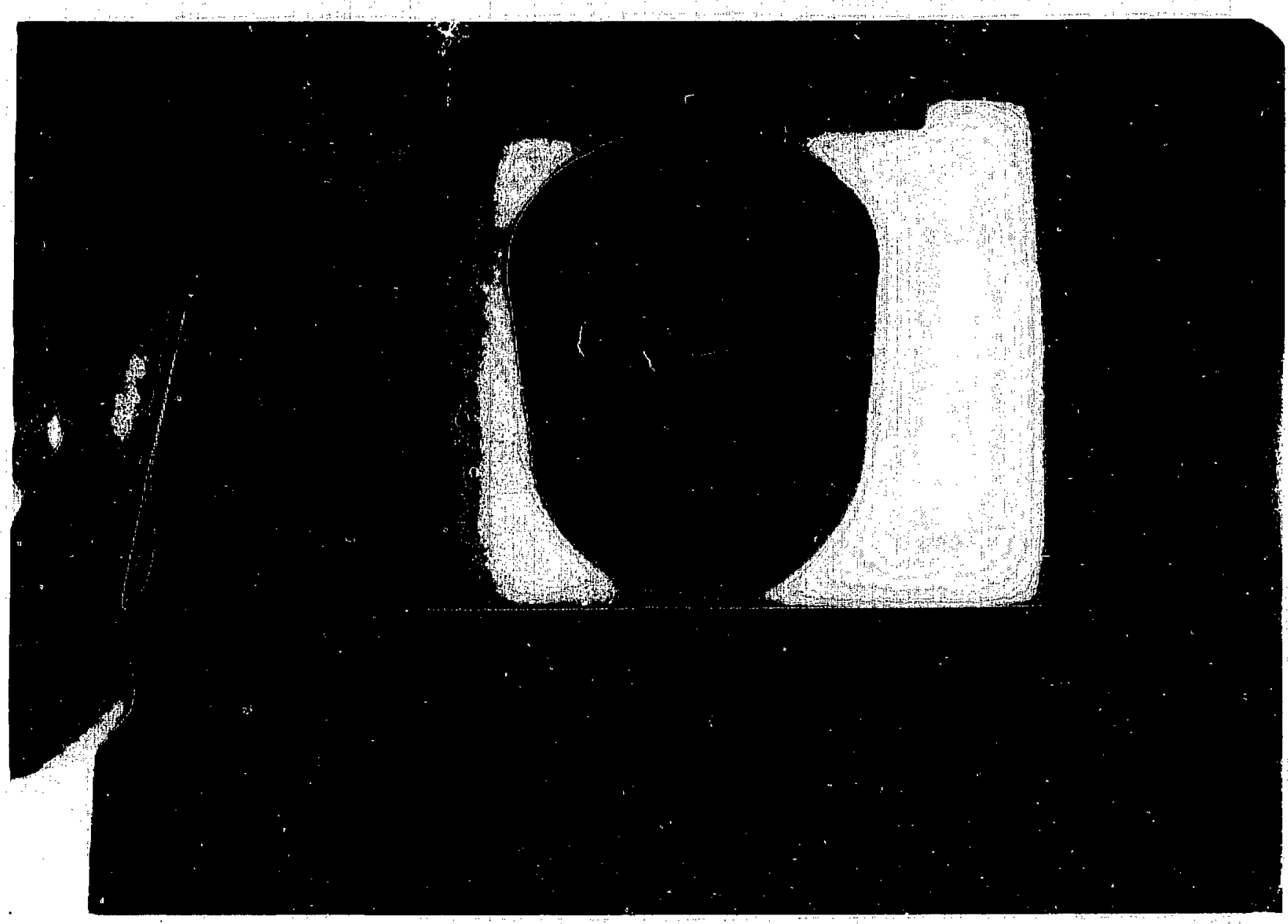

Fig. 23. Plutonium product ring from ER. 
TABLE IV

BEHAVIOR OF IMPURITY ELEMENTS IN ER

Concentration

(g Element) $\left.10^{6} \mathrm{~g} \mathrm{Pu}\right)$
Location Where

Element Is

Concentrated

\begin{tabular}{|c|c|c|c|}
\hline Element & Feed & Product & \\
\hline Ir & 4,500 & 100 & -- \\
\hline $\mathrm{Ni}$ & 1,000 & $<0.5$ & Anode \\
\hline $\mathrm{Cu}$ & 500 & $<1.5$ & Anode \\
\hline $\mathrm{Ta}$ & 5,000 & 80 & Anode \\
\hline $\mathrm{Pb}$ & 2,000 & $<0$ & $\cdots$ \\
\hline $\mathrm{Fe}$ & 25,000 & 20 & Anode \\
\hline $\mathrm{Si}$ & 320 & $<5$ & Anode \\
\hline $\mathrm{Cr}$ & 340 & $<5$ & Anode \\
\hline Ga & 10,000 & $<25$ & Anode \\
\hline $\mathrm{Zn}$ & -- & -- & Anode \\
\hline Mn & 70 & $<2$ & $\cdots$ \\
\hline $\mathrm{T} \mathbf{i}$ & 15,000 & 10 & -- \\
\hline Al & 2,700 & $<5$ & Anode \\
\hline $\mathbf{U}$ & 330 & $<20$ & Anode \\
\hline $\mathrm{Zr}$ & 10,000 & 14 & $\therefore$ \\
\hline Th & 1,300 & 10 & Anode \\
\hline $\mathrm{Pu}$ & $\cdots$ & $\cdots$ & $\cdots$ \\
\hline $\mathrm{Ce}$ & 527 & $<25$ & Electrolyte \\
\hline Am & 850 & 82 & Electrolyte \\
\hline
\end{tabular}




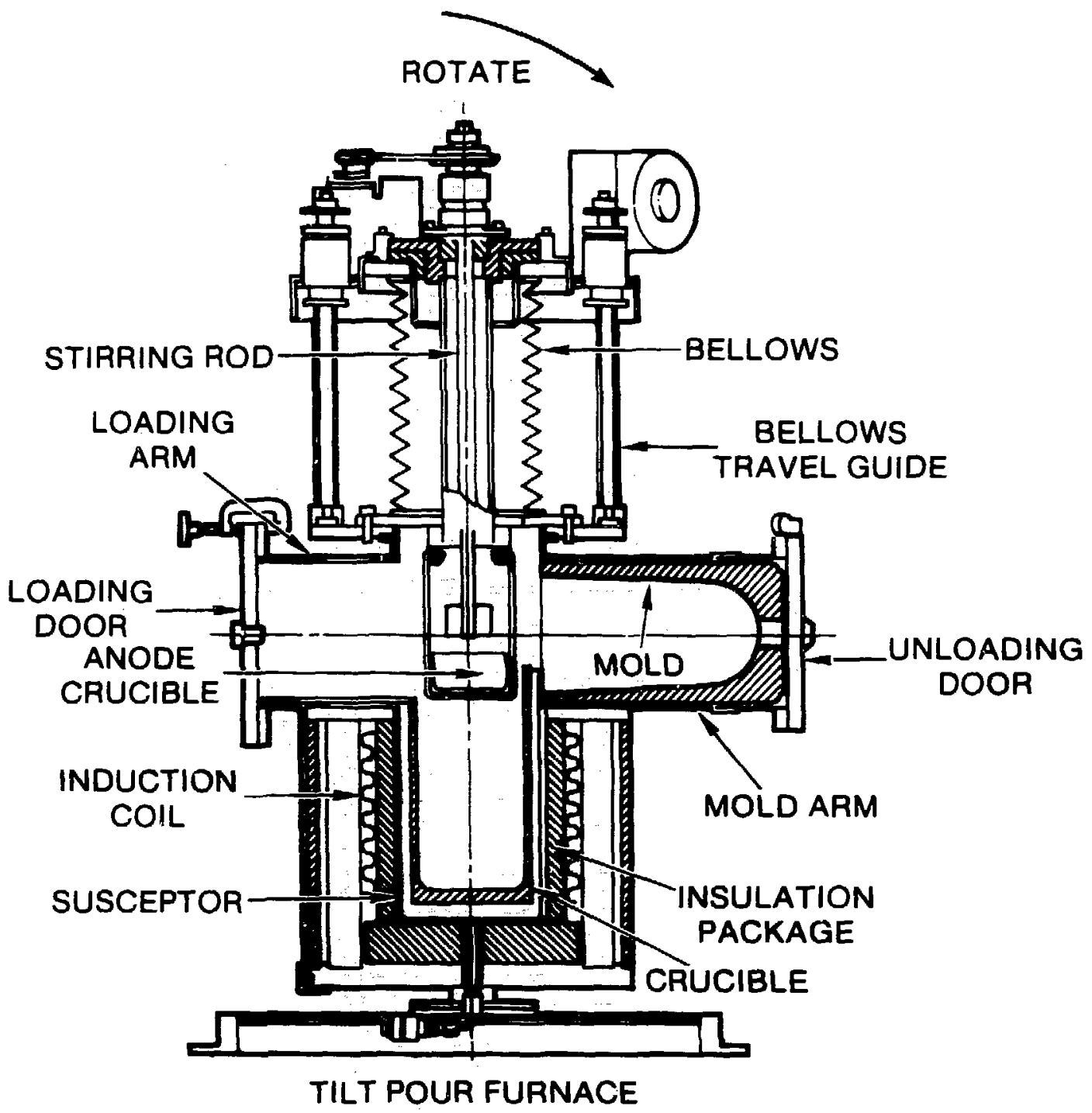

Fig. 24. Schematic of RFP's tilt-pour ER furnace. 
In the pyroredox process, workers initially polish the spent anode with calcium to ensure that all the plutonium is present as metal. ${ }^{2}$ They then oxidize the metal to plutonium(III) with $\mathrm{ZnCl}_{2}$ dissolved in $\mathrm{KCl}$. All elements more active than zinc will be oxidized into the salt phase. This process forms a zinc button that may be discarded. The technicians then mix the salt with a $\mathrm{Ca} / \mathrm{CaCl}_{2}$ salt to reduce plutonium and all elements less active than calcium. The reaction product is a salt phase above a twophase button. The salt phase is mechanically separated and discarded. The bottom, denser metal phase is composed of plutonium and small quantities of calcium and zinc. The upper phase is typically 508 plutonium with the remainder being primarily zinc. Several buttons are allowed to coalesce at $850^{\circ} \mathrm{C}$ for $6 \mathrm{~h}$ to separate the ingots into a plutonium-rich lower phase suitable for ER and a less-pure upper phase that is recycled to the oxidation step.

Racovery operations treat the electrolyte salt from ER, which contains up to 88 of the feed plutonium and any elements more active than plutonium (such as americium), by salt-stripping to recover the plutonium. Operators add cacium to the salt in a DOR crucible and heat the mixture to $850^{\circ} \mathrm{C}$, stir it, and allow it to cool. The metal product is recycled to ER. Aqueous methods for recovery leach crucible shards with HCl to recover plutonium. If plutonium from the residues is included in the calculation, recovery yields are quite high.

Since facilities first adopted ER in 1962, the process has produced large quantities of metal with greater than 99.968 purity. Once-through yields, particularly in conjunction with DOR and casting, are rather disappointing, and investigators are conducting additional research. $\$ 3$

\section{WASTE MANAGEMEINT}

Solution processing technologies discussed in this report, as well as other processing technologies, produce both liquid and solid wastes that 
must be disposed of in an acceptable manner. We will now discuss methods of dealing with these wastes.

\section{A. Liquid Wastes}

The evaporator process is the first step in the waste management stream for all solutions that can be discarded. Feed for this process consists of effluent (approximately $7 \underline{\mathrm{M}} \mathrm{HNO}_{3}$ ) generated by the ion-exchange columns. This solution contains plutonium concentrations from several milligrams to $0.5 \mathrm{~g} / \ell$ and is processed in one of two evaporators. An evaporator run usually concentrates $600 \ell$ of solution to about $20 \ell$, designated bottom. The distillates from this process contain relatively low plutonium concentrations (usually below $7 \times 10^{7}$ (counts/min)/ $\ell$ total alpha) and are discarded to a final waste-treatment facility. Technicians cool the bottoms, separate the salts by supernate filtration, and sample the filtrate for plutonium to ensure it may be discarded. If the sample results are acceptable, the filtrate $(20 l)$ is fixed in cement for disposal. The salts are also sampled for plutonium to establish criteria for discard. Following assay, workers place the salts in a PVC-lined drum and send them to a 10-yr retrievable storage. Another source of solutions is the oxalate filtrates, which are handled in the same manner as the effluents. A reduced distillation rate, however, compensates for the reactivity of the oxalate filtrate, which contains $\mathrm{NH}_{2} \mathrm{OH} \cdot \mathrm{HNO}_{3}$.

Waste management is also responsible for all caustic solutions that are generated by the various head-end and purification sections. At present, facilities filter, sample, and assay these solutions to determine the need for further processing. If the filtrates meet the discard criterion $\left(\leq 5 \times 10^{9}\right.$ (counts/min)/ total alpha), the filtrates are transferred to the waste management facility.

A low-level-waste facility (Fig. 25) provides further treatment of the acid distillates and caustic solutions. The means of transfer is a gravity-flow stainless steel pipe encapsulated in PVC plastic. The wastes 


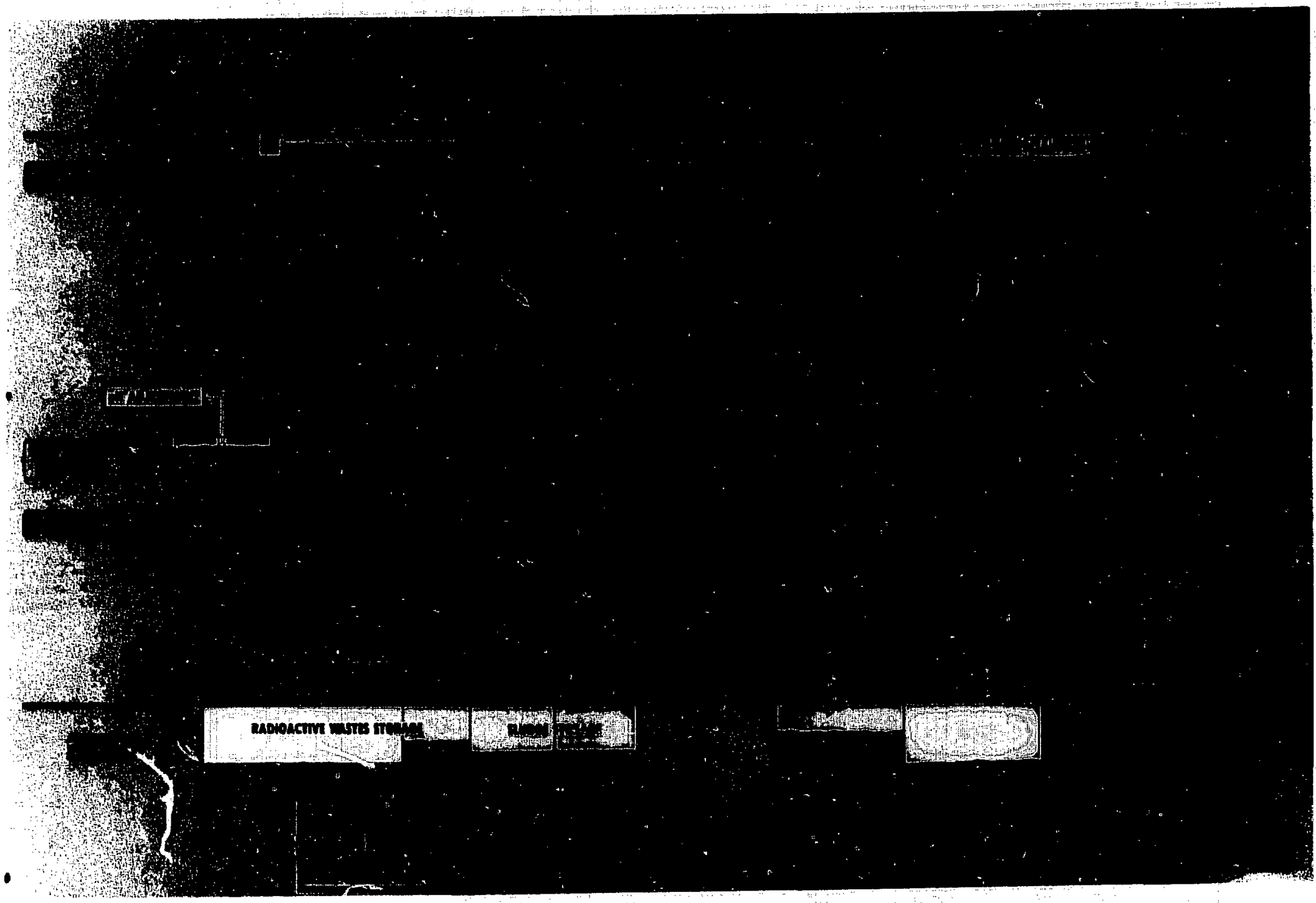

Fig. 25. Liquid Waste Treatment Facility TA-50 at Los Alamos Nationai Laboratory. 
collect in two $11,000-\ell$ storage tanks located in a below-grade vault. The waste treatment at this facility includes the neutralization, chemical precipitation, settling, clarification, sand filtration, sludge collection, and solidification of sludges by addition of portland cement. Operators discard the effluent if the gross alpha activity is less than $4,000 \mathrm{~d} / \mathrm{m} / \mathrm{l}$; if it is not, the effluent is recycled through the plant. Development of the TRUEX process for $\mathrm{HNO}_{3}$ systems has been concerned with the removal, plutonium and americium from Hanford TBP-based solvent-extrac: :raffinates. Experimental work by R. A. Leonard and associates 50 of Ar National Laboratory has attained levels of $<10 \mathrm{nCi} / \mathrm{g}$ (TRU ele $\because$. Extraction of $0.25 \mathrm{M}$ CMPO-0.75M TGP in $\mathrm{CCl}_{4}$ produced a raffinate co $2 \mathrm{nCi} / \mathrm{g}$. Development of this potentially important and large-scale a . - ess continues.

\section{B. Solid Wastes}

Plutonium-contaminated solid wastes can be divided into TRU waste, $>100 \mathrm{nCi} \mathrm{Pu} / \mathrm{g}$, and low-level waste, $<100 \mathrm{nCi} \mathrm{Pu} / \mathrm{g} .{ }^{82}$

The Waste Management Group retrievably stores solid TRU defense wastes above grade on asphalt pads and covers them with layers of wood, plastic sheet, and earth. Currently, operators must certify the defense wastes to meet the WAC for mandatory disposal at WIPP. ${ }^{2}$ The WIPP facility is scheduled to receive its first waste shipments in 1989.

1. Process Residues. Immobilization of process residues in cement is a common method to ensure that solution and fine-particulate-containing waste will meet the WIPP WAC. Materials to be immobilized include solutions, sludges, organic liquids, processing residues, filter media, salts, ion-exchange resins, and nuclear materials such as americium oxide.

often the immobilizing agent is portland cement mixed in a screw mixer, jet mixer, pug mill, or turbling drum. The cement paste drops into a drum to set and cure. Several facilities use gypsum cement to immobilize 
organic liquid waste that is premixed with water and an am. sifier. Los Alamos performs the mixing directly in a 55-gal. drum.

At Los Alamos, the chloride and evaporator bottoms solutions provide the water for the immobilization of the solid process residues with gypsum cement. Sodium hydroxide solutions $(\mathrm{NaOH})$ neutralize the strongly acidic solutions into a $\mathrm{pH}$ range of 2-4. Technicians transfer the neutralized solution into a 55-gal. drum and add cement as the mixture is stirred with an air motor for a few minutes. Most solids are added near the end of the stirring. Americium oxide is stirred manually into the paste afterwards to prevent the spread of high-gamma-emitter material to the stirring equipment and the glove box. The system will employ in-drum stirring for several reasons: ${ }^{3}$ (1) the operator can observe the mixture during stirring and control the time a:d rate of stirring to match the characteristics of the highly variable feed solutions; (2) if the operator judges it necessary to initiate the setting reaction, set-accelerator material can be added to the mix while stirring is continued; (3) the cleanup of mixing equipment is simpler (4); a flash set in the mixing equipment will not force a difficult cleanout of a frozen mixer; (5) finally, should the mix not set up, remixing can occur right in the drum.

Gypsum cement is the fixing agent of choice for the following reasons: ${ }^{70}$ (1) it has a possible higher volume efficiency (708 vs 35\% for portland cement); (2) it provides an optimal $\mathrm{pH}$ of $3-5$ for setting (This setting requires less $\mathrm{NaOH}$ solution for neutralization; also, the acidic $\mathrm{pH}$ minimizes evaporator waste-solution release of ammonia that forms $\mathrm{NH}_{4} \mathrm{NO}_{3}$ particulates in the ventilation ducts and plugs the ventilation system filters.); (3) it demonstrates an ability to immobilize organic liquids when used with an emulsifier; and (4) it shows a tendency to reabsorb any water layer formed on the surface of the setting cement. (A comnon disadvantage for portland cement is the presence of free liquid in a drum after setting occurs.) 
2. Combustibles and Noncombustibles. Solid residues not requiring immobilization consist of common combustibles and noncombustibles. Combustible wastes include paper, wood, rags, plastics, and graphite crucibles. Typical noncombustibles are metal valves, tubing, pipe, furnace tubes, tools, cans, glass, fiberglass, ceramics, and leaded dry-box gloves. These materials normally meet the WIPP WAC without further treatment, although additional processing may significantly redice the volume of waste transported to WIPP.

There is a current plan to segregate and burn much of the combustible waste from the Los Alamos Plutonium Facility in the Waste Management Group's controlled air incinerator. ${ }^{84}$ The resulting ash will be fixed in cement. To date, we have attempted only trial runs with lightly contaminated waste.

In addition bulky nonroutine waste items such as glove boxes will be cut up in the Waste Management Group's Size Reduction Facility if the items cannot be decontaminated to less than TRU levels.

Some of the solid wastes will probably require other types of processing to render them certifiable to WIPP. For example, salts and crucibles containing pyrophoric metals such as sodium or potassium will require roasting in aix for conversion to oxides or treatment with lead chloride to form the chloride salts. ${ }^{85}$

Finally there are special-case wastes whose disposition has not yet been clarified. An example is HEPA filters. They can contain unacceptable quantities of particulate matter. The WAC Certification Committee is still evaluating whether the particles can be entirely released during transportation or in $n$ accident. If the particles are mostly trapped, then the filters may be certified; if the particles can be mostly released, the filter media will be removed from the frame and fixed in cement. 


\section{EMERGING TECHNOLOGIES}

The handling of plutonium scrap and waste is labor intensive, particularly in processing secondary scrap materials that are generally lean in plutonium content and quite often contain contaminants that aggravate the scrap-handling problems. The following are some of the many challerges for evolving technologies:

- reduce secondary scrap generation,

- reduce waste generation including both the bulk weight and plutonium content,

- improve process and system yield,

- reduce personnel radiation exposure,

- become more cost effective, and

- improve accountability and safeguards.

The approaches taken to meet these challenges range from making subtle evolutionary changes to existing processes to making revolutionary approach changes to material processing. Probably the most significant efforts, in terms of overall long-term payoff, are those appioaches aimed at stopping the generation of scrap and waste.

Automation and robotics will most certainly play an important role in defining the direction of new technology. But automation and robotics are not treatment technologies within themselves. They do represent outstanding tools to be used in improving our material handling, accountability, and safeguards, as well as in reducing the radiation exposure to personnel. Many researchers believe that automation and robotics will slowly become the main support activity for all process changes. Numerous projects aimed at automated handling are under way in facilities across the nation. As an example, in the plutonium-scrap processing facility at RFP in Colorado, a large stacker-retriever robot system is the primary means of accessing vault storage. Wcrkers are installing a similar but much smaller stacker-retriever robot in a new vault at the plutonium facility at the Los Alamos National Laboratory. 
Robots such as these can be coupled to computer systems and can thus become the heart of an accounting and inventory system. These functions can now take place with very high reliability and with little or no radiation exposure to personnel.

Vaults are not the only place where robots are demonstrating their usefulness. A new pick-and-place robot has been installed in the plutonium analytical laboratory at the Los Alamos National Laboratory. The robot works with the computer system to perform a variety of sample-preparation, dissolution, dilution, and data-compilation steps. Automation is beginning to move onto the working floor as well.86,87 Automated NDA and bagout systems will replace the operator in performing these tedious, repetitive, and often high-exposure operations.

Computerization is rapidly becoming a second major new support activity appearing in the work place. The low price and compact nature of the new computers have made them highly desirable for data-compilation purposes. Indeed, voice-actuated data sheets preclude the need for personnel to punch the keyboard. Computers coupled with NDA evaluation equipment - also function as process-control systems. With the advent of more sophisi cated processing techniques high-quality rapid-evaluation techniques are essential to avoid process upsets.

The third major evolutionary change that will become an essential tool in future technology is at-line or on-line analysis. Many of the new approaches concern NDA techniques. Gamma-ray counting with multichannel analyses can provide near-real-time analysis in continuous or semicontinuous systems. In processing steps such as solvent extraction, continuous dissolution, and ion exchange, extents of reaction are sometimes difficult to access. On-line NDA techniques will automatically determine column breakthrough. Destructive, wet chemistry techniques will begin to be integrated into the actual process operations to provide at-line process control. Techniques such as inductively coupled plasma spectroscopy can process a sample in a matte $i$ of minutes, thus providing impurity 
information on a near-real-time basis. Coupling the results of the analysis with other automated aspects of process systems will provide enhanced process control.

A major aspect of technology improvement involves more than just modifications to existing processes. Opportunities to make significant changes in processing exist in the actual process chemistry and processengineering areas. Researchers are presently investigating some of the following areas:

- Enhanced Dissolution. As noted earlier, recovery of plutonium from highly refractory plutonium oxide is a severe challenge to conventional aqueous processing. At Los Alamos, research has found that a new approach to the problem is the use of a superacid sich as $\mathrm{HF}_{\mathrm{SbF}} \mathrm{S}^{88}$ This reagent gives complete dissolution of refractory plutonium oxide in a practical time frame. Subsequent solvent distillation and recycle are an economical aspect of this experimental procedure. The fluoride residue is then amenable to either $\mathrm{PuF}_{6}$ volatility techniques or to conventional procedures such as $\mathrm{HNO}_{3}-\mathrm{Al}\left(\mathrm{NO}_{3}\right)_{3}$ dissolution and subsequent plutonium purification by solvent extraction or nitrate anion exchange. The superacid portion of the recovery procedure would add little to waste-stream volumes.

- Low-Temperature Fluorination. Recent work at Los Alamos has shown that a new fluorinating agent, FOOF, will produce $\mathrm{PuF}_{6}$ at low temperatures. ${ }^{20}$ FOOF can be generated from oxygen and fluorine mixtures by (1) ultraviolet photolysis, (2) microwave discharge, or (3) an even newer technique involving thermal dissociation of $F_{2}$. In a FOOF mixture, the two species identified to date are $\mathrm{O}_{2} \mathrm{~F}_{2}$ and $\mathrm{O}_{2} \mathrm{~F}$, the latter being a very reactive intermediate. 89 Although fluorine can produce the volatile compound $\mathrm{PuF}_{6}$ as well, producing and delivering high concentrations of fluorine atoms to reactive sites is very difficult. other potential applications for FOOF include new synthetic methods, surface passivation, and treatment and decontamination of plutonium-containing materials and equipment. 
- Membrane Separation. A neglected area of aqueous materials processing has been thin-film membranes and their potential for metal ion separation. 00 Recent laboratory results have shown that, in principle, membrane techniques using practical equipment sizes can recover the actinide metal ions to well below 1 ppm. 91 Membrane development itself is starting to be a growth area for actinide separations involving (1) polymeric membrane development for metal ion separations, (2) modified concepts of supported liquid membranes, and (3) polymeric membranes containing covalently tonded, actinide-specific chelating agents. A major challenge for these endeavors will be the removal of plutonium and americium from acidic waste streams to the very low level required for discard to final waste processing. Currently, evaporation produces distillates with these low activity levels, but the concentrated residues may contain gram amounts of plutonium and americium that require immobilization in cement.

- Molten Salt/Molten Metal Redox Systems. Molten electrochemical techniques provide the capability to study and characterize complex chemical reactions in solution. In-depth application of many of these techniques to actinide chemistry in molten salts has yet to be completed, but the promise of a better understanding of electrode reactions in various molten-salt electrolytes may completely alter current actinide processing systems. In addition to improving the efficiency of plutonium purification by ER, intermediate purification and separation operations could benefit by proper application of electrolytic processes. Separation of impurities currently possible only through aqueous techniques could be completed in fewer steps, generating much less residue and achieving faster turnaround of product metal through electrochemical applications. Integration of electrochemical processing coupled with enhanced engineering automation will definitely play an important role in the future of actinide moltensalt processing and purification, as will computer monitoring and control. 
- Integrated Reduction/Purification. Processing spent DOR salts, electrorefining liquid anodes, and generating and using plutonium trichloride $\left(\mathrm{PuCl}_{3}\right)$ are intended to lead to a system in which the oxide could be reduced to metal and electrorefined in the same equipment, the salt could be regenerated and reused, and the product metal could maintain the same high standards as our current electrorefined metal. Experts are investigating the use of $\mathrm{PuCl}_{3}$ for the removal of americium to help maintain the purity of the extracted metal and for the potential of singlepass extraction of metals with very high americium content. The trichloride is also of interest for the introduction of the ionic plutonium species into electrolytic operations. Additional work is studying the use of reference electrodes in molten-salt systems to more fully understand and control the electrochemical processes occurring during the purification of plutonium and the subsequent recovery of pyrochemically generated residues. By combining the appropriate features of all of this work, researchers may be able to design and build a cell that has oxide as the feed and pure metal as the product and that generates a residue for discard at a fraction of the current residue-generation rate.

Regardless of where new technologies guide the processing of plutonium-bearing scrap and the handling of wastes, administrative issues will become a much more dominant driving force. These issues will most certainly involve aspects of environmental control, safeguards, material control and accountability, health and safety, and human reliability. These issues will predominately be politically motivated and implemented. The true challenge for both existing and emerging technologies will be to successfully address the administrative issues while simultaneously promoting safer, better, and more cost-effective processing. 


\section{ACKNOWLEDGMENTS}

From reading this chapter you will realize the historical significance of plutonium processing technology. The industry is very young compared with other inorganic processing industries. As a result, many of the original processing approaches are still in use today in some fashion. It is therefore necessary to recognize all of the original pioneers in the plutonium business for their contributions in establishing the technology base. In line with this acknowledgment, the authors apologize to all researchers whose specific work has not been cited here. The chapter was intended to highlight the status of plutonium processing and waste management. We encourage all readers to inquire further for in-depth processing information.

Finally, the authors would like to acknowledge Brian Thompson for editing and the staff of IS-12 for preparing all the illustrations. The authors would especially like to acknowledge Marion Harris for typing and coordinating the material. 


\section{REFERENCES}

1. L. E. Kusler, "Proposed Method for Calculating Economic Discard Limits for Weapons-Grade Plutonium," U.S. Department of Energy, Office of Nuclear Material Production report, MMP 86-1 (1986).

2. "TRU Waste Acceptance Criteria for the Waste Isolation Pilot Plant," Westinghouse Electric Corporation report WIPP-DOE-069, Rev. 2., UC-70 (1985).

3. E. A. Hakkila, C. C. Thomas, Jr., D. B. Smith, C. A. Ostenak, and R. G. Gutmacher, "Materials Management in an Internationally Safeguarded Fuels Reprocessing Plant," Los Alamos Scientific Laboratory report LA-8042, Vol. III, Appendix K, "Conventional Measurement Techniques" (1980).

4. E. L. Christensen and W. J. Maraman, "Plutonium Processing at the Los Alamos Scientific Laboratory," Los Alamos Scientific Laboratory report LA-3542 (1969).

5. A. E. Nixon, B. J. Mckerley, and E. L. Christensen, "Plutonium Scrap Processing at the Los Alamos Scientific Laboratory," Los Alamos National Scientific Laboratory document LA-UR-80-835 (1980).

6. B. J. McKerley and R. L. Nance, "Rotary Calcination of Incinerator Ash," Los Alamos National Laboratory document LA-UR-81-1447 (1981).

7. J. L. Long and C. J. Smith, "Unstable Material Formed by Reacting Leaded Glove Box Gloves with Nitric Acid," Rockwell International report RFP-2648 (1977).

8. J. J. Balkey, R. L. Nance, and B. J. McKerley, "Sand, Slag, and Crucible Processing at Los Alamos National L-boratory - A Process Technology Review," Los Alamos National Laboratory document LA-UR-86-1475 (1986).

9. H. Meininger (Rockwell International) and J. J. Balkey, (Los Alamos National Laboratory), private communication.

10. A R. Kazanjian and J. R. Stevens, "Dissolution of Plutonium Oxide in Nitrid Acid at High Hydrofluoric Acid Concentrations," Rockwell International report RFP-3609 (1984).

11. 0 . X. Tallent and J. C. Mailen, "Study of the Dissolution of Refractory $\mathrm{PuO}_{2}$ in Nitric - Hydrofluoric Acid Dissolvents at $100^{\circ} \mathrm{C}, "$ Nuc1. Technol. 32, 167-175 (1977).

12. C. W. Bjorklund and E. Staritsky, "Some Observations on the Reactivity of Plutonium Dioxide," Los Alamos Scientific Laboratory report LA-1869 (1954). 
13. R. D. Baker, "Preparation of Plutonium Metal by the Bomb Method," Los Alamos Scientific Laboratory report LA-473 (1946).

14. R. D. Baker and W. J. Maraman, "Calcium Reduction of Plutonium Halidrs to Metal," in Extractive and Physical Metallurgy of Piutonium and Its Alloys, W. D. Wilkinson, Ed., (Interscience Publishers, Inc., New York, 1960), pp. 43-59.

15. L. J. Mullins, D. C. Christensen, and B. R. Babcock, "Fused Salt Processing of Impure Plutonium Dioxide to High-Purity Plutonium Metal," Los Alamos National Laboratory report LA-9154-MS (1982).

16. G. A. Burney and F. W. Taber, "Precipitation of Plutonium Trifluoride," Ind. Eng. Chem. Process Des. Dev., 4, 28 (1965).

17. D. A. Orth, Ind. Eng. Chem. Process Des. Dev. 2, 121 (1963).

18. R. M. Greimetz and D. H. Neal, "Plutonium III Oxalate Precipation and Calcination Process for Plutonium Nitrate to Oxide Conversion," Rockwell International report RFP-2603 (1980).

19. J. A. Porter and A. E. Symonds, Jr., "Preceiptation of Plutonium II Oxalate and Calcination to Plutonium Dioxide," E. I. du Pont de Nemours \& Company report DP-981 (november 1965).

20. J. G. Malm, P. G. Ellerand, and L. B. Asprey, "Low Temperature Synthesis of Plutonium Hexafluoride using Dioxygen Difluoride," J . Am. Chem. Soc. 106, 2726 (1984).

21. J. K. Dawson and R. M. Elliott, British report AERE-C/R-1207 (1953).

22. G. R. Waterbury, R. M. Douglass, and C. F. Metz, "Thermogravimetric Behavior of Plutonium Metal, Nitrate, Sulfate, and Oxalate," Anal. Chem. 33, 1018 (1961).

23. J. F. Facer, Jr., and K. M. Harmon, "Precipitation of Flutonium IV Oxalate," United States Atomic Energy Commission report HW-31186 (1954).

24. K. M. Harmon and W. H. Reas, United States Atomic Energy Commission report HW-49597-1 (1957).

25. G. T. Seaborg, J. J. Katz, and W. H. Manning, "The Transuranium Elements," Natl. Nucl. En. Ser., Div. IV, 14B, (McGraw Hill Book Co, New York, 1949).

26. J. A. Leary, A. N. Morgan, and W. J. Maraman, "Plutonium Peroxide Precipitation," Ind. Eng. Chem. 51(1) (1959).

27. L. L. Martella, M. T. Saba, and G. K. Fufubara, "Factors Affecting Plutonium Peroxide Liquefaction During Calcination," Rockwel1 International report CRD-82-083 (1982). 
28. J. L. Ryan and E. J. Wheelwright, "Recovery and Purification of Plutonium By anion Exchange In Nitric Acid," United States Atomic Energy Commission report HW-55893 (1959).

29. S. F. Marsh and T. D. Gallegos, "The Influence of Plutonium Concentration and Solution Flow Rate on the Effective Capacity of Macroporous Anion Exchange Resin," Los Alamos National Laboratory report LA-10990 (1987).

30. D. B. James, "The Processing of Plutonium by Ion-Exchange: I. The Concentration Dependence of Distribution Coefficients on Dowex $1 \times 4$ Froin 7M Nitric Acid, " J. Inorg. Nuc1. Chem. 25, 711-718 (1963).

31. S. F. Marsh, "Improved Recovery and Purification of Plutonium at Los Alamos Using Macroporous Anion Exchange Resin," Los Alamos National Laboratory report LA-10906-MS (1987).

32. G. S. Barney, "A Kinetic Study of the Reaction of Plutonium IV With Hydroxylamine," Atlantic Richfield Hanford Company report ARH-SA-207 (March 1975).

33. J. E. Keare, Jr., and J. D. Navratil, "Redox Behavior of Plutonium in Nitric Acid Process Solutions," Rockwell International report RFP- 3719 (1985).

34. S. F. Marsh and T. D. Gallegos, "Chemical Treatment of Plutonium with Hydrogen Peroxide Before Nitrate Anion Exchange Processing," Los Alamos National Laboratory report LA-10907-MS (1987).

35. S. F. Marsh, "The Effect of Fluoride and Aluminum on the Anion Exchange of Plutonium from Nitric Acid," Los Alamos National Laboratory report LA-10999-MS (1987).

36. S. F. Marsh and M. C. Miller, "Plutonium Process Control Using an Advanced On-line Gamma Monitor for Uranium, Plutonium, and Americium," Los Alamos National Laboratory report LA-10921-MS (1987).

37. N. G. Pope and S. F. Marsh, "An Improved Computer-Based, On-Line Gamma Monitor for Plutonium Anion Exchange Process Control," Los Alamos National Laboratory report LA-10975-MS (1987).

38. P. Clotisner, "Evaluation of On-line Passive Gamma Analyzer for Plutonium in Purex Soiutions," Savannah River Laboratory, 11 th Actinide Conference, Lawrence Livermore National Laboratory (1987).

39. L. W. Gray, "The Interactions of Hydrazine, Ferrous Sulfamate, Sodium Nitrite and Nitric Acid in Nuclear Fuel Processing Solutions, "Nucl. Tech. 40, 185-193 (1972).

40. D. B. James, "Anion Exchange Processing of Plutonium," Los Alamos Scientific Laboratory report LA-3499 (1967).

41. W. Van Slyke, G. Jansen, and W. H. Swift, "Thermal Effects in Anion Exchange Resin-Nitric Acid Systems," Pacific Northwest Laboratory report BNWL-114 (August 1965). 
42. A. C. Muscatello, M. E. Killion, and D. C. Fisher, "Plutonium Recovery from Direct Oxide Reduction and Electrorefining Residue Salts by Chloride Anion Exchange," Rockwel1 International report PPC 86-112 (December 1986).

43. A. C. Muscatello, M. E. Killion, and D. C. Fisher, "Aqueolis Methods for Recovery of Plutonium from Pyrochemical Residues," Rockwell International report RFP-4106 (May 1987).

44. D. B. James and E. L. Christensen, "The Processing of Plutonium by Ion Exchange II. The Anion-exchange Separation of Plutonium and Thorium," Trans. Am. Nucl. Soc. $5(2), 459$.

45. D. G. Clifton and T. W. Blum, "Thoriun-Plutonium Chemical Separation Process," Los Alamos National Laboratory report LA-9611-MS (1983).

46. K. W. Fife, M. H. West, R. L. Nance, S. L. Yarbro, "An Integrated Pyrochemical Aqueous Procedure for Recovering Plutonium From Spent MSE Salts," Las Alamos National Laboratory poster LA-UR-86-1766 (1986).

47. R. L. Nance, L. J. Brede, C. W. Mills, and S. L. Yarbro, "Development of a Precipitation Process for Recovery of Pu, Am from MSE Salts," Los Alamos National Laboratory poster LA-UR-86-1477, presented at 1986 Actinide Conference, Los Alamos, NM (1986).

48. G. P. Horwitz, H. Diamond, K. A. Martin, and R. Chiarizia, "Extraction of Americium (III) from Chloride Media by Octyl (Phenyl) N, N - Düsobytylcarbamoylmethylphosphine Oxide," Solvent Extr. Ion Exch. (to be published).

49. R. A. Leonard and M. J. Steindler, "Summary Report on the Development of Annular Centrifugal Contractors," Argonne National Laboratory report ANL-82-21 (1982).

50. R. A. Leonard, G. F. Vandegrift, E. C. Gay, D. R. Fredrickson, C. S. Sabau, D. J. Chaiko, L. Burris, et al., "The Truex Process for Recovery of Plutonium and Americium from Nitric Acid Waste Solutions-Continuing Development Studies, FY 1986," Argonne National Laboratory report ANL-87-3 (1987).

51. G. Vandegrift, R. Leonard, and L. Reichley-Yinger, "Purex-Truex Recovery of $\mathrm{Pu}$ and Am from Chloride Salt Wastes," Chemical Technical Division presentation, Argonne National L-aboratory (1987).

52. J. M. Cleveland, The Chemistry of Plutonium (Gordon and Beach, New York, 1970).

53. J. A. Leary, et al., "Pyrometallurgical Purification of Plutonium Reactor Fuels," in Proceedings of the Second United-Nations International Conference on the Peaceful Use of Atomic Energy, 01.17 (United Nations, Geneva, 1958), pp. 376-382. 
54. R. D. Baker, "Preparation of Uranium Metal by the Bomb Method," Los Alamos Scientific Laboratory report LA-472 (1946).

55. J. A. Leary and L. J. Mullins, "Practical Applications of Thermodynamics to Plutonium Process Reactions at High Temperature," in Thermodynamics: Vol. 1 (International Atomic Energy Agency, Vienna, 1966.), PP. $459-471$.

56. J. G. Reavis, J. A. Leary, and W. J. Maraman, "Method for Obtaining Plutonium Metal from its Trichloride,"U.S. Patent No. $3,049,423$ (1962).

57. M. H. West, Los Alamos National Laboratory, private communication (1986).

58. R. P. DeGrazio, "A Prototype Hydriding Apparatus," U.S. Energy Research and Development Agency report RFP-2340 (1975).

59. M. S. Coops, J. B. Knighton, and L. J. Mullins "Pyrochemical Processing of Plutonium," in Plutonium Chemistry, W. T. Carnall and C. R. Coppin, Eds. (American Chemical Society, washingtori, 1983), PP. 381-408.

60. J. G. Reavis, "Fused Salt Oxidation-Reduction Process for Plutonium Recycle Fue1," presented at Fall AIME Meeting, Detroit, Michigan (1961).

61. J. G. Reavis and J. A. Leary, "Non-Aqueous Dissolution of Massive Plutonium, "U.S. Patent No. 2,886,410 (1959).

62. J. A. McNeese, D. F. Bowersox, and D. C. Christensen, "Recovery of Plutonium by Pyroredox Processing," Los Alamos National Laboratory report LA-10457-MS (1985).

63. D. C. Christensen and L. J. Mullins, "Plutonium Metal Production and Purification at Los Alamos in Plutonium Chemistry," in Plutonium Chemistry, W. T. Carnall and C. R. Coppin, Eds. (American Chemical Society, Washington, 1983), pp. 369-380.

64. C. L. Sohn, D. C. Christensen, and C. W. Thorn, "Enhanced Production of Plutonium Metal Using $\mathrm{PuO}_{2}$ in the PuF $/$ Bomb Rediction Process," Los Alamos National Laboratory document LA-UR-82-1230 (1982).

65. L. J. Mul $\perp$ ins and $C$. L. Foxx, "Direct Reduction of ${ }^{238} \mathrm{PuO}_{2}$ and $239 \mathrm{PuO}_{2}$ to Metal," Los Alamos National Laboratory report LA-9073 $(1982)^{2}$.

66. D. A. Wenz, I. Johnson, and $R$. D. Wolson, " $\mathrm{CaCl}_{2}-\mathrm{Rich}$ Region of the $\mathrm{CaCl}_{2}-\mathrm{CaF}_{2}-\mathrm{CaO}$ System," J. Chem. Eng. Data 14, 250-252 (1969).

67. J. B. Knighton, R. C. Auge, J. W. Berry, and R. C. Franchini, "Molten Salt Extraction of Americium from Molten Plutonium Metal," Rockwell International report RFP-2365 (1976). 
68. J. B. Knighton and R. K. Steunenberg, "Distribution of Transuranium Elements Between Magnesium Chloride and Zinc-Magnesium Alloy," J. Inorg. Nucl. Chem. 27, 457-462 (1965).

69. J. A. Leary and L. J. Mullins, "On Divalent Americium in Molten Salt and Plutonium Systems," J. Chem. Thermodyn. 6, 103-104 (1974).

70. L. J. Mullins, A. J. Beaumont, J. A. Leary, "Distribution of Americium Between Liquid Plutonium and a Fused Salt. Evidence for Divalent Americium," J. Inorg. Nuc1. Cherr. 30, 147-156 (1968).

71. C. E. Baldwin and J. D. Navratil, "Plutonium Process Chemistry at Rocky Flats," in Plutonium Chemistry, W. T. Carnal1 and C. R. Coppin, Eds. (American Chemical Society, Washington, 1933), pp. 369-380.

72. J. W. Anderson and W. J. Maraman, "Plutonium Foundry Practices," Trans. Am. Foundrymen's Soc. 70, 1057-1072 (1963).

73. D. R. Harbur, J. W. Anderson, and W. J. Maraman, "Unusual Problems Encountered in Casting High Density, High Purity Plutonium," Mod. Cast. 53, 80-84 (1968).

74. L. J. Mullins, "A Review of Los Alamos Experience in Cortainment of Molten Plutonium and Molten Salt," Presentation for Technology Review for Molten Contaiment, Lawrence Livermore National Laboratory, (January 10,1984$)$.

75. W. W. Hiner, A. S. Coffinberry, F. W. Schonfeld, J. T. Walker, et al., "Plutonium," in Rare Metals Handbook, 2nd Ed., C. A. Hampe1, Ed., (Reintold Publishing Corp., London, 1961).

76. L. J. liullins and A. N. Morgan, "A Review of Operating Experience at the Los Alamos Plutonium Electrorefining Facility, 1963-1977," Los Alamos National Laboratory report LA-8943 (1981).

77. L. J. Mullins and J. A. Leary, "Fused Salt Electrorefining of Molten Plutonium and Its Alloys by the LAMEX Process," Ind. Eng. Chem. Process Des. Dev. 4, 394 (1965).

78. L. J. Mullins, A. N. Morgan, S. A. Apgar, III, and D. C. Christensen, "Six-Kilogram Scale Electrorefining of Plutonium Metal," Los Alamos National Laboratory report LA-9469-MS (1982).

79. J. B. Knighton and R. C. Auge, "Purification of Plutonium by Oxidation-Reduction," in "Research and Development Quarterly Progress Report, October, November, and December 1970," M. A. Thompson, Ed., Rocky Flats Plant report RFP-1638-A (1971).

80. I. B. Knighton, R. C. Auge, and J. C. Brown., "Purification of Plutonium by Oxidation-Reduction Process," Rockwell International report RFP-550 (1972). 
81. J. B. Knighton and J. W. Berry, "Pyroredox Research," in "Chemistry Research and Development Annual Progress Report, November 1, 1980 to September 30, 1981," Fred John Miner, Ed., Rockwell International report RFP-3324 (1982).

32. Department of Energy Order 5820.2.

83. T. L. Rosenstie1, M. D. Joss, and R. G. Lange, "ENVIROSTONE Gypsum Cement: Solidifaction Medium for Low Level Radioactive Wastes," United States Gypsum Company, Chicago, Illinois (1983).

84. A. S. Neuls, W. E. Draper, R. A. Koenig, J. M. Newmyer, and C. L. Warner, "The Los Alamos Controlled Air Incinerator for Radioactive Waste," Vols. 1 and 2, Los Alanos National Laboratory report LA-9427 (1982).

85. H. D. Ramsey, Los Alamos National Laboratory, private communication (1987).

86. N. M. Levitz, G. J. Vogel, E. L. Carls, D. Grosvenor, B. Kullen, D. Rave, and W. Murphy, "Kilogram-Scale Production of Plutonium Hexafluoride by Fluorination in a Fluidized Bed," Trans. Am. Nuc1. Soc. 11, 35 (1968).

87. N. M. Levitz, B. Kullen, D. Rave, and W. Murphy, et al., "Production of Plutonium Hexafluoride by Fluorination in the Fluidized Bed," Nucl. App1. Technol. 6, 147 (1969).

88. G. A. Olah, G. K. S. Prakash, and J. Sommer, Superacids, (J. Wiley Sons, New York, 1985).

89. A. G. Streng, "The Oxygen Fluorides," Chem. Rev. 63, 607 (1969).

90. H. K. Lonsdale, "The Growth of Membrrane Technology," J. Membr. Sci. 10, 81 (1982).

91. J. P. Deininger, "Ion-Exchange Membrane Separations in Actinide Aqueous Processing," in "Proc. of the 1986 Plutonium/Uranium Chemical Recovery Operations Conference," October 14-16, 1986, Savannah River Plant, Aiken, South Carolina (1986). 